Portland State University

PDXScholar

$1-1-1982$

\title{
Iron acquisition by cyanobacteria: siderophore production and iron transport by Anabaena
}

Peter James Lammers

Portland State University

Follow this and additional works at: https://pdxscholar.library.pdx.edu/open_access_etds Let us know how access to this document benefits you.

\section{Recommended Citation}

Lammers, Peter James, "Iron acquisition by cyanobacteria: siderophore production and iron transport by Anabaena" (1982). Dissertations and Theses. Paper 407.

https://doi.org/10.15760/etd.407

This Dissertation is brought to you for free and open access. It has been accepted for inclusion in Dissertations and Theses by an authorized administrator of PDXScholar. Please contact us if we can make this document more accessible: pdxscholar@pdx.edu. 
IRON ACQUISITION BY CYANOBACTERIA:

SIDEROPHORE PRODUCTION AND IRON TRANSPORT BY ANABAENA

By

PETER JAMES LAMMERS

A dissertation presented in partial fulfillment of the requirements for the degree of

DOCTOR OF PHILOSOPHY

ENVIRONMENTAI SCIENCES AND RESOURCES - CHEMISTRY

Portland State University

1982 
TO THE OFFICE OF GRADUATE STUDIES AND RESEARCH:

The members of the Committee approve the dissertation of Peter James Lammers presented June 4, 1982 .

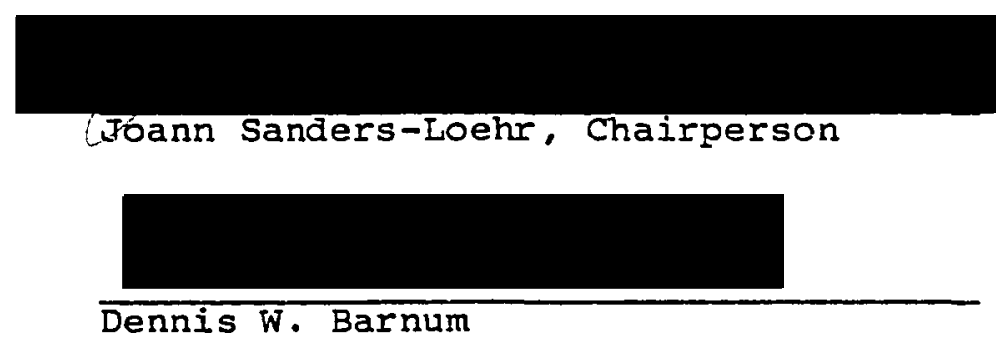

Dennis $w \cdot$ Barnum
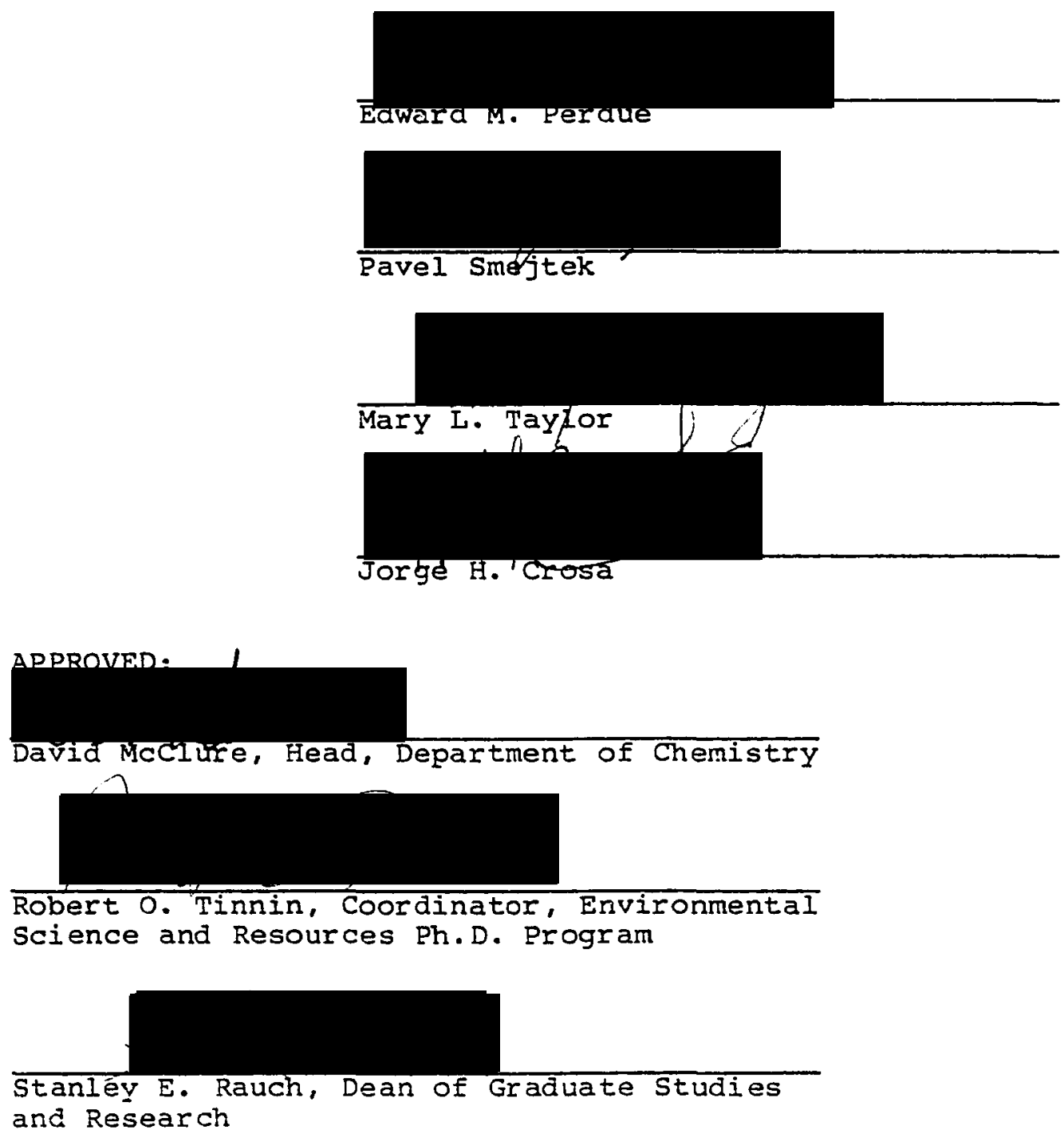
AN ABSTRACT OE THE DISSERTATION of Peter James Lammers for the Doctor of Philosophy in Environmental Sciences and Resources - Chemistry, presented June 4, 1982.

Title: Iron Acquisition by Cyanobacteria: Siderophore Production and Iron Transport by Anabaena

APPROVED BY MEMBERS OF THE DISSERTATION COMMITTEE:

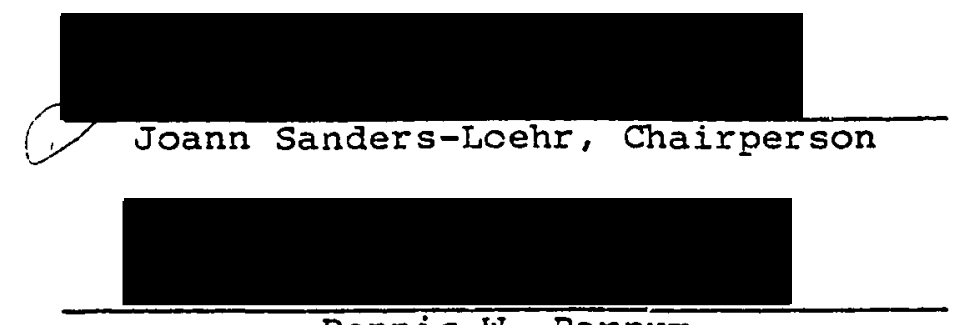

Dennis W. Barnum

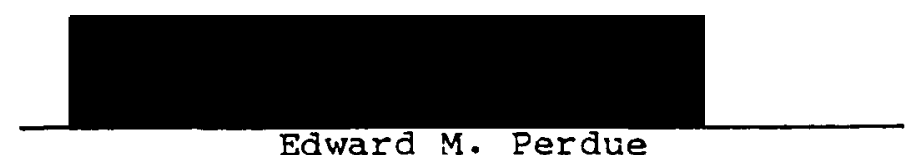

Edward M. Perdue

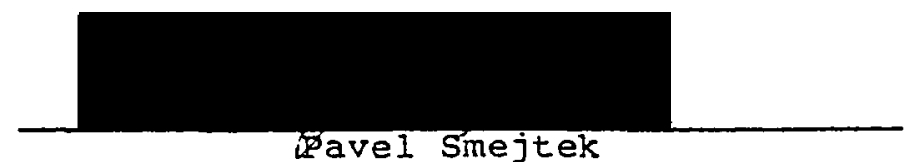

pavel Smejtek
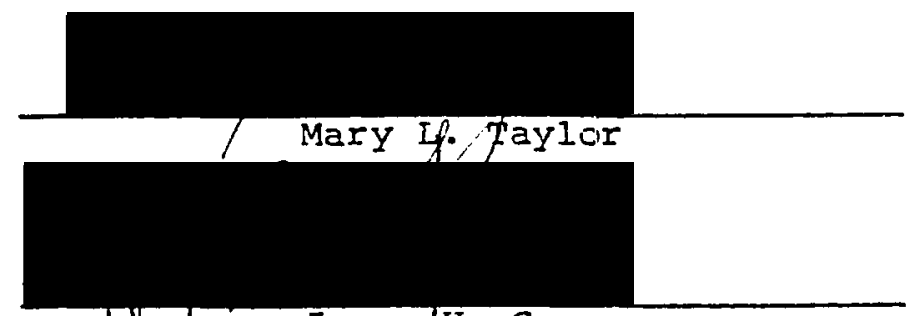

Th Jorge'H. Crosa 
The cyanobacterium Anabaena sp. (PCC \#6411) is known to produce the siderophore, schizokinen, in response to iron limitation. Environmental factors which influence schizokinen production have been examined utilizing a bioassay method based upon the stimulation of growth of the siderophore-requiring bacterium Arthrobacter flavescens JG-9. Schizokinen production by Anabaena increased in low-iron media and was stimulated approximately five-foid media containing one millimolar citric acid. Growth of Anabaena under nitrogen-fixing conditions reduced extracellular schizokinen concentrations 3-4 fold, in late growth phase, compared to cells grown on nitrate. Cells grown in ammonium-containing medium yielded intermediate concentrations of schizokinen. The Csaky assay, which is often used to detect hydroxamate siderophores, was found to be subject to interferences that can yield erroneously high values. The problems associated with detection and quantitation of cyanobacterial siderophores are discussed. Anabaena was found to utilize schizokinen to accumulate $>908$ of the $[55 \mathrm{Fe}]$-ferric iron added to the medium. Iron transport capability was increased in iron-starved cells. The transport system a pears to be fairly specific for schizokinen, in that an acetylated derivitive of schizokinen also supported iron transport, but the structurally related siderophore, aerobactin, and the trihydroxamate siderophore, ferrioxamine B, did not support iron uptake by Anabaena. The uptake of ferric schizokinen 
displayed saturation-type kinetics with an apparent $K_{M}$ of $35 \mathrm{nM}$, and required the input of metabolic energy. Lightdriven transport was blocked by uncouplers and ATPase inhibitors. Transport in dark-adapted cells was additionally blocked by inhibitors of respiration. We conclude that ATP serves as an energy source for the cellular uptake of schizokinen.

Two other kinds of Anabaena were examined for siderophore production. Anabaena sp. (PCC \#7120) was found to produce a substance which stimulates the growth of the Arthrcioacter JG-9. This substance binds iron and has a similar absorbance maximum to schizokinen in ferricperchlorate solutions. Anabaena 7120 also utilized ferric schizokinen and ferric acetyl-schizokinen for iron uptake, but not aerobactin or ferrioxamine B. These results suggest that the iron transports systems of Anabaena 6411 and 7120 may be the same. Anabaena cylindrica Lemm. apparently does not produce or utilize a schizokinen-type siderophore. No Arthrobacter JG-9 stimulating material coild be detected in low-iron filtrates, even if concentrated 25-fold. 


\section{ACKNOWLEDGMENTS}

I am profoundly indebted to many people who made the efforts presented in this dissertation possible. Of paramount importance was the guidance of Joann Loehr who has done her best to imprint upon my undisciplined curiosity and enthusiasm, the lesson that hard and critical thinking is usually more important than hard work in science. The freedom, tolerance, criticism, and example she has provided are the major factors behind my development as a scientist.

I am also indebted to the members of my committee who have provided encouragement as well as valuable ideas and discussions. Their critical evaluations have significantly improved the quality of the work. I have also been greatly aided by many helpful discussions with Drs. Jack Meyers, Jon Abramson, and Thomas Loehr.

To Alden Pritchett I owe special thanks for his good natured and competent technical assistance. I would also like to acknowledge the assistance of Kathy Morefield in the preparation of this manuscript.

Most importantly, I owe a huge debt of gratitude to my wife, Mindy, whose encouragement and sacrifice allowed me to pursue the educational opportunities I have been lucky enough to encounter. I also must acknowledge the 
help of my parents, specifically my mother who taught that there is, no such thing as a stupid question; and my father whose wonder in the face of this universe proved contagious. 
TABLE OF CONTENTS

PAGE

ACKNOWLEDGMENTS. ...................... ii

LIST OF TABLES....................... vii

LIST OF FIGURES........................

SECTION

I. INTRODUCTION

STATEMENT OF PROBLEM................. I

BIOAVAILABILITY OF IRON............... 5

STRUCTURES AND CHARACTERISTICS OF

MICROBIAL SIDEROPHORES................ 9

SIDEROPHORE-DEPENDENT IRON TRANSPORT SYSTEMS... 22

II. EXPERIMENTAL

GROWTH MEDIA AND CUIJURE CONDITIONS......... 30

SCHIZOKINEN PRODUCTION FROM BaCillus megaterium. 42

Characterization of schizokinen........ 51

Modifications of schizokinen......... 55

AEROBACTIN FROM Aerobacter aerogenes......... 58

SIDEROPHORE ASSAYS................... 6 I

Csaky assay for hydroxamic acids.......6 61

Arthrobacter JG-9 bioassay for

siderophores..................66

Iron binding assay for siderophores...... 71

IRON UPTAKE ASSAYS.................. 73 


\section{RESULTS}

EFEECTS OF IRON AND CHELATORS ON GROWTH OF Anabaena $6411 \ldots \ldots \ldots \ldots \ldots \ldots \ldots \ldots$

SIDEROPHORE PRODUCTION BY Anabaena $6411 \ldots \ldots . \ldots 87$ TRANSPORT OF FERRIC SCHIZOKINEN BY Anabaena $6411 \ldots \ldots \ldots \ldots \ldots \ldots \ldots \ldots \ldots . \ldots . \ldots . \ldots 1$

KINETICS AND ENERGY DEPENDENCE OF FERRIC SCHIZOKINEN TRANSPORT............... 95 SPECIFICITY OF IRON UPTAKE IN Anabaena $6411 \ldots . .100$ SIDEROPHORE ACTIVITY IN DIFFERENT STRAINS

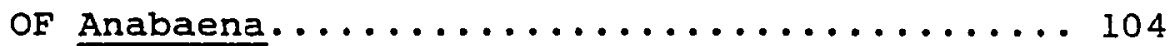
SIDEROPHORE ASSAYS WITH Anabaena cylindrica.... 108

IV. DISCUSSION................................ 109 SIDEROPHORE ASSAYS................... 110

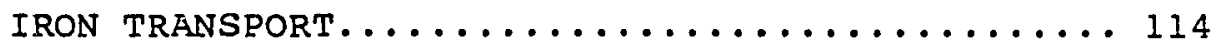
RESPONSES TO IRON LIMITATION............. 119 ENVIRONMENTAL IMPLICATIONS.............. 125 CONCLUSIONS....................... 126

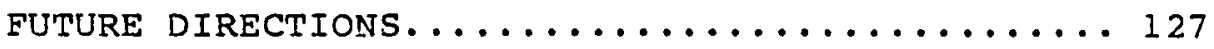

V. REFERENCES......................... 130 


\section{IIST OF TABLES}

TABLE

PAGE

I Media for Cyanobacteria................. 31

II Compounds that Satisfy Growth Requirement of Arthrobacter flavescens JG-9......... 39

II Media for Bacterial Species............... 40

IV Concentrations of Schizokinen in Anabaena Filtrates...................... 67

$\mathrm{V}$ Concentration of Schizokinen $(\mu \mathrm{M})$ in Anabaena Filtrates.................. 88

VI Effect of Metabolic Inhibitors on Ferric Schizokinen Uptake in Anabaena $6411 \ldots \ldots . . .999$

VII Iron Speciation in BG-11 Medium as Predicted by MINEQL................. 121 
1 Structure of Ferrichrome-type Siderophores...... II

2 Structures of Ferrioxamine B, Fusarinines, and Rhodotorulic Acid................ 15

3 Structures of Catechol-type siderophores....... 18

4 Structures of Citrate-hydroxamate Siderophores Including Schizokinen................ 20

5 Sumnary of Membrane Uptake Systems for Specific

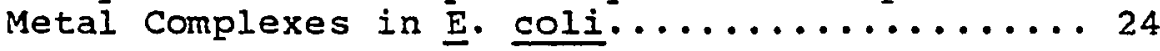

6 Growth of Anabaena 6411 in Uptake Medium and

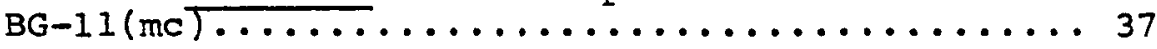

7 Anion Exchange Chromatography of Crude Schizokinen...................... 46

8 Gel Permeation Chromatography of Schizokinen.... 48

9 MMR Spectra of schizokinen.............. 50

10 Visible Absorption Spectrum of Ferric Schizokinen as a Function of $\mathrm{pH} . \ldots \ldots \ldots \ldots \ldots$

11 Spectrophotometric Titration of Schizokinen

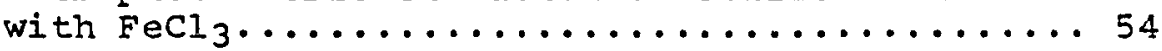

12 NMR Spectrum of Acid Hydrolyzed Schizokinen.... 57

13 NMR Spectrum of Acetyl-Schizokinen...........60

14 NMR Spectrum of Aerobactin..............663

15 Standard Curve for Csaky Assay.............65

16 Growth Response of Arthrobacter flavescens to Various Concentrations of purified

Schizokinen....................... 69

17 Visible Absorption Spectra for Anabaena Filtrates in $5 \mathrm{mM} \mathrm{Fe}$ (III), $0 .{\overline{14 \mathrm{M} \mathrm{HClO}_{4}}}_{4} \ldots \ldots .72$

18 Growth of Anabaena 6411 in BG-11 Medium as a Function of Added Iron............. 81

19 Growth of Anabaena 6411 with and Without

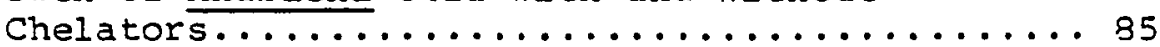


20 Growth of Anabaena 6411 in BG-11(mc)

Without Combined Nitrogen.............. 86

21 Uptake of $\left[5^{55} \mathrm{Fe}\right]$ Ferric Schizokinen........... 93

22 Rate of Uptake of [55 Fe] Ferric Schizokinen as a Function of Iron Concentration in the

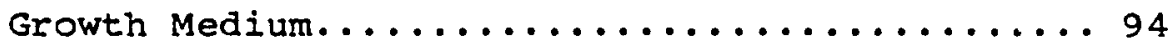

23 Kinetics of Uptake of Ferric Schizokinen........ 96

24 Effect of CCCP and DCCD on the Uptake of Ferric Schizokinen in Anabaena $6411 \ldots \ldots \ldots . .98$

25 Iron Uptake Activity by Anabaena for Several Ferric Siderophore Complexes.............103

26 Iron Uptake Activity by Anabaena $7120 \ldots \ldots \ldots \ldots \ldots 107$ 


\section{INTRODUCTION}

Cyanobacteria, also known as blue-green algae, are the most plant-like of all procaryotic organisms. They are widely distributed from polar seas to thermal springs as well as in soils and fresh water. Cyanobacteria derive their metabolic energy from sunlight, abstracting hydrogen atoms from water and liberating oxygen gas. Reducing power thus generated is used to fix carbon dioxide gas as carbohydrate. For most cyanobacteria, $\mathrm{CO}_{2}$ is the sole source of cell carbon. Many of these organisms are also capable of reducing molecular nitrogen $\left(\mathrm{N}_{2}\right)$ to ammonia for amino acid biosynthesis. As a result, cyanobacteria have exceedingly simple nutritional requirements; consisting mainly of phosphorus, magnesium, calcium, and trace metals including iron and molybdenum. Cyanobacteria have long been studied as model systems for photosynthesis and nitrogen fixation. Genetic analysis of these processes, made possible by recent advances in recombinant DNA technology, holds promise for eventually producing more efficient and possibly new nitrogen-fixing agricultural crops(1).

In the natural environment, cyanobacteria have something of a Jekyll and Hyde reputation. On the positive 
side, some blue-greens form productive symbiotic associations with other organisms. The most notable of these is the Anabaena-Azolla symbiosis that is currently being used in southeast Asia to fertilize rice paddies instead of expensive chemical fertilizers (2). On the negative side, however, are the many species that form "blooms" in lakes that can totally dominate other phytoplankton and adversely affect water quality(3). Toxins are produced by many species and floating scums associated with blooms are particularly objectionable (4).

The factors that govern phytoplankton succession and dominance in aquatic ecosystems are poorly understood. Competition for available nutrients is certainly a factor along with seasonal variations in temperature and light intensity. In addition, a potentially important parameter is the availability of the micronutrient iron. Iron is a component of many essential biological catalysts including the cytochromes and iron-sulfur proteins involved in the photosynthetic electron transport chains of all phytoplankton. Iron containing proteins are also involved in the metabolism of $\mathrm{N}_{2}$ and $\mathrm{H}_{2}$, in the reduction of ribotides to deoxyribotides (precursors of DNA), in oxidation and hydroxylation of a host of inorganic and organic metabolites and finally in the decomposition or utilization of hydrogen peroxide (5). The availability of iron for biological use is not a simple matter however. Ferric ions, as $\mathrm{Fe}\left(\mathrm{H}_{2} \mathrm{O}\right)_{6}{ }^{3+}$, have a great tendency to form 
polymeric ferric hydroxide that is extremely insoluble. The presence of natural chelators such as humic acids can keep ferric ions in solution, but whether this increases or decreases iron bioavailability is an open question. Many microorganisms have evolved the capability to produce powerful iron chelators, known as siderophores, to complex insoluble iron which can then be transported inside the producing cells via specific, siderophore-dependent uptake systems (6). The production of a hydroxamate-type siderophore during a cyanobacterial bloom of Anabaena flos-aqua in a eutrophic bay has been documented (7). Furthermore, partially purified preparations of this compound were found to greatly inhibit the growth of Scenedesmus, a green alga which had disappeared during the bloom. The growth inhibition caused on addition of the hydroxamate was reversed by the addition of excess iron, suggesting that siderophore-induced iron limitation for competing species may well be important in establishing bloom conditions.

Despite the potential importance of iron limitation on phytoplankton competition in aquatic ecosystems, very little is known about the subject. Only one cyanobacterial siderophore has been structurally characterized (8), and the extent of cyanobacterial siderophore production is not well understood. No investigations of siderophoredependent iron transport by cyanobacteria have been reported to date. As a result, it is very difficult to 
evaluate the potential significance of iron limitation and competition for iron as a determinant of aquatic ecosystem composition and stability.

This dissertation will deal with the dual questions of cyanobacterial siderophore production and siderophoredependent iron transport across cyanobacterial membranes. The organism chosen for study is Anabaena sp. (ATCC \#27898, Pasteur Culture Collection \#6411) which is known to produce the dihydroxamate siderophore, schizokinen (8). Techniques for measuring siderophore production have been evaluated in addition to factors that quantitatively affect siderophore production. The iron transport system has been examined with respect to induction, substrate specificity, substrate affinity, and energy requirements.

In addition, the production of siderophores by two other species of Anabaena, strain 7120 (Pasteur Culture Collection) and Anabaena cylindrica Lemm., has been examined along with their ability to take up iron complexed by several siderophores.

A brief review of the factors influencing the bioavailability of iron and a description of the properties of known siderophores and their associated uptake systems will follow to provide a frame of reference for the results of the present study. 
Bioavailability of Iron

Despite the fact that iron comprises nearly five percent of the earth's crust, soluble iron in oxygenated waters is often extremely scarce. Under these conditions, iron will exist primarily in the +3 oxidation state which readily hydrolyzes to form polymeric ferric hydroxide species. The solubility product constant of $\mathrm{Fe}(\mathrm{OH})_{3}$ is $10^{-38.7} \mathrm{M}$ at $25^{\circ} \mathrm{C}(9)$. This value leads to a concentration of $\mathrm{Fe}(\mathrm{III})(\mathrm{aq})$ of only $10^{-18} \mathrm{M}$ at $\mathrm{pH} 7$. However, this ignores the contribution of soluble Fe(III) species such as $\mathrm{Fe}(\mathrm{OH})^{2+}, \mathrm{Fe}(\mathrm{OH})_{2}^{+}$, and $\mathrm{Fe}(\mathrm{OH})_{3}$. The formation constant for $\mathrm{Fe}(\mathrm{OH})_{3}(\mathrm{aq})$ is very difficult to measure experimentally. An upper limit on the solubility of ferric hydroxide of $10^{-8} \mathrm{M}$ has sen calculated by taking advantage of the nearly linear plots of the free energy of formation of each successive hydrolysis product versus the number of coordinated hydroxides (10) to estimate the formation constant for $\mathrm{Fe}(\mathrm{OH})_{3}(\mathrm{aq})$. Even this higher value is considerably below the optimal values for cyanobacterial growth. For example, Nostoc muscorum requires $3 \times 10^{-6} \mathrm{M}$ iron for maximal growth on nitrate and $2 \times 10^{-5} \mathrm{M}$ iron for maximal growth under nitrogen-fixing conditions (11). In this case the solubility of iron in the growth medium was increased above $10^{-8} \mathrm{M}$ by the presence of phosphate and EDTA; such complexes are excellent sources of iron for organisms which make siderophores. In natural systems 
where the level of chelators is much lower, iron tends to become a limiting nutrient due to its removal from solution as a ferric hydroxide precipitate (12, 13). The fact that iron can be a limiting nutrient to natural algal populations has been known for over twenty years. Enrichment experiments conducted with water samples from Lake Erie, The Sargasso Sea, and the Indian Ocean have demonstrated increased algal productivity with added iron (14-16). The formation of ferric hydroxide is not the only mechanism reducing the bioavailability of iron. The precipitation of iron-phosphorous complexes is thought to be an important pathway for the loss of these nutrients to sediment (17). Furthermore, while the phosphorous can be returned to the water column following reduction of iron (III) to iron (II) in anoxic sediments (18), Murphy and Lean have shown that a large fraction of iron returning from sediments to open water is not available for biological uptake (19). This iron was associated with magnesium and had a molecular weight between 1000 and 5000 daltons. To further complicate the picture, the effect of potential chelators present in sediments such as humic acids on iron bioavailability is not well understood. Fulvic acid, a fraction of humic acids, has been shown to be an effective trace metal chelator for some cyanobacteria that require EDTA and citrate in order to grow in a synthetic medium (20). This effect required that the fulvic acid be used in a proper ratio with the essential nutrients, a condition 
that is hard to predict in natural systems. The effect of the other fractions of humic acids upon iron speciation and the resulting influence on cyanobacterial growth has not been established.

Potentially the most important factor controlling the availability of iron to phytoplankton is the projuction of biological chelators. Among the first efforts to study this possibility was the report by Fogg and Westlake on extracellular pigment-polypeptide complexes produced by Anabaena cylindrica Lemm. (21). The extracellular concentration of this substance was shown to be quantitatively affected by iron (22), and it was later demonstrated that up to 128 of the iron supplied to the medium was bound by a large peptide (23). The specific biological function of this pigmentpolypeptide complex has never been established however. It is doubtful that this material represents a true siderophore (see below), however a roie in iron metabolism cannot be ruled out.

Only recently have efforts to detect true cyanobacterial siderophores been undertaken. Van Baalen and coworkers have detected siderophore activity from cyanobacterial mats collected from nearshore marine environments (24), and also in axenic culture of the marine cyanobacterium Agmenellum quadruplicatum (25). The structure of these compounds is not yet known. Simpson and Neilands have isolated the dihydroxamate siderophore, schizokinen, from Anabaena sp. (PCC \#6411). This siderophore is also 
produced by the Gram positive bacterium Bacillus megaterium and is the only structurally characterized cyanobacterial siderophore known to date (7).

other studies have given indications that siderophore production by cyanobacteria may not be uncommon. Several different Anabaena strains have been studied by Mcknight and Morel with respect to their production of strong extracellular copper chelators that are probably siderophores (26). Here again, the identity of these compounds is not known, since their identification as siderophores is based on the fact that iron limitation greatly increases the extracellular concentration of the strong copper-complexing compound. Lange has proposed that the ability to grow on synthetic medium without added chelators can be used as an assay for the production of biological chelators by cyanobacteria (27). Six of the ten species he examined grew well without synthetic chelators present. Furthermore, sterile filtrates from cultures that grew normally were able to overcome the chelator requirements of the other four species. In order to prove that these presumptive chelators are actually siderophores, three criteria need to be demonstrated. A "true" siderophore must display nigh affinity for iron, accumulate in response to iron limitation, and promote the uptake of iron by the siderophore-producing cells. These questions have not yet been ad dressed. 
Structures and Characteristics of Microbial Siderophores

Since the evolution of an oxidizing atmosphere on this planet by photosynthetic $\mathrm{O}_{2}$ production from water, the availability of iron in most aquatic systems has been limited by formation of iron(III) minerals of low solubility and perhaps by the formation of high molecular weight hydroxybridged ferric polymers. This condition has encouraged biological systems to evolve specific chelating agents for ferric iron, called siderophores (6). Since the first isolation of a siderophore (ferrichrome) by Neilands in 1952 (28), scores of siderophores have been identified from bacteria, fungi, yeast, and cyanobacteria. There are now seven recognized families of siderophores: ferrichromes, ferrioxamines, fusarinines, rhodotorulic acids, enterobactins, mycobactins, and aerobactins. Hydroxamate ligands prevail in all of the above families except the enterobactins, which contain catecholate ligands. Both form stable five membered ring complexes with iron.

The iron atom in these complexes is $d^{5}$, high spin $(29,30)$, and as a result of a lack of crystal field stabilization energy, is readily exchangeable (31). The siderophores as a group are characterized by tremendous formation constants with Fe(III) that range from $10^{23}$ to 1052 (6). The hydromamate containing siderophores are much more numerous than the tri-catecholate ligands which are Iimited to the true bacteria (6). 
The ferrichrome family of siderophores are characterized by three hydroxamate groups linked to a cyclic hexapeptide (Figure 1, source ref. 6). Ferrichrome itself is produced by Ustilago sphaerogena, a fungus, but it is also utilized for iron transport by severil bacteria that do not produce it, including Escherichia coli, Salmonella, and Arthrobacter flavescens (32). Other members of this family include ferrichrome A, ferrichrysin, ferrirubin, ferrirhodin, sake colorant $A$, and ferrichrome $C$. The antibiotic albomycins are also ferrichrome derivitives produced by Actinomyces grisens, and they are effective against bacteria which utilize ferrichrome for iron transport. Ferrichrome-type siderophores are commonly produced by Aspergillus, Penicillium, Neurospora, Ustilago, and other smut fungi, and one yeast species Cryptococcus which produces ferrichrome C (6). 

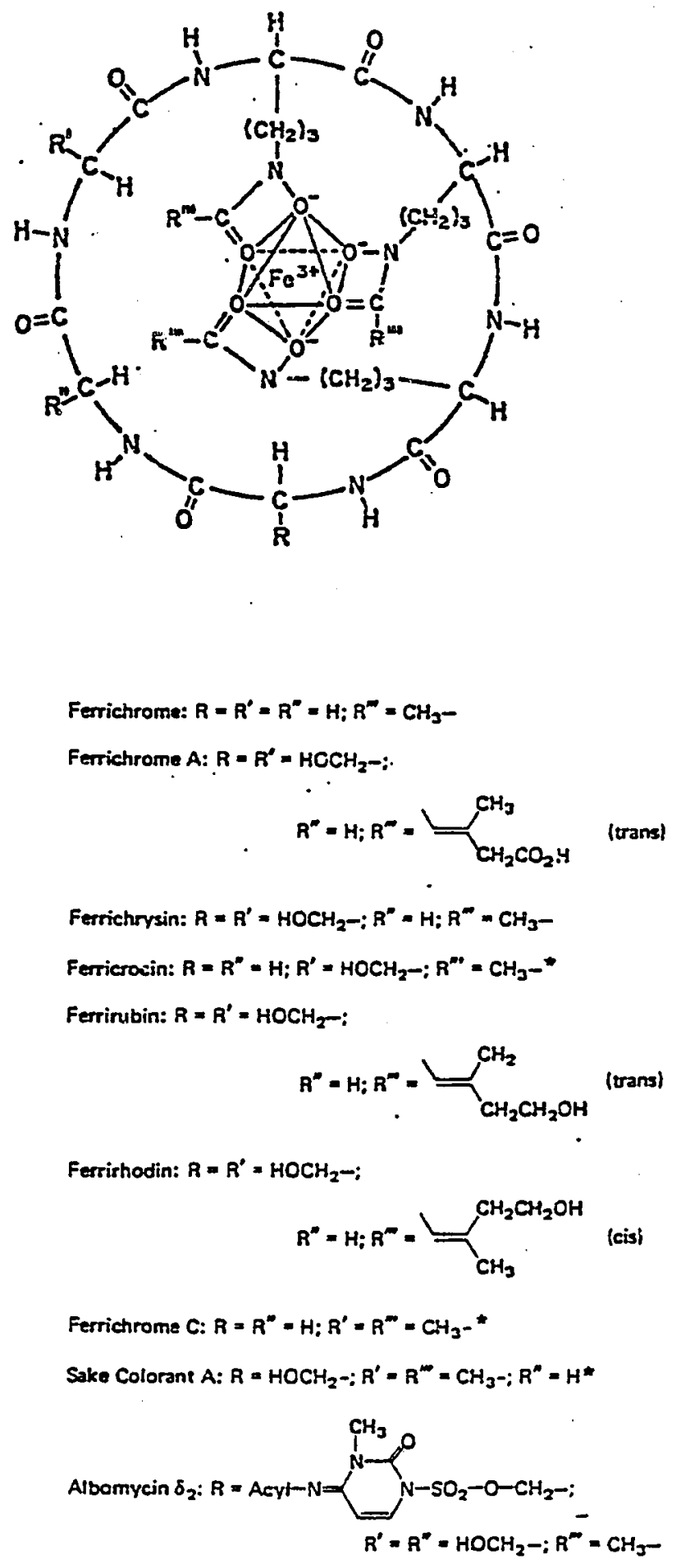

Figure 1. Structure of ferrichrome-type siderophores. 
Ferrichrome-type siderophores will form stable complexes with six coordinate metal ions which prefer octahedral geometry, with iron (III) being the most efficiently complexed metal ( $\mathrm{K}_{\mathrm{f}}=10^{29.1}$ for ferrichrome). Ferrichrome complexes with chromic ions have been prepared in addition to aluminum and gallium complexes $(33,34)$. The chromic complex is kinetically inert because of the $d^{3}$ electronic configuration which leads to sizeable crystal field stabilization energy and slow ligand substitution (35). These chromic-desferri-ferrichrome derivatives have been useful in determining the absolute configuration of the possible coordination and optical isomers and the fate of the siderophore-metal complex during transport into cells (to be described below). In the case of the ferrichromes, the trans geometric isomer is unlikly to form due to steric hindrance, while both the cis $\Delta$ and $\Lambda$ cis diosteromers are possible. Both solution methods (circular dichroism) and crystal structure data indicate that the $\wedge$ cis form predominates (35).

Two ferrichrome-fanily members are of special interest in that the ferric complexes of ferrichrome $A$, produced by Ustilago sphaerogena (36), and malonichrome, produced by Fusarium roseum (37), are not active as iron transport agents for the producing organism or for the test organism Arthrobater flavescens JG-9 which responds to nearly all siderophores. The biological function of these compounds 
is still in question. The formation constant for ferrichrome $A$ is $10^{32}$ which is higher than most other natural hydroxamates (6). One possibility is that these compounds are designed to solubilize iron which can thereafter exchange with the functional siderophore and enter the cell. Also, both compounds are more acidic than the functional siderophores produced by the same organism. It has been suggested that this quality may be helpful in solubilizing iron minerals (37).

The ferrioxamine family of siderophores contains three hydroxamate groups inserted into a linear backbone as shown in Figure 2A which presents the structure of ferrioxamine $B$ (38). The ferrioxamines are produced by a number of species of Streptomyces and Nocardia (39). Two members of this class, ferrioxamines $E$ and $D_{2}$, undergo cyclization via amide bond formation between a terminal succinyl group and a teminal amino group (6). Certain ferrioxamine derivatives display antibiotic activity and are thus termed ferrimycins. As with the albomycins, the toxic agent is an extra group attached to a complete and functional iron transport agent (38). The ferrioxamines are devoid of optical activity and several have been prepared by chemical synthesis $(40)$. One of these, the mesylate salt of ferrioxamine B (Desferal), is used in the treatment of iron toxicity and the iron overload associated with the transfusion treatment of Cooleys anemia and thalassemia (35). 
The fusarinines are also trihydroxamate siderophores produced by Fusarium species (6). The structure of fusarinine $B$ is shown in Figure 2B. Note the unusual aminoacyl ester linkages, and also the free amino groups which cause these compounds to be basic in contrast to the neutral ferrichromes. The amino acyl ester linkage is quite rare (amino acyl-tRNA being the notable exception) and is rapidIy hydrolyzed under mild conditions (39).

The rhodotorulic acid (RA) group of siderophores are all dihydroxamate compounds that combine with two iron atoms to form a complex of the formula $\mathrm{Fe}_{2} \mathrm{RA}_{3}$ at $\mathrm{pH}$ values between four and eleven (41). The structure of rhodotorulic acid is shown in Figure 2C. These siderophores are produced by at least 52 different strains of yeast among the genera Aessosporoa, Cryptococcus, Leucosporidium, Rhodosporidium, Rhodoturula, Sporidiobolus, and Sporobolomyces (6). Perhaps the most striking feature common to this group are the prodigious yields of siderophore that can be isolated. While some siderophores are isolated with yields of only 1-10 milligrams per liter of culture fluid, and sometimes less, yields of 3-4 grams per liter are often obtained from RA producing cultures (42). Rhodotorulic acid is a potent growth factor for Arthobacter flavescens JG-9 and is also being tested for use in treatment of iron overload (35).

The family of catecholate siderophores is typified by enterobactin, also called enterochelin (Figure $3 A$ ). 
A.

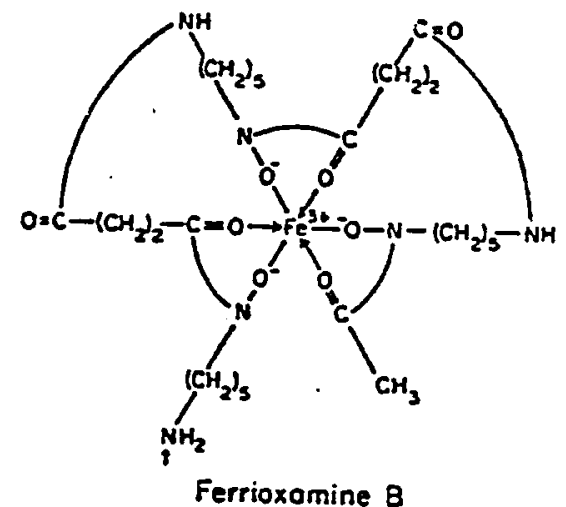

B.

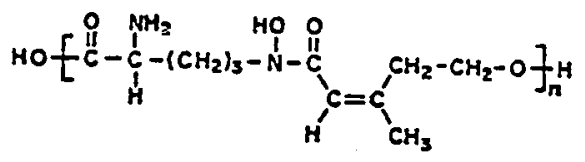

XIII Fusarinines

XIIIa Fusarinine: $n=1$

$\mathrm{Xum}$ Fusarinine $A: n=2$

XIIIC Fusarinine B: $n=3$

XIII Fusarinine C (Deferrifusigen): $n=3$, cyclo

c.<smiles>CC(=O)N(O)CCC[C@@H]1NC(=O)[C@@H](CCCN(O)C(C)=O)NC1=O</smiles>

Rhodotorulic acid

Figure 2. Structure of ferrioxamine B, fusafinines, and rhodotorulic acid. 
This siderophore is produced by Escherchia coli, Salmonella typhimurium, and Aerobacter aerogenes (now Klebsiella pneumoniae) (32). Enterobactin is sparingly soluble in water above $\mathrm{pH} 7$ to 8 where the 2 -hydroxyl group begins to ionize, the pKs of the catechol group being near 8.4 and 12.1 (23). At less than neutral pH, the molecule's ester linkages hydrolyse to form the monomer dihydroxybenzoyl serine.

The stability constant for ferric enterobactin has been obtained spectrophotometrically at pH 5, where a measurable distribution of iron between enterobactin and EDTA can be obtained (23). The stability constant is

$$
K^{*}=\frac{\left[\mathrm{Fe}(\text { ent })^{3-}\right][\mathrm{H}+]^{6}}{\left[\mathrm{Fe}^{3+}\right]\left[\mathrm{H}_{6} \text { ent. }\right]}=10^{-9.7}
$$

Using the above values for the protonation constant and substituting for the hydrogen ion concentration, the formation constant $\left(K_{f}\right)$ can be estimated as

$$
K_{f}=\frac{\left[\mathrm{Fe}(\mathrm{ent})^{3-}\right]}{\left[\mathrm{Fe}^{3+}\right]\left[\mathrm{ent}^{6-}\right]}=10^{52}
$$

This is the largest formation constant of any known iron chelate, and is 7-12 log units larger than the $\log 3$ values of the bidentate catecholates. This "chelate effect" is much greater than the relatively small difference between the trihydroxamate siderophore chelates and 
the 3 of triacetohydroxamate, which in the case of ferrichrome is 0.8 and for ferrioxamine $B$ is $2.2 \log$ units (6).

The enterobactin molecule is a trimer of 2,3dehydroxylbenzoyl serine joined through labile ester linkages between the serine hydroxyl and the carboxylate group of the adjacent serine (Figure 3 ). The monomers are often found in culture fluid together with the cyclic parent compound. A related compound 2,3 dihydroxybenzoyl glycine (also called itoic acid) has been isolated from low iron cultures of Bacillus subtilis (44). The compound facilitates iron transport in B.subtilis and is an example of a "monomeric" siderophore (6). Other phenolate siderophores are 2-N, 6-N-Di- (2,3-dihydroxybenzoy 1$)-L-1$ ys ine produced by Azotobacter vinelandii (25), and two linear tricatechols, parabactin produced by paracoccus denitrificans (46) and agrobactin which is produced by Agrobacterium tumefaciens, the agent of crown gall disease in plants (47). These last two are also referred to as "spermidine" siderophores due to the presence of a residue of spermidine providing the linear backbone. InterestingIy, the ferric ion is coordinated to the two distal catechols and the 2-(2-hydroxyphenyl) oxazoline residue (Figure 3 ), with an affinity very similar to enterobactin (48a).

Recently, experiments designed to determine if agrobactin is important to Agrobacterium tumefaciens invasion 


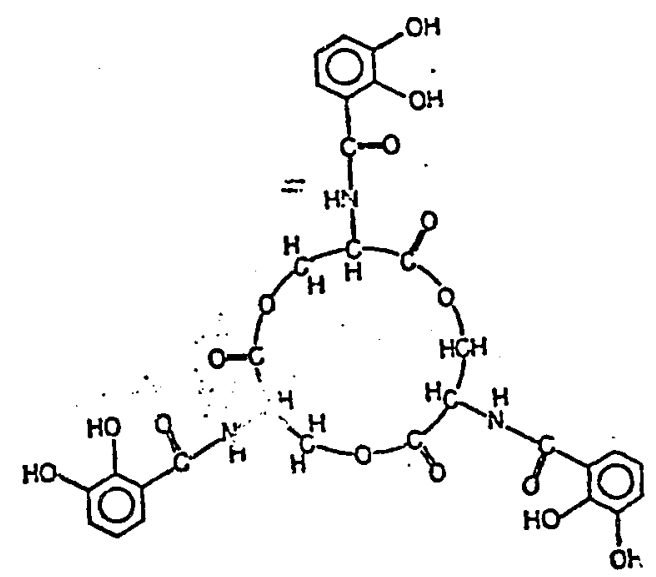

Enterobactin

B.

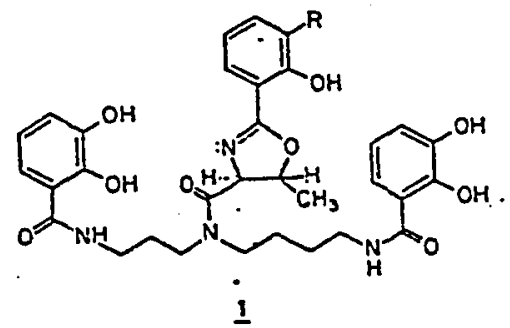

Parabactin $(\mathrm{R}=\mathrm{H})$

Agrobactin ( $\mathrm{R}=\mathrm{OH})$

c.

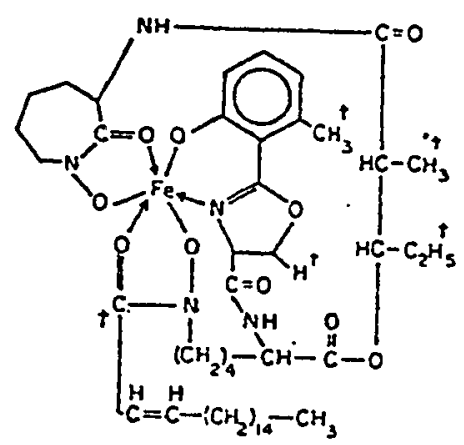

Fe(II)-Mycoboctin P

Figure 3. Structures of catechol-type siderophores. 
of plant tissue through chelation of iron present in the plant, were conducted. Surprisingly, no agrobactin could be detected in the diseased plant tissue and the bacteria may have been utilizing citrate coordinated iron provided by the plant (48a).

The mycobactin family of siderophores is unique in that all are lipophilic molecules that are strictly cell membrane associated and, thus, may behave as Fe(III) ionophores (49). The structure of mycobactin $P$ is shown in Figure 3. All members of this group are dihydroxamate molecules with the fifth and sixth ligands provided by the phenolic hydroxyl and the nitrogen of the oxazoline ring. Estimates of the binding affinity of mycobactin $P$ suggest that it is higher than that of ferrioxamine $B(49)$. The chromium, aluminum, gallium, vanadium, and copper complexes with mycobactin $\mathrm{P}$ have all been prepared and the chromium complex has been found to reverse the growth promoting effect of mycobactin for M.paratuberculosis (50). Seven distinct groups of mycobacteria are known to produce mycobactins peculiar to that group. This property has been utilized for taxonomic purposes whereby thin-layer chromotography of cell extracts from low iron media is used to identify the mycobactin produced (51).

The last family of siderophores to be considered is the aerobactin group. This family includes the siderophore under investigation in this study, schizokinen, which is produced by the cyanobacterium Anabaena (strain ATCC 

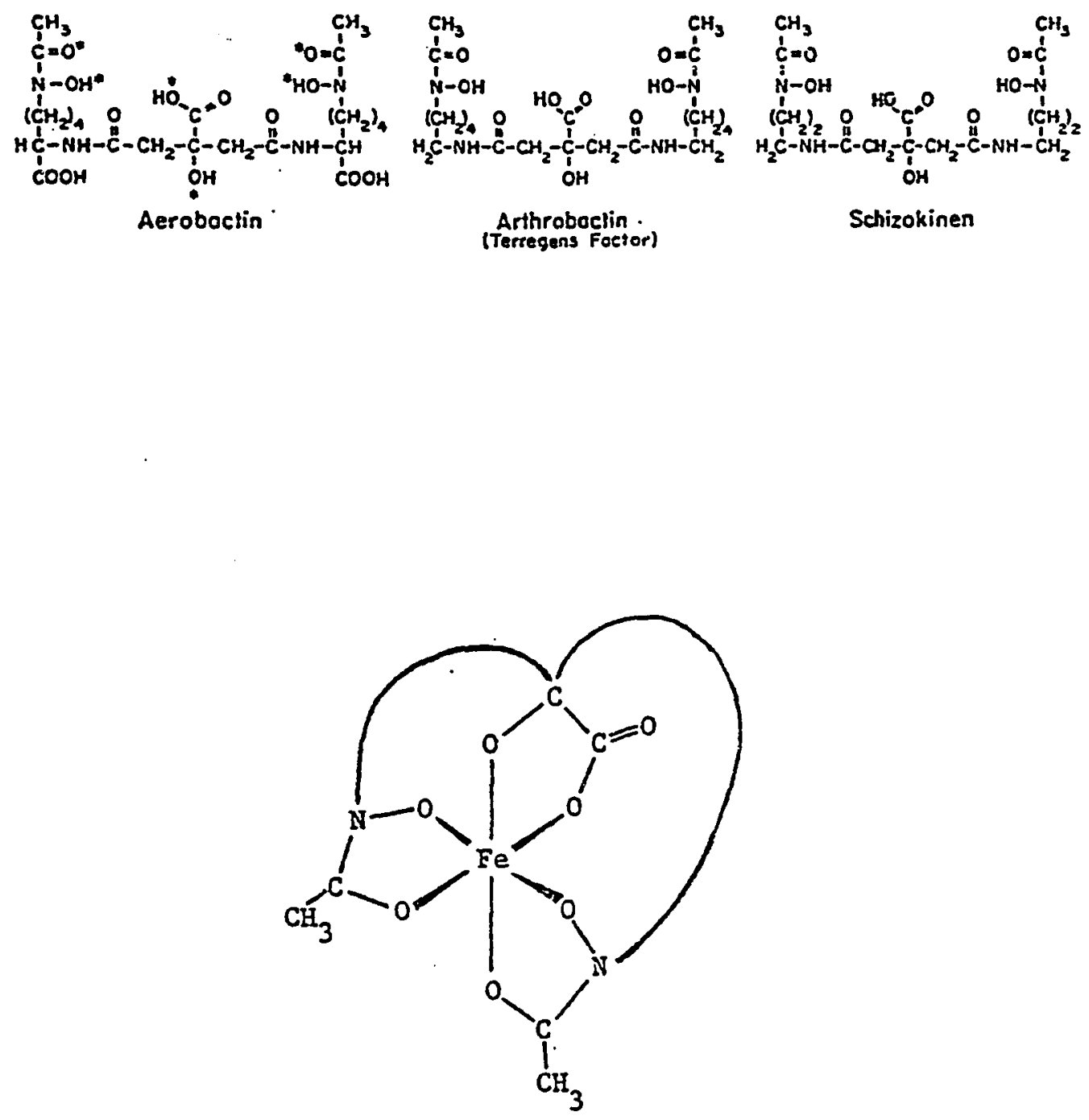

FE (III)-SCHIZOKINEN

Figure 4. Structures of citrate-hydroxamate siderophores including schizokinen. 
\#27898) and also the Gram positive bacterium, Bacillus megaterium $(8,52)$. Arthrobactin (also called terregens factor) produced by Arthrobacter terregens (53), and aerobactin produced by Aerobactin aerogenes 62-1 complete this group (54). All of these compounds possess two hydroxamate-containing sidearms connected through amide bonds to the terminal carboxyls of a citric acid residue (Figure 4). The coordination of the ferric ion is provided by the four hydroxamate oxygens and the carboxyl and hydroxyl oxygens from the citrate moiety $(6,45-46)$. These compounds all display a $\mathrm{pH}$ dependent spectral shift to the red below $\mathrm{pH} 7.0$, due to the protonation of the citrate hydroxyl and carboxyl groups. The absorbance maxima for aerobactin and schizokinen at pH 7 are $398 \mathrm{~nm}$ and $395 \mathrm{~nm}$ respectively, with aerobactin existing as a trivalent anion at physiological $\mathrm{pH}$ while schizokinen is a monovalent anion in its biologically active form. These siderophores are effective chelators of iron over a broad pH range, with only $3.5 \%$ of the total iron in the form of the free hexaaquo-ferric ion at $\mathrm{pH} 2.3$ for the aerobactin species (and essentially no free iron above $\mathrm{pH} 2.7$ ) (45). Above $\mathrm{pH} 4-5$, the additional coordination by the citrate hydroxyl provides extra stability to the complex throughout the neutral and alkaline $\mathrm{pH}$ regions. Even so, the formation constant for ferri-aerobactin $(\log K=22.9)$ is $6-9$ orders of magnitude smaller than the trihydroxamate siderophores discussed above. 
Recently, several iron binding compounds have been isolated that contain sulfur ligands. Their synthesis is repressed by iron which strongly suggests that they are true siderophores. The thiohydroxamate group has been found in Pseudomonas fluorescens filtrates attached to the parent compount thioformin (57). These compounds form very stable copper(II) and iron(III) complexes and also display potent antibiotic activity. Another sulfur containing growth promoter that chelates iron has been isolated from Pseudomonas aeruginosa, and named pyochelin (58). The literature on siderophores from higher plants and animals is very sparse. However, at least one siderophore/ ionophore-like substance able to bind iron has been isolated from mammalian cells transformed by the SV 40 virus. When tissue cultures ar given picolinic acid their growth is interrupted due to interference with their iron metabolism. Mutant cells that can overcome the interference of picolinic acid produce a heat stable, trypsin-insensitive peptide capable of binding iron (59). A provocative possibility is that cancer cells may secrete siderophore-like substances in vivo which satisfy the metal requirements of the neoplasin (60).

\section{Siderophore-Dependent Iron Transport Systems}

Iron transport via siderophore-dependent uptake systems has been the subject of a great deal of research in the last decade and several reviews have been published to 
cover this material $(32,61-63)$. In general these systems are highly specific for a given siderophore and require the input of metabolic energy to operate. In many cases an organism will maintain, in addition to an uptake system for its native siderophore, one or more alternative transport systems for siderophores it doesn't produce but may encounter in the environment. Other organisms, notably the soil bacterium Arthrobacter flavescens JG-9, do not produce any siderophores of their own but utilize a great variety of naturally occurring siderophores for iron uptake (see Table 2 below). At least two siderophore systems have been located on genes carried by extrachromosomal elements (plasmids), which may help explain how such a great variety of organisms have come to utilize common siderophores (64, 65).

By far the most well characterized iron transport systems are those of the enteric bacterium Escherichia coli. This organism utilizes at least four separate and genetically distinct systems that recognize ferrienterobactin, ferrichrome, ferric citrate, and a low affinity system for which no ligand is known (62). [The recently discovered aerobactin system coded by the Col $V$ plasmid (65) may constitute a fifth system or ferric aerobactin may enter via one of the other transport systems (66)]. A model for these uptake systems is shown in Figure 5. 
Genetic Determinant

Metal

Complex

Inhibitory

Outer

Agent

Membrane

Inner

Membrane

Cytoplasm

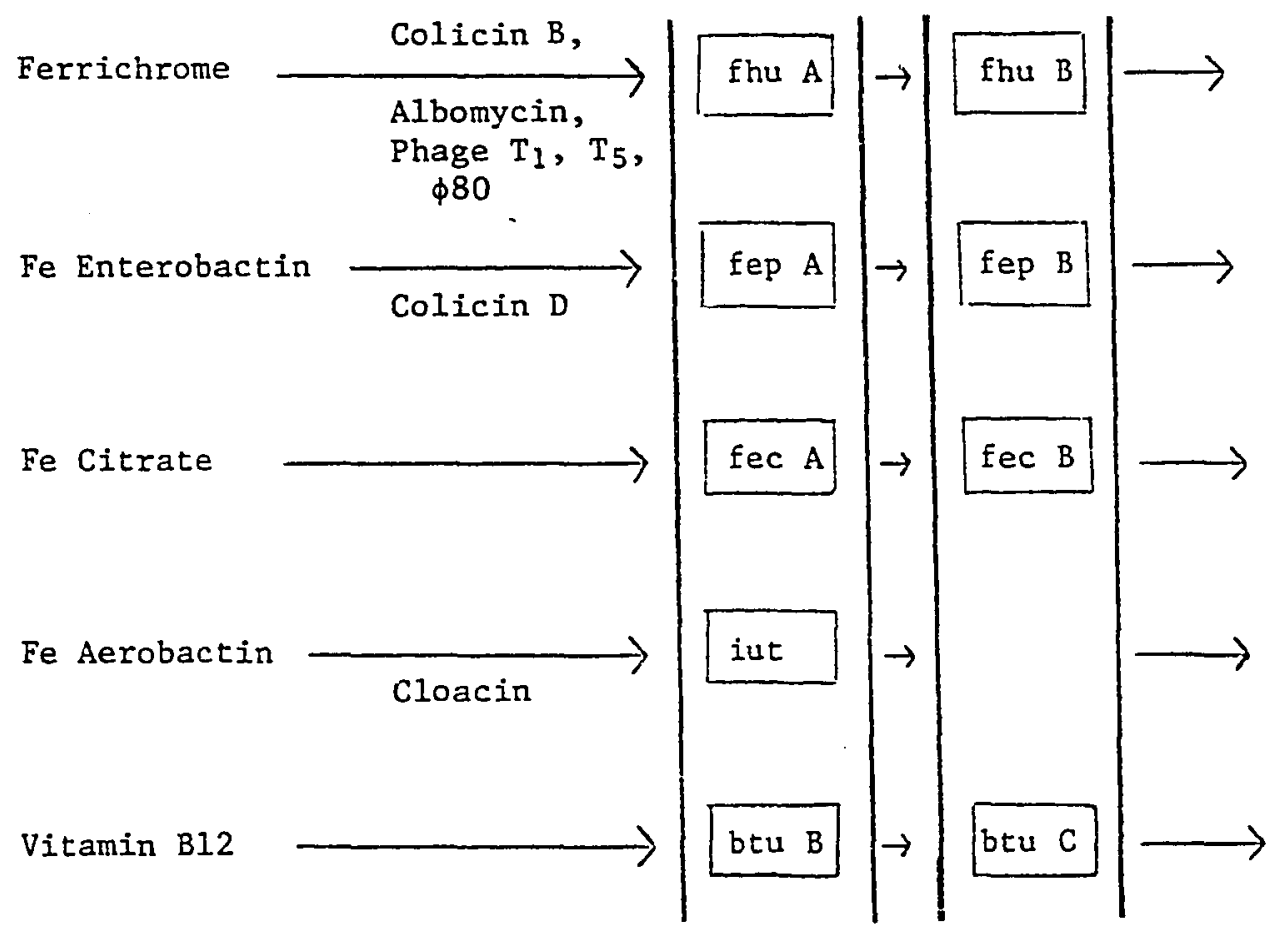

Figure 5. Summary of membrane uptake systems for specific metal complexes in E. coli. Membrane receptor genes have been identified by uptake-defective mutants which have lost particular membrane proteins on SDS polyacrylamide gels. Infective or inhibitory agents are ones which have evolved to take advantage of pre-existing membrane receptors. Compilation from references $32,62-70$. 
The enterobactin system is the most well characterized of the four transport systems in E. coli. At least thirteen genes are known to be involved in the enterobactin cycle and genetic mapping studies are well under way (62). The cycle begins with the formation of enterobactin and its release from the interior of the cell. These functions are controlled by the seven ent genes $(A-G)$. Transport of ferrienterobactin across the outer membrane requires the presence of inducible outer membrane proteins, in particular the fep B gene product and a protein coded by the ton B gene, which is required for all except the low affinity iron uptake system. The function of the ton $B$ protein remains an open question, as does its location. A putative ton $B$ gene product has been identified in E. coli minicells (which do not have a chromosome) containing a ton $B$ hybrid. plasmid (67), and may be located on the cytoplasmic rather than the outer mentrane (68). Three other outer membrane mutants affecting iron-siderophore transport have been isolated on the basis of resistance to phages or colicins which utilize those proteins for receptors (62). Little is known about how these proteins facilitate passage across the outer membrane, although a porin-type structure may be involved. Ferrienterobactin transport across the inner membrane occurs via a specific energy-requiring permease controlled by the fep gene (69). This process requires an energized membrane as evidenced by the sensitivity of the process to uncouplers, azide, and cyanide. Transport 
activity is also sensitive to arsenate and iodoacetic acid, indicating an ATP requirement for transport. Once inside the cell, the enterobactin molecule is hydrolyzed to three residues of dihydroxybenzoyl serine (DBS). This reduces the "chelate effect" and reduces the redox potential of the Fe(III)atom into the range of physiological reductants, making possible the release of the iron for cellular proteins (70). These DBS monomers are not reutilized for enterobactin synthesis, but are released to the medium. The ferrichrome transport system in E. coli, like the enterobactin system, requires an outer membrane receptor (fhu A) and the ton B gene product. It is also thought the entire complex is transported inside the cell since [55 $\mathrm{Fe}$ ] ferrichrome and the kinetically inert $\Lambda$-cis-chromic [ $\left.{ }^{3} \mathrm{H}\right]$ deferriferrichrome enter the cell at identical rates (71). Evidence for a single hydroxamate permease in the cytoplamic membrane, necessary for transport of all hydroxamate siderophores following their receptor mediated passage across the outer membrane, has been published (66). The transport of ferrichrome by inner membrane vesicles is known to require an energized membrane but not direct ATP bond energy. Uptake activity was inhibited by the ionophore valinomycin which collapses the electrical component of the electro-chemical membrane potential (72). A symport mechanism of transport has been proposed based on the presence of a binding site for divalent cations on the ferrichrome molecule (73). This 
provides a net +2 charge to ferrichrome, enabling it to respond to the electrical component of the electrochemical gradient (interior negative).

Like ferrienterobactin, which is modified by ligand hydrolysis to help release the tightly bound iron atom, ferrichrome is modified during transport to a form which does not serve as an effective iron chelator. This occurs by the addition of one mole of acetate per mole ferrichrome, via ester linkage to a hydroxamate -OH group (74). Because deferri-ferrichrome is also modified by cells with a functional uptake system, it is possible that the iron is released by reduction before modification takes place. This modification has also been demonstrated during ferrichrome transport by Salmonella typhimurium LT-2 (75). The modified product can be converted back to ferrichrome by mild hydrolysis in acid or base. The modification of both enterobactin and ferrichrome would seem to serve two purposes. It would facilitate removal of iron from the extremely stable ferrisiderophore complexes for cellular use, and also be a mechanism by which cells rid themselves of a potentially deleterious ligand for iron in the cytoplasm. (74)

The third iron transport system in $\underline{E \text {. coli }}$ is strictIy inducible and utilizes citric acid as an iron chelator and transport intermediate $(70,76)$. The detection of this system was greatly aided by the availability of mutants incapable of synthesis of the native siderophore, 
enterobactin. The addition of purified enterobactin represses the citrate system, which is known to involve a new outer membrane receptor.

The low affinity iron transport system of E. coli is a non-energy-dependent event that is thought to involve a membrane carrier but has not been saturatable under normal assay conditions $(62,77)$. This activity can only be measured when the enterobactin, hydroxamate, and citrate systems are blocked due to mutation or lack of substrate. In addition, the presence of the iron chelator nitrilotriacetate (100 UM) which binds Fe (III) tightly, will block the low affinity system.

Another siderophore transport system that is relevant to the present study is the ferrischizokinen system in Bacillus megaterium, a Gram positive bacterium. This organism produces only schizokinen biat also makes use of ferrioxamine $B$ as an iron transport intermediate, while aerobactin, a close structural relative of schizokinen is not utilized (78). Ferrischizokinen uptake is an energydependent process, however, the exact site of energy coupling may involve iron incorporation into cellular acceptors rather than transport per se. Byers and co-workers have postulated a facilitated-diffusion type process with uptake being driven by energy-dependent incorporation of iron into cellular macromolecules (79). The ferrischizokinen complex is thought to enter the cell intact from studies of transport using $\left[59 \mathrm{Fe},{ }^{3} \mathrm{H}\right]$-ferrischizokinen 
(78). Competitive binding experiments with B. megaterium vesicle preparations that display no transport activity have shown that separate receptors for ferri-schizokinen and ferrioxamine $B$ exist on the cell surface ( 80$)$. Scatchard analyses revealed that the ferrioxmine B receptor had a higher affinity for its substrate than the schizokinen receptor, but a much smaller maximum binding capacity (one eighth as large as the schizokinen receptor). It is not clear whether these receptors led to separate transport systems or converge to a single carrier protein.

At least one report of iron transport studies on a cyanobacterium has appeared in the literature. Iron assimilation in the marine cyanobacterium Gomphosphaeria aponina was studied because iron metabolism was postulated to be important in the proliferation of this organism, thought to be antagonistic towards the Florida red tide dinoflagellate Pytochodiscus brevis ( 81 ). Iron transport was biphasic (absorption and uptake) and first-order with respect to iron (added as 59 FeEDTA). Hydroxamate-containing siderophores were not involved as revealed by the absence of a positive response to chemical (Csaky) or biological (Arthrobacter JG-9) assays. 
EXPERIMENTAL

GROWTH MEDIA AND CULTURE CONDITIONS

\section{Cyanobacteria}

Anabaena sp (\#27898) was obtained from the American Type Culture Collection (ATCC, Rockville, Maryland). This strain is also on deposit with the Pasteur culture collection ( $\# 6411)$ and the University of Texas Culture collection (UTEX \#1597) where it is named as Nostoc sp (82). It will be referred to in this report by the PCC number 6411. The strain was originally isolated from California pond water by M. M. A3.?en ( 82$)$. Another species used in this study previously identified as a Nostoc species is Anabaena 7120 which was kindly provided by R. Haselkorn. This strain is also on deposit with the Pasteur Culture Collection (\$7120) and ATCC (\#17893); its source is unknown. Anabaena cylindrica Lemm., obtained from ATCC ( $\$ 27899)$, was isolated by S. P. Chu from pond water, Cambridge, England in 1939 (83).

For routine maintenance of the Anabaena species, medium BG-11 was used (84). The composition of this medium is listed in Table $I$. The medium was normally made up in advance and stored in acid washed polyethylene bottles at $4^{\circ} \mathrm{C}$. The $\mathrm{Mg}$ and $\mathrm{Ca}$ salts were prepared as a separate $10 \mathrm{X}$ 
TABLE I

MEDIA FOR CYANOBACTERIA

\begin{tabular}{|c|c|}
\hline $\begin{array}{l}\text { Complete BG-l1 } \\
\text { Tper liter, dist } \\
\text { deionized water }\end{array}$ & $\frac{71.11}{11 e d-}$ \\
\hline $\begin{array}{l}\mathrm{NaNO}_{3} \\
\mathrm{~K}_{2} \mathrm{HPO}_{4} \\
\mathrm{MgSO}_{4} \cdot 7 \mathrm{H}_{2} \mathrm{O} \\
\mathrm{CaCl} 2 \cdot 2 \mathrm{H}_{2} \mathrm{O} \\
\text { Citric acid } \\
\text { Ferric ammonium } \\
\quad \text { citrate } \\
\text { EDTA } \\
\mathrm{Na}_{2} \mathrm{CO}_{3} \\
\text { A5 Trace Metal } \\
\text { Mix }\end{array}$ & $\begin{array}{l}1.5 \mathrm{gram} \\
0.04 \mathrm{~g} . \\
0.075 \mathrm{~g} . \\
0.036 \mathrm{~g} . \\
6.0 \mathrm{mg} \cdot \\
6.0 \mathrm{mg} . \\
1 \mathrm{mg} \cdot \\
0.02 \mathrm{mg} . \\
1.0 \mathrm{ml} \text {. }\end{array}$ \\
\hline
\end{tabular}

A5 Trace Metal Mix Tper liter, distilleddeionized water)

$\begin{array}{ll}\mathrm{H}_{3} \mathrm{BO}_{3} & 2.86 \mathrm{grams} \\ \mathrm{MnCl} 2 \cdot 4 \mathrm{H}_{2} \mathrm{O} & 1.81 \mathrm{~g} \cdot \\ \mathrm{ZnSO} \cdot 7 \mathrm{H}_{2} \mathrm{O} & 0.222 \mathrm{~g} \cdot \\ \mathrm{Na}_{2} \mathrm{MOO}_{4} \cdot 2 \mathrm{H}_{2} \mathrm{O} & 0.390 \mathrm{~g} \cdot \\ \mathrm{CuSO}_{4} & 0.051 \mathrm{~g} \cdot \\ \mathrm{Co}\left(\mathrm{NO}_{3}\right)_{2} \cdot 6 \mathrm{H}_{2} \mathrm{O} & 0.049 \mathrm{~g} .\end{array}$

Uptake Medium* (pH 7.0)

(per liter, distilled-deionized water)

$\begin{array}{ll}\mathrm{NaNO}_{3} & 1.10 \mathrm{gram} \\ \mathrm{NH}_{4} \mathrm{Cl} & 0.05 \mathrm{~g} \cdot \\ \mathrm{K}_{2} \mathrm{HPO}_{4} & 0.25 \mathrm{~g} . \\ \mathrm{MgSO}_{4} \cdot 7 \mathrm{H}_{2} \mathrm{O} & 0.531 \mathrm{~g} . \\ \mathrm{CaCl}_{2} \cdot 2 \mathrm{H}_{2} \mathrm{O} & 0.058 \mathrm{~g} \cdot\end{array}$
ॠUptake medium was prepared as two stock solutions. A 100X solution of $\mathrm{NaNO}_{3}, \mathrm{NH}_{4} \mathrm{Cl}$, and $\mathrm{K}_{2} \mathrm{HPO}_{4}$ was treated with Chelex 100 (Bio Rad) to remove endogenous iron. A lox solution of $\mathrm{Mg}+\mathrm{Ca}$ was prepared separately and added to the Chelex- treated nutrients just prior to filter sterilization as a complete $1 X$ solution.

solution. The other reagents were dissolved at lox concentrations in the order listed in approximately $800 \mathrm{ml}$ of glass-distilled, demineralized water (Milli-Q system, Millipore Corporation). It was important to solubilize each reagent before the addition of the next to insure complete dissolution of all components. The media was then titrated to $\mathrm{pH} 7.1$ and diluted to 1 liter. The A5 trace metal mix was stored as a $1000 x$ solution. The media was 
sterilized immediately prior to use by passage through

$0.45 \mu \mathrm{m}$ filters (Millex, Millipore Corporation).

For growth on solid media, BG-II was supplemented

with $1.5 \%$ agar (Difco) separately sterilized by autoclav-

ing, and cooled to $45^{\circ} \mathrm{C}$ before mixing with complete

filter-sterilized $\mathrm{BG}-11$ also at $45^{\circ} \mathrm{C}(85)$. Slants or

plates thus prepared, when innoculated with a growing

culture of Anabaena 6411, showed visible growth within

three to four days at $34^{\circ} \mathrm{C}$ and continuous light $(2500$

lux). Maintenance slants were shifted from these condi-

tions after one week and left on a bench top at room tem-

perature and out of direct sunlight. These slant cultures

remained viable for up to one year although stocks were routinely transferred every six months.

A further modification of the standard BG-11 media was made for studies of iron metabolism. The chelators, EDTA and citric acid, were omitted unless otherwise noted, as was the ferric ammonium citrate. A stock solution of $0.50 \mathrm{mM} \mathrm{FeCl} 3$ in $10 \mathrm{mM} \mathrm{HNO}_{3}$ was used to make iron additions to the modified BG-11 immediately prior to filter sterilization. This modified $B G-11$ will be referred to as BG-Il(mc) (minus chelators). The residual iron concentration of BG-11 media (minus Fe) was estimated using atomic absorption spectroscopy on concentrated stock solutions at I $x 10^{-8} \mathrm{M}$. While the residual iron in $B G-1 I$ (mc) was not determined it is probably equal to or less than the value for complete $B G-11$. 
In order to avoid iron introduced by glassware, all vessels used for growth, iron uptake assays, or media storage and transfer were rinsed in $6 \mathrm{~N} \mathrm{HCl}$, followed by extensive rinsing with distilled-demineralized (Milli-Q) water.

All Anabaena species were routinely grown in continuous light provided by two cool white fluorescent bulbs (Sylvania) approximately 12 inches from the surface of the culture medium. The light intensity was measured at 2500 lux with a light meter (Westinghouse) at the same distance from the light source as the media surface. Reflective white paper was placed underneath the cultures to increase reflectivity. The incubator was maintained at $34^{\circ} \mathrm{C}$.

To prepare an inoculum for an Anabaena culture, filaments gathered from the surface of an agar slant were added aseptically to BG-II(mc) supplemented with $0.1 \mu M$ Fe(III) and grown until the absorbance was between 100 and 200 klett units (see below). An aliquot of this inoculum was then adied to a $25 \mathrm{ml}$ test culture to achieve 10 to 20 Klett units. The inoculum was not normally washed since the presence of buoyant gas vacuoles inside the cells makes it difficult to obtain a good pellet of Anabaena filaments by centrifugation.

Turbidity, as determined in a klett-Summerson colorimeter, was chosen as a convenient measure of growth for Anabaena 6411 and 7120. Both of these strains grow as 
an even suspension in liquid culture (82), although a tendency for clumping was noted in the second transfer of 6411 in media free of combined nitrogen. Most cultures were grown in $125 \mathrm{ml}$ sidearm flasks that enabled turbidity measurements without opening the flask and risking contamination. The colorimeter was fitted with a green (\#54) filter, unless otherwise noted, so that changes in chlorophyll pigmentation observed in strain 6411 as a function of added iron would have a minimal effect on the turbidity measurements. Several alternative methods for growth measurements were considered but rejected due to lower accuracy. For example, dry weight determinations had only a small linear region between 30 to 90 Klett units, and were also variable in absolute terms from culture to culture, presumably due to differences in extracellular polysaccharide. Viable counts are difficult to determine reproducibly with filamentous organisms since it is necessary to sonically disrupt the filaments to form single cells which can give rise to countable isolated colonies on agar plates. This sonication can disrupt or break some cells and leave others as doubles or triples which reduces the accuracy of the procedure. Direct microscopic counting was considered excessively tedious and a coulter counter was not available on a routine basis.

Two different tests were used to examine for bacterial contamination of Anabaena strains. The most important test was careful microsopic examination of aging cultures 
in which the cyanobacteria have begun to lyse, as the presence of contaminating bacteria is very evident urder these conditions (84). It was noted that very small granules were liberated by lysed cells. These granules move very rapidly via brownian motion but can be distinguished from bacteria by their smaller size and their similarity to granules present inside intact cells. It is possible that these are cyanophycin granules known to be present in many cyanobacteria (86). The second test used to determine algal purity was incubation of $0.1 \mathrm{ml}$ of an aged culture on a standard nutrient agar plate at $37^{\circ} \mathrm{C}$ (84). The lack of bacterial colonies on complex media should be considered as necessary but not sufficient criteria of an axenic culture of Anabaena, due to the great variety of possible contaminants.

One contaminating bacterium was isolated from Anabaena 6411, a smali gram positive rod-shaped organism discovered approximately six months after work with Anabaena 6411 had begun. This organism was detected as small pink colonies on a spread plate of Anabaena 6411 on complete BG-II agar. This organism grew well on BG-II plates with and without associated Anabaena, and has not been identified to date. The organism gave negative Csaky assays for hydroxamate siderophores and did not take up [55 Fe] ferrischizokinen. Treatment of the contaminated culture in the dark with phenol using the procedure of Gorham and Charmichael (87), and plating on BG-11 agar 
produced agar cores containing axenic filaments of Anabaena. However, due to fears that the phenol treatment may have damaged the Anabaena, a new culture of 6411 was obtained from the American Type Culture Collection. All work presented in this report concerning Anabaena 6411 was performed with this new culture.

Growth experiments with another growth medium for cyanobacteria were performed before deciding to use BG-lI(mc) as a standard growth medium. Simpson and Neilands (8) used the uptake medium listed in Table I for growing Anabaena 6411. We found that while 6411 did grow on this medium, several modifications were required before growth would equal that demonstrated by 6411 with BG-11(mc). As shown in Figure 6, it was necessary to bubble this medium with $18 \mathrm{CO}_{2}, 998$ nitrogen to achieve maximum growth rates. However, bubbling BG-II medium with this mixture prevented cells from growing at all. The uptake medium was also supplemented with the A5 trace metal mixture $(1.0 \mathrm{ml} / \mathrm{liter})$. Temperature and light conditions were as used for $\mathrm{BG}-1 \mathrm{I}(\mathrm{mc})$ culture. While both of these media have the advantage of no chelators present, the overall ease of working with BGII(mc), and the higher growth yields routinely obtained with $B G-1$ l(mc) resulted in our chosing that medium for routine growth studies. With the exception of the experiments designed to determine the $\mathrm{Km}$ for ${ }^{55} \mathrm{Fe}-\mathrm{sch} i z o k i n e n$ uptake (see below), all work 


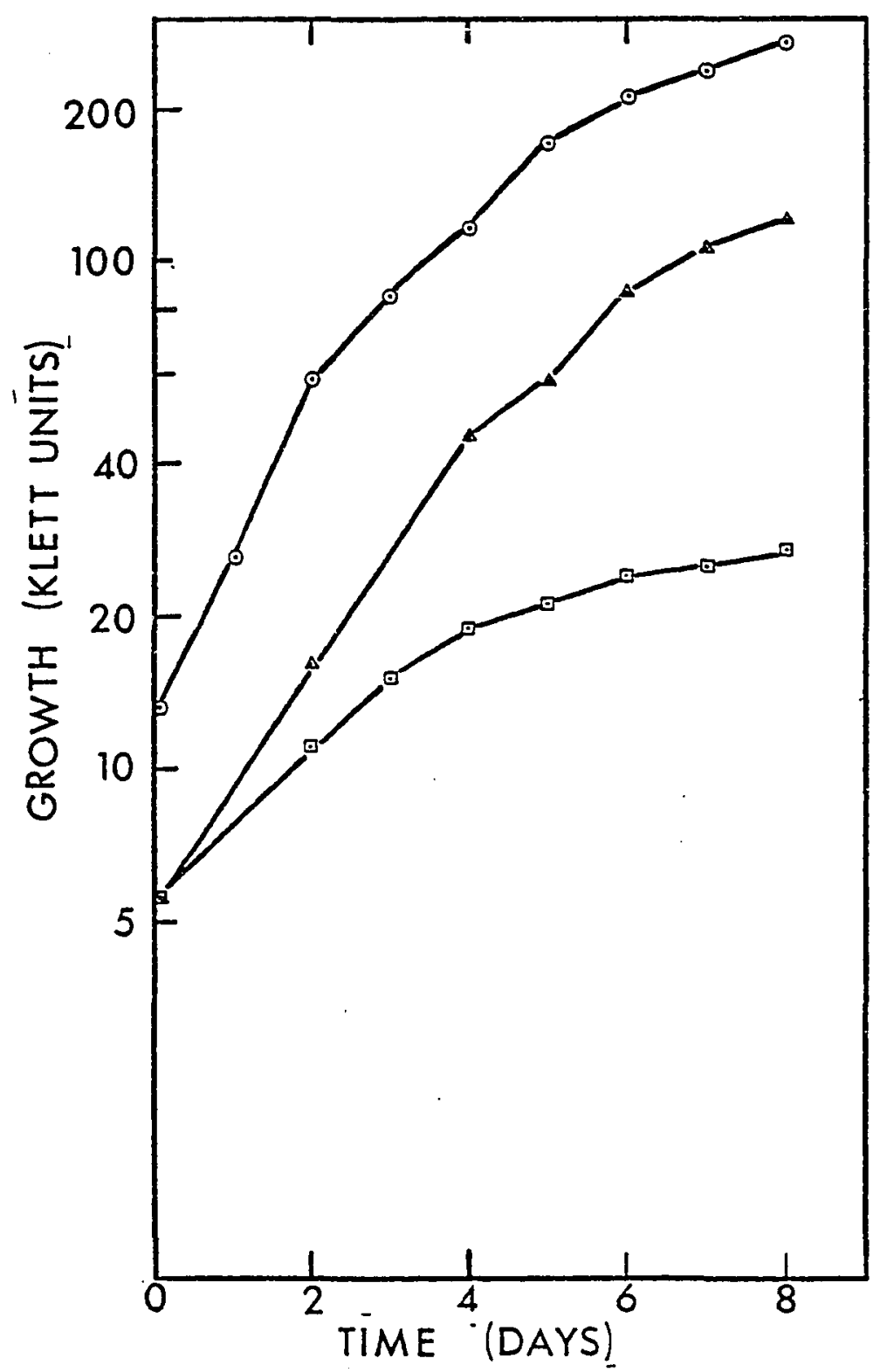

Figure 6. Growth of Anabaena 6411 in uptake medium and $B G-1 I(m \mathrm{c})$. Iron ( $1.0 \overline{\mu M}$ ) was added to each culture immediately prior to filter sterilization. ( $\square-\square$ ) uptake medium wi thout $18 \mathrm{CO}_{2}, 99 \% \mathrm{~N}_{2}$ bubbling. ( $\left.\Delta-\Delta\right)$ uptake medium with 1 \% $\mathrm{CO}_{2}, 99 \% \mathrm{~N}_{2}$ bubbling (approximately $10 \mathrm{ml} / \mathrm{minute})$. ( 0 - 0 ) standard $\mathrm{BG}-11$ (mc) medium. 
reported here was performed with BG-ll(mc) grown cells. The $\mathrm{Km}$ experiments were performed on cells grown in both uptake medium and $B G-11(m c)$ with no detectable difference in the results.

Culture Conditions for Arthobacter flavescens JG-9

Arthrobacter flavescens JG-9 is a siderophorerequiring (auxotrophic) strain that can be used as an assay for a variety of siderophores (32). A partial list of siderophores with growth factor activity for JG-9 appears in Table II.

The organism was grown at $30^{\circ} \mathrm{C}$ on slants or streak plates of maintenance medium (Table III) containing 20 micrograms Desferal per liter. Desferal is the methane sulfonate sale of ferrioxamine B (Ciba Pharmaceuticals) and yields free ferrioxmine $B$ upon dissolution in water. Liquid cultures were grown at $30^{\circ} \mathrm{C}$ in JG-9 assay medium (Table III) in $15 \times 180 \mathrm{~mm}$ culture tubes in a rotary shaker set at $200 \mathrm{rpm}$. The details of the assay for siderophore activity will be discussed below. 
TABLE II

COMPOUNDS THAT SATISFY GROWTH REQUIREMENT

OF ARTHROBACTER FLAVESCENS JG-9 a

\begin{tabular}{lc}
\hline Compound & Concentrations $(\mu g / \mathrm{ml})$ \\
for half maximal growth
\end{tabular}

Ferrichromes

ferrichrome

ferrirubin

albomycin

Aerobactins

arthrobact in

schizokinen

Ferrioxamines

ferrioxamine $B$

Mycobactins

mycobactin

0.008

Rhodotorulic acids
rhodotorulic acid
0.0002
coprogen
0.007

Heme compounds

protohemin IX coprohemin III

0.08

0.1

Catechols

dihydroxybenzoylserine

10.0

a Taken from Lankford (32). 
TABLE III

MEDIA FOR BACTERIAL SPECIES

JG-9 Maintenance Medium ( $\mathrm{pH} 7.4$ before autoclaving) (per liter distilled-deionized water)

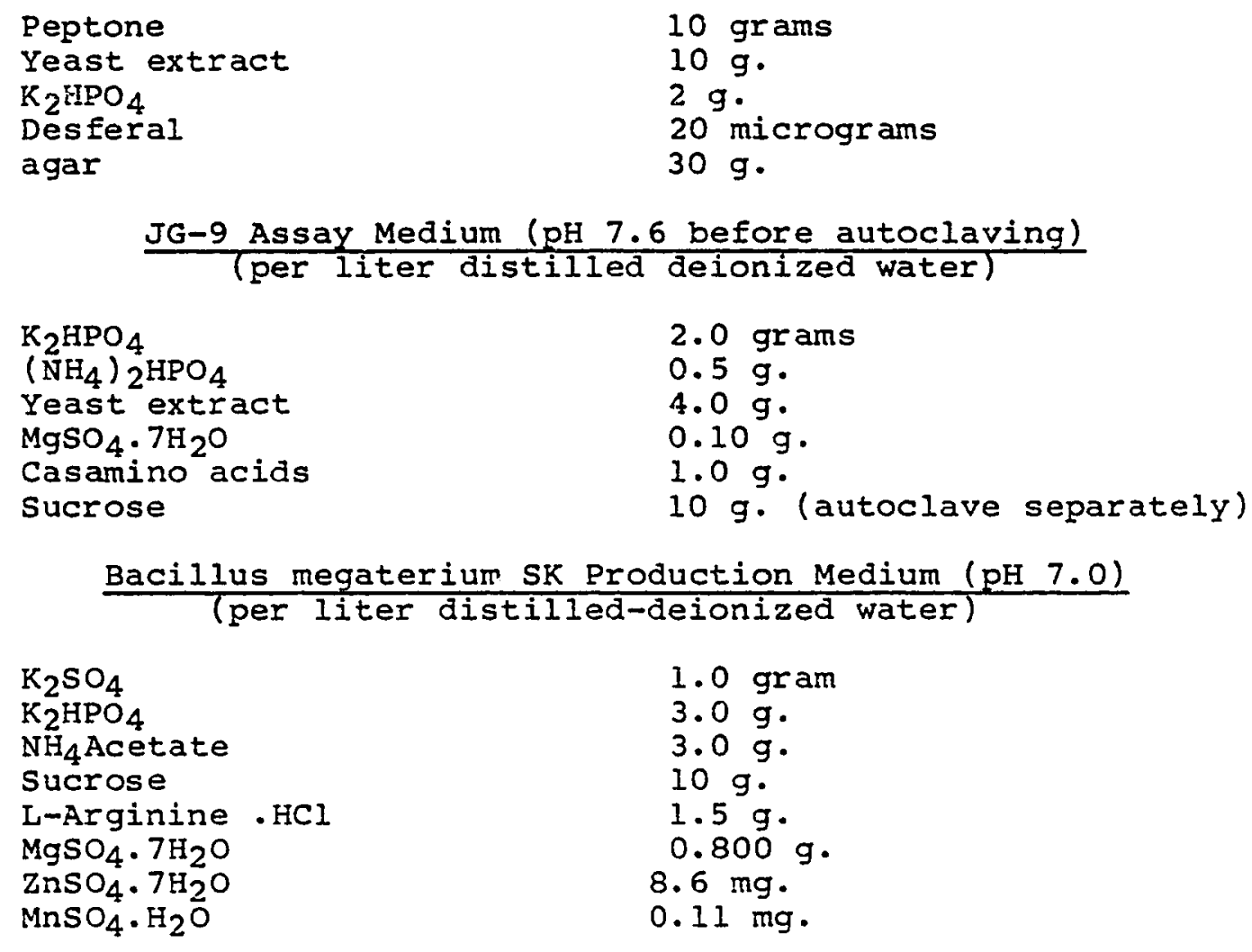

Bacillus megaterium SK Production Medium (pH 7.0 ) (per liter distilled-deionized water)

$\begin{array}{ll}\mathrm{K}_{2} \mathrm{SO}_{4} & 1.0 \mathrm{gram} \\ \mathrm{K}_{2} \mathrm{HPO}_{4} & 3.0 \mathrm{~g} \cdot \\ \mathrm{NH}_{4} \mathrm{Acetate} & 3.0 \mathrm{~g} \cdot \\ \mathrm{Sucrose} & 10 \mathrm{~g} \cdot \\ \mathrm{L}-\mathrm{Arginine} \cdot \mathrm{HCl} & 1.5 \mathrm{~g} \cdot \\ \mathrm{MgSO}_{4} \cdot 7 \mathrm{H}_{2} \mathrm{O} & 0.800 \mathrm{~g} \cdot \\ \mathrm{ZnSO}_{4} \cdot 7 \mathrm{H}_{2} \mathrm{O} & 8.6 \mathrm{mg} \cdot \\ \mathrm{MnSO}_{4} \cdot \mathrm{H}_{2} \mathrm{O} & 0.11 \mathrm{mg} .\end{array}$


Culture Conditions for SK Production by Bacillus Megaterium

Bacillis megaterium (ATCC \#19213) was used as a source of schizokinen instead of Anabaena 6411 due to its faster growth rate and ease of handing large scale cultures. B. megaterium was grown in the medium of Mullis et.al. (52) with a decreased sucrose concentration to minimize caramelization during Csaky assays. To prepare this medium with a minimal iron concentration, all components except the $\mathrm{Mg}, \mathrm{Zn}$, and $\mathrm{Mn}$ were dissolved at $10 \mathrm{X}$ concentrations in distilled-deionized water and run through a column of Chelex 100 resin (Bio Rad) in the sodium form to remove endogenous $F e$. The metals were added to the deferrated medium and the $\mathrm{pH}$ adjusted to 7.0 prior to filter sterilization $(0.22 \mu \mathrm{m}$, Millipore). The residual iron concentration after this treatment was estimated to be less than $0.5 \times 10^{-8} \mathrm{M}$ according to the growth response at different concentrations of added iron. On several occasions the medium was autoclaved in which case the sucrose was treated with Chelex 100 separately and autoclaved separately from the other non-metal salts before addition of the filter sterilized metals.

Large batch cultures of B. megaterium were grown to produce 7 to 10 liters of culture medium for a schizokinen preparation. Usually $500 \mathrm{ml}$ cultures in 2.0 liter acidwashed erlenmeyer flasks were employed. The incubator was set at $37^{\circ} \mathrm{C}$ and highest shaker speed available since 
heavy aeration is necessary to maximize schizokinen yields (52). An eight liter batch culture in a 10 liter carboy was grown once with agitation by a three inch magnetic stirring bar and a stream of forced sterile air. However, problems associated with carboy cultures including sterility control and inadequate aeration discouraged the use of this approach.

\section{SCHIZOKINEN PRODUCTION FROM Bacillus megaterium}

Bacillus megaterium was grown with several iron concentrations to determine the optimum level of added iron to maximize schizokinen yields. This experiment was necessary because higher schizokinen production levels per cell at the lower iron concentrations were offset by low cell numbers. The optimum level of iron was found to be about $0.5 \mu \mathrm{M}$ Fe(III) adder. At this concentration approximately $95 \mathrm{\mu g} / \mathrm{ml}$ schizokinen was detected via the Csaky assay after 72 hours (below).

The batch cultures were harvested by centrifugation in acid washed $250 \mathrm{ml}$ plastic centrifuge bottles using a GSA rotor and a Sorval RC2-B centrifuge set at $6,000 \mathrm{rpm}$ for twenty minutes. The supernatants were pooled and stored frozen in acid washed polyethylene bottles. The combined supernatants were concentrated by rotary evaporation to approximately $200 \mathrm{ml}$. This procedure was greatly accelerated by running a polyethylene glycol solution at 
$2-4^{\circ} \mathrm{C}$ through the condensing coils of the Rotovap, and heating the bulk solution to $37^{\circ} \mathrm{C}$.

\section{Organic Extraction of Concentrated Supernatants}

The first step in the purification of schizokinen is an extraction at low pH into a 50/50 (wt/wt) mixture of chloroform and phenoj. (52). The concentrated supernatant was first adjusted to $\mathrm{pH} 2.0$ with concentrated $\mathrm{HCl}$. Care must be taken to avoid large local HCl concentrations by vigorous stirring while adding the acid because of the tendency of schizokinen to break down at low pH. For this reason, it is also important to immediately begin the extraction after $\mathrm{pH}$ adjustment, and to readjust the $\mathrm{pH}$ after extraction to $\mathrm{pH} 4$ or 5 .

For $200 \mathrm{ml}$ of concentrated medium at pH $2.0,500 \mathrm{ml}$ of $\mathrm{CHCl}_{3} /$ phenol should be used in three batches of approximately $170 \mathrm{ml}$ each for the complete removal of ironreactive material (as judged by color formation with $\left.\mathrm{FeCl}_{3}\right)$. The addition of two liters of ethyl ether to the combined organic layers will make them sufficiently non-polar for the schizokinen to be reextracted into distilled-deionized water $(3 \times 100 \mathrm{ml})$. The crude schizokinen solution is then concentrated by rotary-evaporation to about $50 \mathrm{ml}$.

Ferrischizokinen was found to be extractable by the above procedure as it also carries a net charge of zero at $\mathrm{pH} 2$. Thus, it would be possible to purify schizokinen as 
the ferric-complex, and then remove the iron by treatment with 8-hydroxyquinoline (see below). The primary advantage would be direct visualization of the red-colored complex during purification. However, all schizokinen preparations to date have been purified as iron-free schizokinen.

\section{Purification of Schizokinen by Column Chromotography}

Crude extracts of schizokinen from ㅂ. megaterium were partially purified on a column of the anion exchanger AG-2-X10 (Bio Rad). The resin was first converted to the acetate counter-ion from the chloride form as follows. A $22 \times 2.5 \mathrm{~cm}$ column of $A G-2-\times 10$ in the chloride form was treated with two volumes of $1 \mathrm{~N} \mathrm{NaOH}$ to convert the resin to hydroxide counter-ions followed by a four volume distilled-deionized water rinse. The hydroxide ions were then neutralized by the addition of 4 volumes of 1 M acetic acid which completes the conversion. The column must be rinsed with 4 volumes of water and further treated with $100 \mathrm{ml}$ of $0.1 \mathrm{M}$ Tris buffer [tri-(hydroxymethyl) aminomethanel at $\mathrm{pH} 8.0$ and a 2 volume water rinse. This is to insure that the resin is above $\mathrm{pH}$ 5.0. Without this final $\mathrm{pH}$ adjustment a significant fraction of schizokinen elutes with the void volume. This is likely due to protonation of the citrate carboxyl group of SK which produces a neutral molecule that will not bind to the column.

The crude schizokinen was loaded on to the column at $\mathrm{pH} 7.0$ and rinsed in with $100 \mathrm{ml}$ of distilled-deionized 
water. Sample volumes of 50 to $100 \mathrm{ml}$ have been used successfully. The bound SK was eluted with a linear gradient of $\mathrm{NH}_{4} \mathrm{Cl}$ prepared with a gradient maker (Pharmacia) containing $250 \mathrm{ml}$ of $0.1 \mathrm{M} \mathrm{NH}_{4} \mathrm{Cl}$ in the mixing chamber and $250 \mathrm{ml}$ of $1.0 \mathrm{M} \mathrm{NH}_{4} \mathrm{Cl}$ in the second chamber. An elution profile for such a column is shown in Figure 7 . Several methods for detecting eluted schizokinen have been used. Two methods were based on the formation of a colored product upon addition of iron to an aliquot from each fraction. In early work a $0.10 \mathrm{ml}$ aliquot was added to $0.90 \mathrm{ml}$ of water containing 25 microliters of $0.18 \mathrm{FeCl}_{3}$ in dilute $\mathrm{HCl}$. Under these conditions the absorbance maximum was at $440 \mathrm{~nm}$. However, the variability of the final $\mathrm{pH}$ and light scattering caused by precipitated excess iron sometimes resulted in confusing elution profiles. A better procedure is to add a $0.1 \mathrm{ml}$ aliquot of each fraction to $0.9 \mathrm{ml}$ of $5 \mathrm{mM} \mathrm{FeCl}_{3}$ in $0.14 \mathrm{M} \mathrm{HClO}_{4}$. This results in a constant low $\mathrm{pH}$ and an absorbance maximum at $490 \mathrm{~nm}$ without any precipitation problems (90). The Csaky assay (see below for experimental details) was also used to detect hydroxamate groups in column effluents. In all cases tested the hydroxamate peak identified by Csaky coincided with the ferric-positive peak. As a result the $\mathrm{Fe}(\mathrm{III})-\mathrm{HClO}_{4}$ reagent became the method of choice for schizokinen detection. 


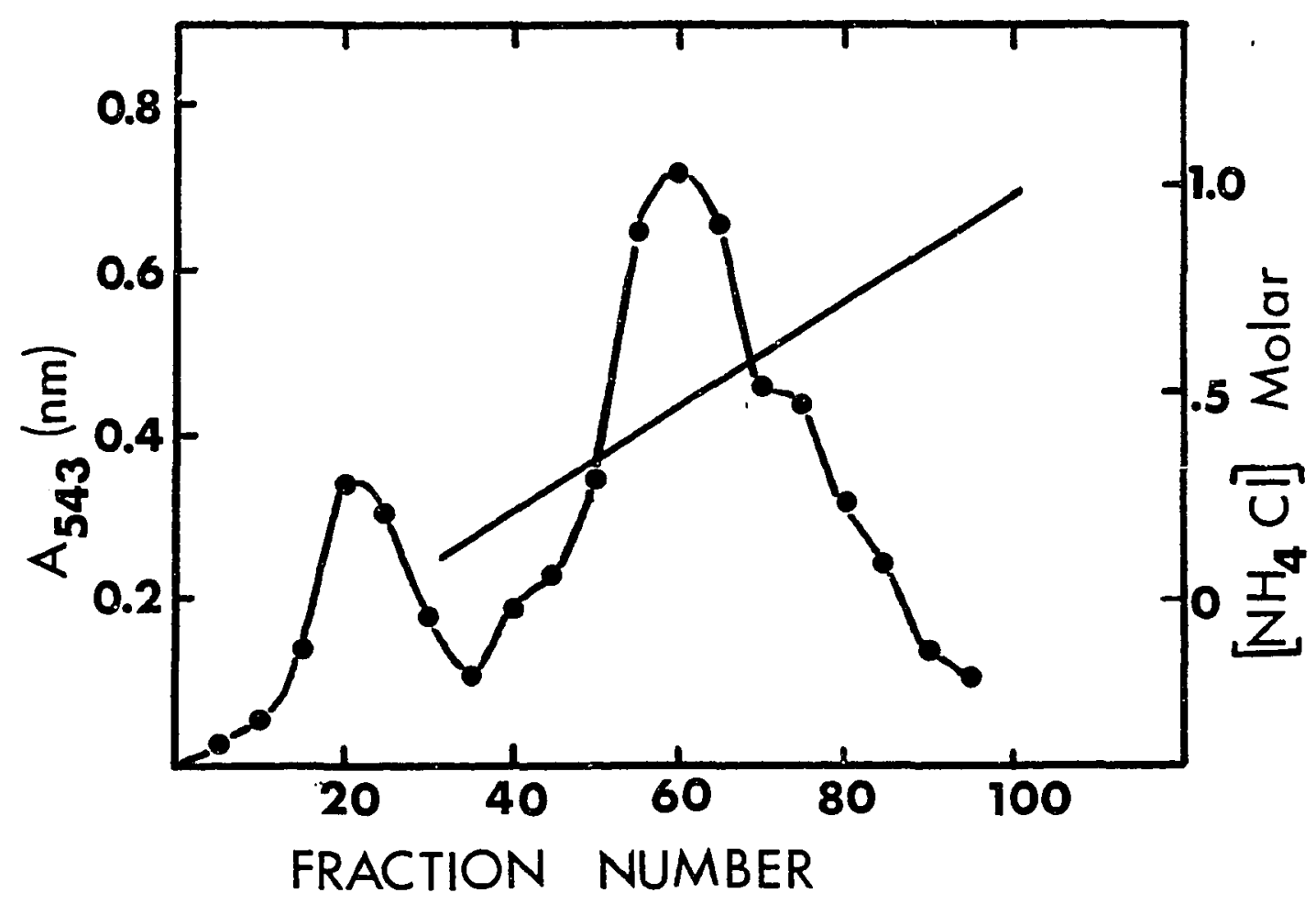

Figure 7. Anion exchange chromatography of crude schizokinen on BioRad AG-2-X10 resin (acetate form) $\mathrm{pH} 5.0$ in $2.5 \times 25$ $\mathrm{cm}$ column. $100 \mathrm{ml}$ sample followed by $100 \mathrm{ml}$ distilled water rinse. Anionic material was then eluted with a linear gradient of $0.1-1.0 \mathrm{M} \mathrm{NH}_{4} \mathrm{Cl}$. Fractions were analyzed for hydroxamic acid using Csaky assay $\left(\mathrm{A}_{543}\right)$. Fraction volume $=7.2 \mathrm{ml}$. 
A hydroxamate positive peak that elutes with the void volume on $A G-2-X 10$ columns was always noted from $B$. megaterium filtrates and was also reported by Simpson and Neilands from Anabaena filtrates ( 8 ). This material is thought to be a neutral decomposition product of schizokinen, the structure of which is unknown (52). The anionic ferric positive material (schizokinen) was desalted by either repeating the chloroform phenol extraction or passage through a gel filtration column of Biogel P2 (Bio Rad) or Sephadex G-10 (Phamacia).

Purified schizokinen was prepared by careful fractionation of the eluant from a BioGel P2 column (run subsequent to the desalting procedure used after the AG-2X10 column). Figure 8 presents an elution profile from a P-2 column analyzed by iron binding $\left(\mathrm{A}_{440}\right)$ or with the Csaky assay $\left(A_{543}\right)$. Pure schizokinen was obtained from fractions $31-40$ as determined by proton NMR spectroscopy. The NMR spectrum of these fractions together with a published spectrum of authentic schizokinen is shown in Figure 9. It has been our experience that the late fractions from the ferric-positive peak are the most likely to be contaminated. It is usually necessary to obtain NMR spectra on each of the trailing fractions prior to pooling to avoid including contaminated material. The elution volume of pure schizokinen was between 46 and 54 percent of the bed volume of the $\mathrm{P}-2$ column. 


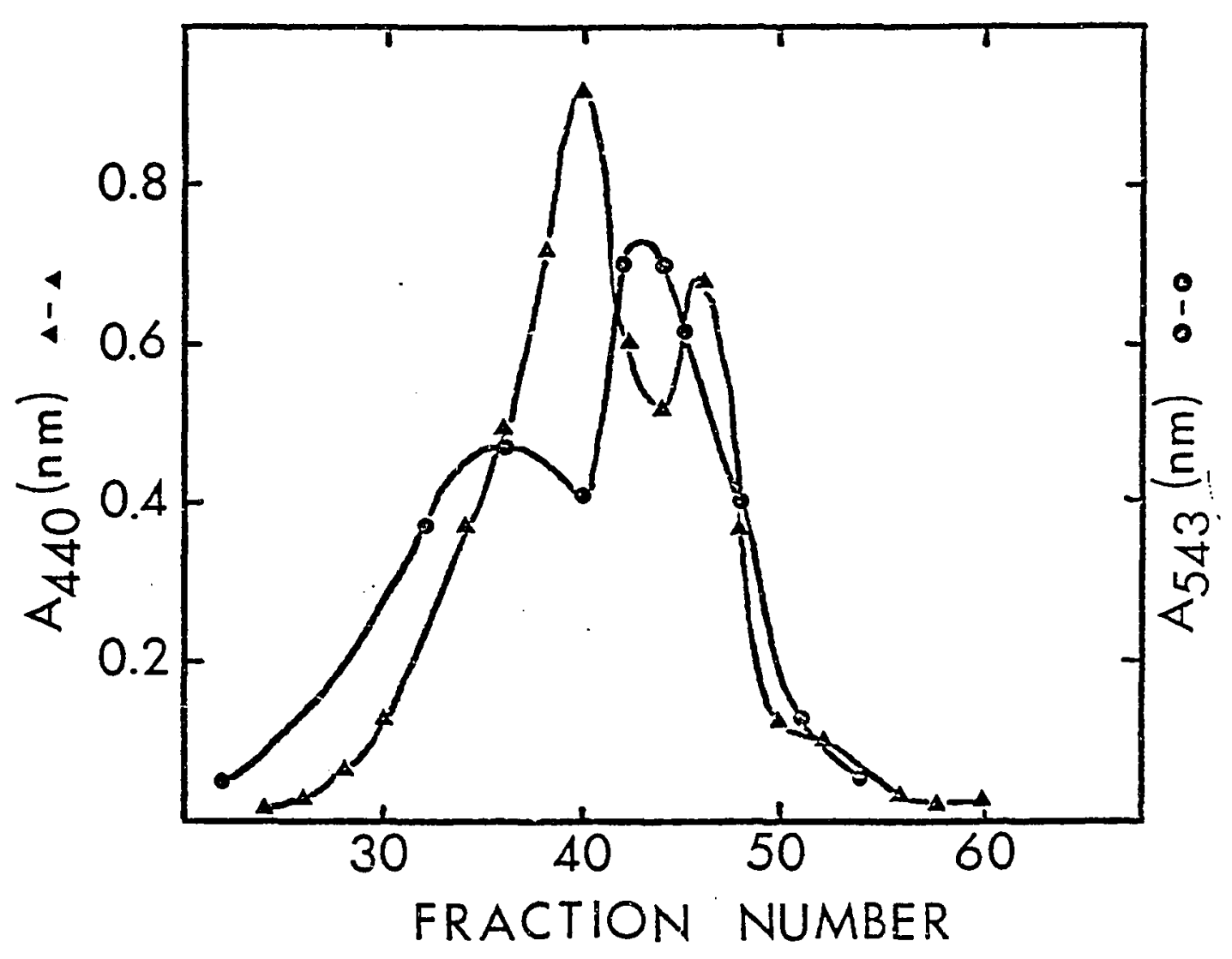

Figure 8. Gel permeation chromatography of schizokinen AG-2-X10 column. Bio Gel P2 column $(1.5 \times 80 \mathrm{~cm})$ eluted with water. ( ) hydroxamates by Csaky assay (A 543 ) and ( ) iron kinding assay $\left(\mathrm{A}_{440}\right)$. [0.10 $\mathrm{ml}$ each fraction, $0.9 \mathrm{ml} \mathrm{H}_{2} \mathrm{O}$, and $25 \mu \mathrm{H} 0.5 \% \mathrm{FeCl}_{3}$ in $0.1 \mathrm{~N}$ HCl]. Fraction volume $2.3 \mathrm{ml}$. Fractions 31-40 contained pure schizokinen. 


\section{Figure 9.}

NMR spectra of schizokinen. Peak assignments:

a, methylene protons adjacent to hydroxamates.

$b$, methylene protons adjacent to amides.

$c$, methylene protons of citric acid residue.

d, methyl protons of terminal acetyl groups.

e, inner methylene protons of n-propyl chains. 


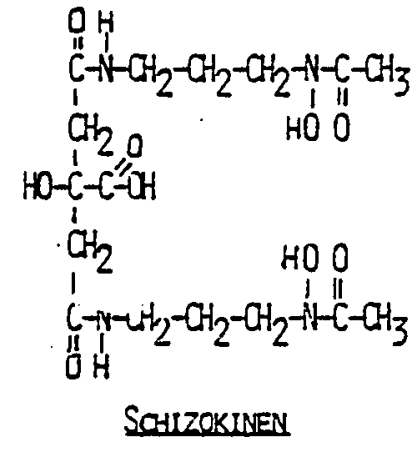

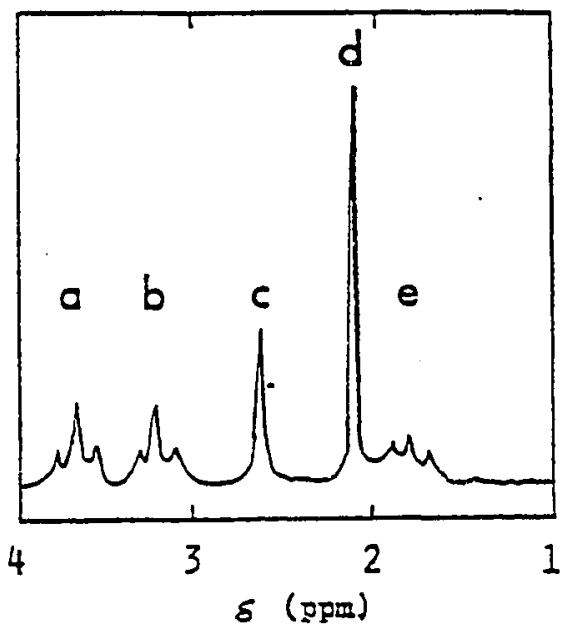

MR SPECTRLM OF SK FROM ANabaena SP. Sinpson and NeILANDS L. Prycol, 12:48 (1976)

STRAIN: ATCL\# 27898, PCCH 6411

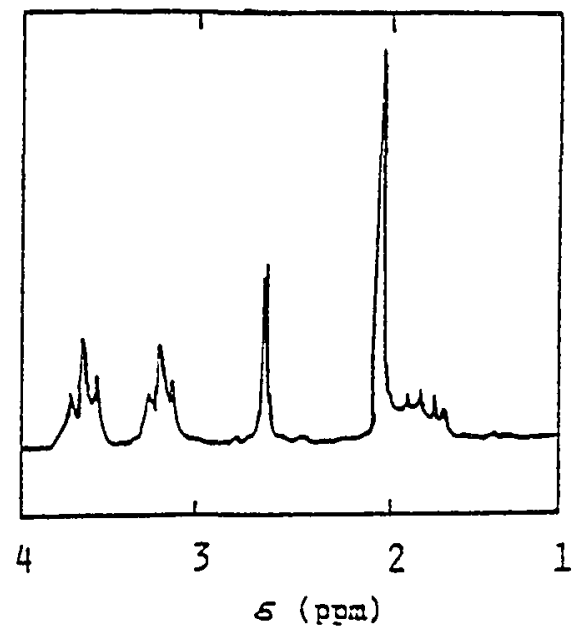

MR SPECTRUM OF SK LSED IN LPTAKe Assays, SOURCE: BACILLUS MEGATERHUM ATCC: 19213 
Characterization of Schizokinen

Purified iron-schizokinen was characterized spectroscopically to demonstrate that our isolate displayed a shift toward the red in the wavelength of maximum absorbance with decreasing $\mathrm{pH}$ as expected of citrate-type siderophores (35). As shown in Figure 10, Fe-SK produces a broad visible absorbance peak centered about $390 \mathrm{~nm}$ at $\mathrm{pH} 7$, which shifts to $450 \mathrm{~nm}$ at $\mathrm{pH} 2.3$. By contrast, the aerobactin complex with iron has a maximal absorbance at $399 \mathrm{~nm}$ at $\mathrm{pH} 7.0$ (55).

The relative stability of the absorbance peak position near $\mathrm{pH} 7$ was utilized for quantitation of purified schizokinen preparations. Spectrophotometric titrations wth standard iron (III) solutions (Harleco Chemicals, 1000 parts per million) were carried out by adding small aliquots of iron $(17.9 \mathrm{mM})$ in dilute $\mathrm{HCl}$ to a known volume of the schizokinen stock solution. The pH was then readjusted with $0.1 \mathrm{~N}$ NaOH to $\mathrm{pH} 6.8-7.2$ and the spectrum from 350-450 nm recorded after each addition. A typical plot of the abosrbance at $390 \mathrm{~nm}$ versus added iron is shown in Figure 11. Using the volume corrected absorbance at the equivalence point, a molar extinction coefficient of 2050 liter mol-1 $\mathrm{cm}^{-1}$ was calculated. The comparable value for ferric aerobactin is 2170 liter mol-1 $\mathrm{cm}^{-1}$ (55). Using the standardized schizokinen solution we also calculated an extinction coefficient for ferric schizokinen in the $5 \mathrm{mM} \mathrm{Fe}$ (III) $-\mathrm{HClO}_{4}$ reagent used to detect schizokinen 
Figure 10.

Visible absorption spectrum of ferric schizokinen as a function of $\mathrm{pH}$. Concentration of $\mathrm{pH} 6.7$ sample is $0.2 \mathrm{mM}$. Absorbances are not corrected for small changes in concentration due to the addition of 0.1 or $1.0 \mathrm{M} \mathrm{HCl}$. 


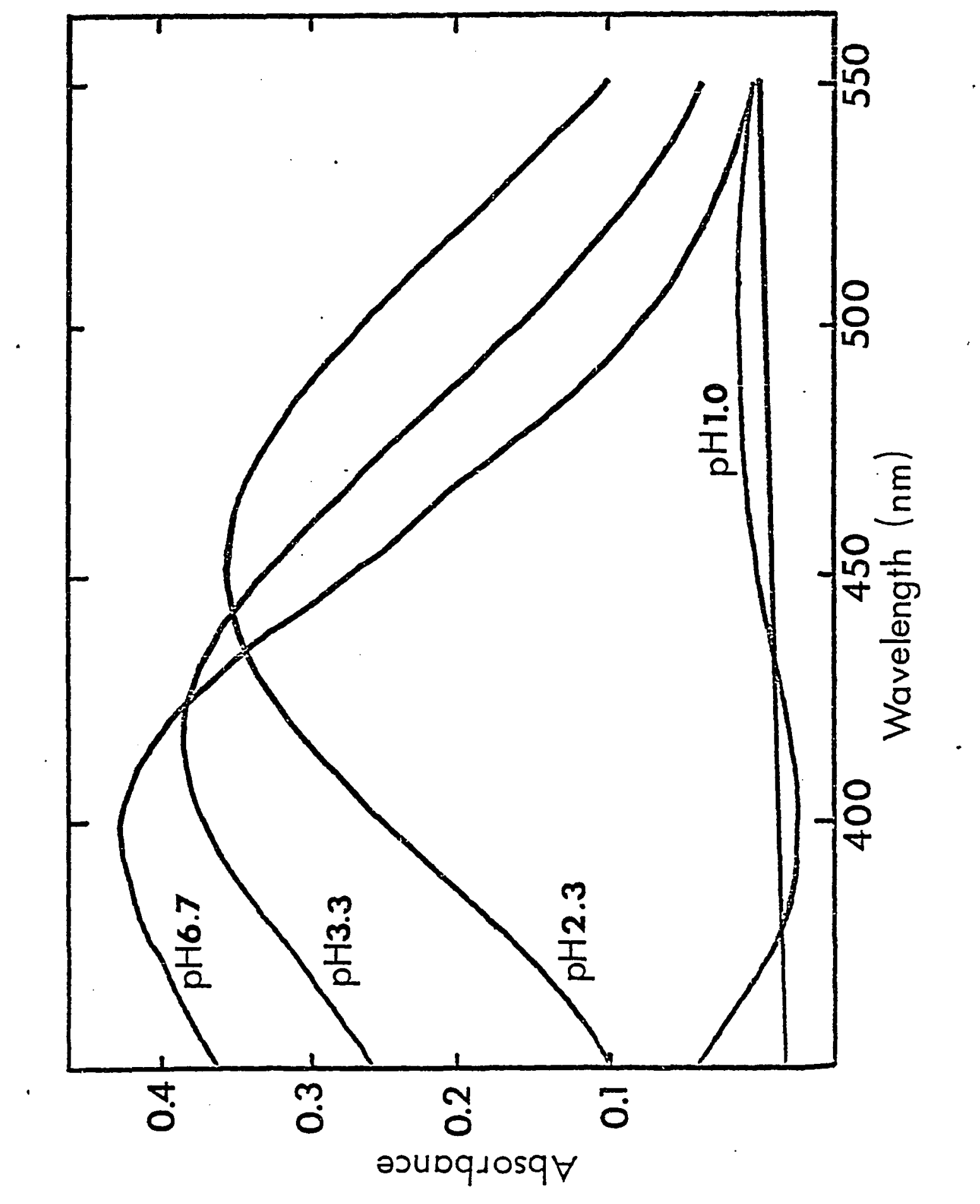




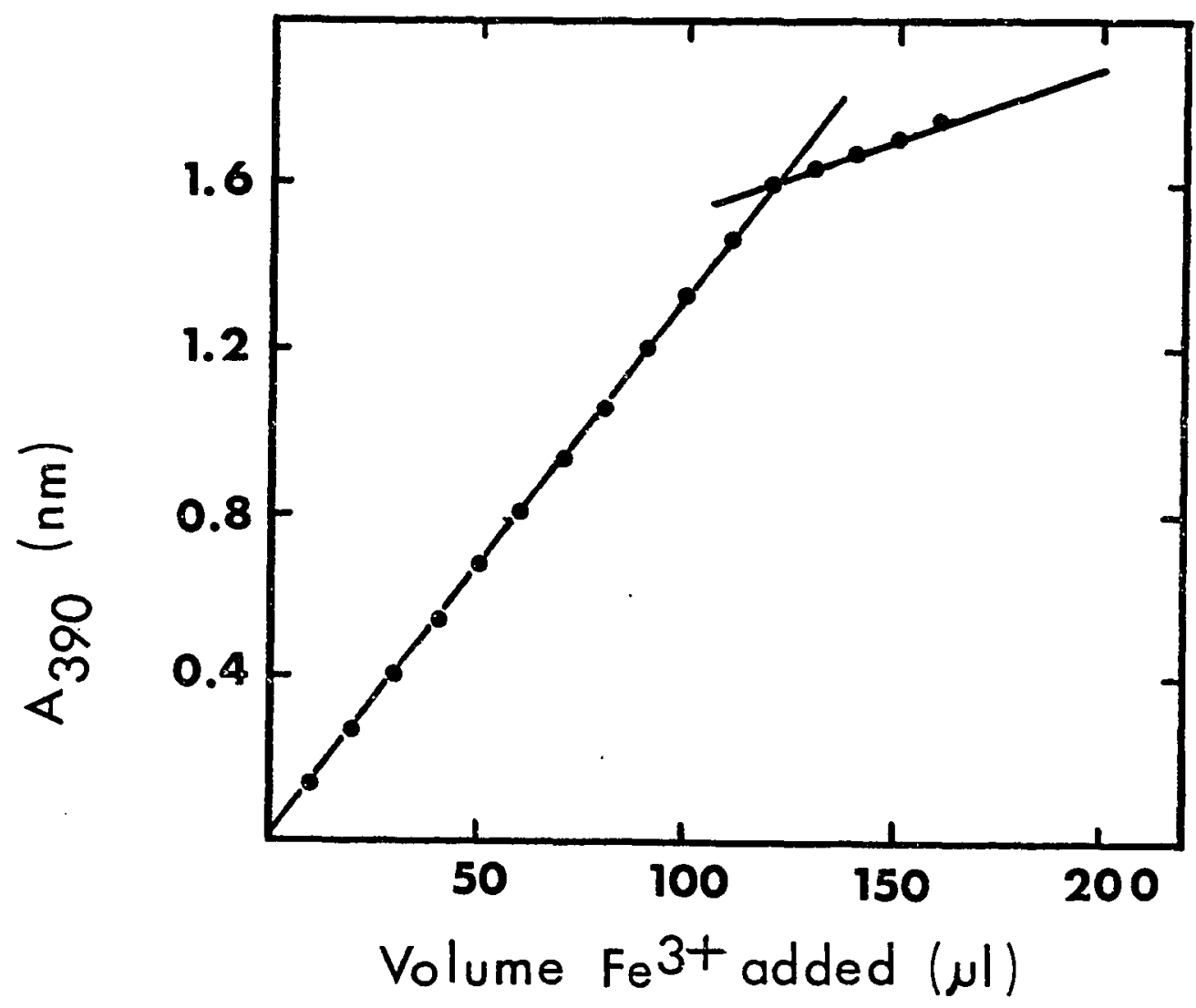

Figure 11. Spectrophotometric titration of schizokinen with $\mathrm{FeCl}_{3}(17.9 \mathrm{mM})$ in dilute $\mathrm{HCl}$. Sample was titrated to pH 6.8-7.2 after each addition and the spectrum from 500$350 \mathrm{~nm}$ recorded five minutes after each addition. Total volume initially $2.50 \mathrm{ml}$. Change in volume at equivalence point $+0.280 \mathrm{ml}$. 
in the chromotnaraphy work. At $490 \mathrm{~nm}$ an extinction of $6.2 \mathrm{mg} / \mathrm{ml}$ or 2600 liter $\mathrm{mol}^{-1} \mathrm{~cm}^{-1}$ was calculated. This latter value is actually more useful for routine work because of the problems associated with trying to saturate a schizokinen-containing solution with iron at pH 7 without creating a $\mathrm{Fe}(\mathrm{OH})_{3}$ precipitate.

It has been consistently noted that schizokinen is not stable at low pH values (less than 2.5). An NMR spectrum of schizokinen left near pH 2 for three days at room temperature is included for reference (Figure 12).

\section{Modifications of Schizokinen}

Iron was removed from ferric schizokinen using the general procedure described by Lucky et.al. (94). Ferric schizokinen was lyophilized then dissolved in $2.5 \mathrm{ml}$ of methanol containing a fifty-fold molar excess of 8hydroxyquinoline. The mixture was left at $25^{\circ} \mathrm{C}$ for one hour, then the methanol was evaporated in a gentle (cottonfiltered) air stream. The residue was taken up in $5.0 \mathrm{ml}$ $\mathrm{H}_{2} \mathrm{O}$ and extracted with $2 \times 5 \mathrm{ml} \mathrm{CHCl}_{3}$. The colorless water layer contained pure schizokinen as judged by NMR spectroscopy. Recovery according to an iron binding assay was 308 . Acetyl-schizokinen was prepared by dissolving deferrischizokinen in pyridine $(2.0 \mathrm{ml})$ and adding a 2-fold molar excess of acetic anhyaride with stirring. The mixture was left overnight before the addition of concentrated $\mathrm{NH}_{4} \mathrm{OH}$ to a final concentration of $3 \mathrm{~N}$. After three hours, the 
Figure 12

NMR spectrum of acid-hydrolyzed schizokinen in $\mathrm{D}_{2} \mathrm{O}$. The solution was left for three days at $\mathrm{pH} 2$, then adjusted to $\mathrm{pH} 7.8$ prior to lyophilization. The residue was dissolved in $0.4 \mathrm{ml} \mathrm{D}_{2} \mathrm{O}$ for spectrum. Hydrolysis of the terminal acetyl group is evident from the decrease in the $2.1 \mathrm{ppm}$ terminal methyl proton resonance and the presence of a new resonance at $1.8 \mathrm{ppm}$ attributable to free acetate. A further change is the decreased intensity of the $3.6 \mathrm{ppm}$ triplet and appearance of a new multiplet at $2.9 \mathrm{ppm}$ for the methylene protons adjacent to the hydroxamate. 


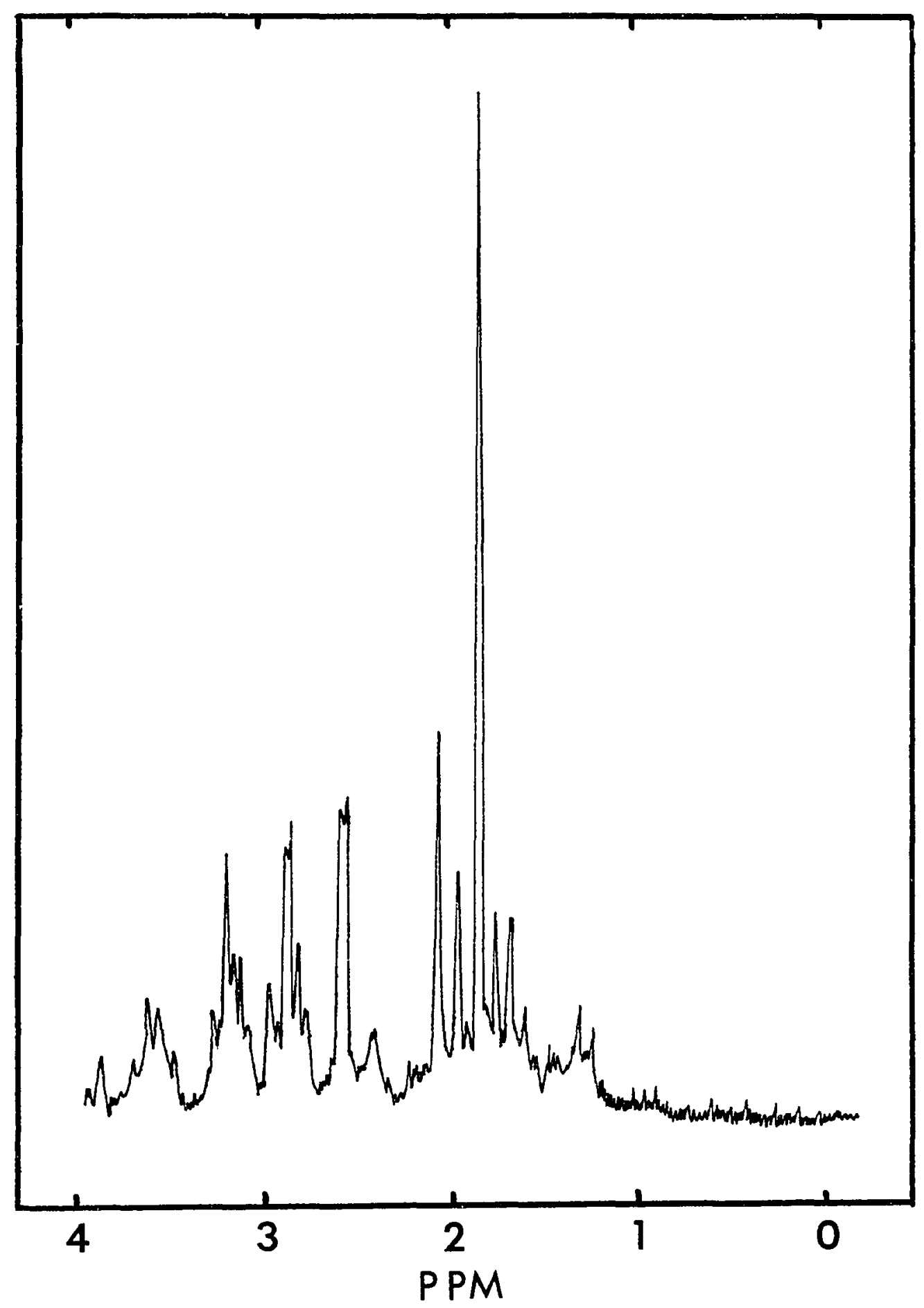


mixture was evaporated to aryness under a stream of nitrogen to volatilize most of the pyridine and ammonium acetate. The material was then dissolved in distilled water, applied to a Sephadex G-10 column, and eluted with distilled water. The product was identified by NMR spectroscopy (Figure 13).

Several attempts were made to remove the terminal acetyl groups of the hydroxamate-containing arms of the schizokinen molecule by acid hydrolysis in hopes of replacing the acetyl moieties with radiolabelled acetic anhydride. However, even under mild conditions (20 minutes at $60^{\circ} \mathrm{C}$ in $0.1 \mathrm{~N} \mathrm{HCl}$ ) the hydrolysis resulted in additional modifications which could be detected in the NMR spectrum. Reacetylation with acetic anhydride (as above) yielded a mixture of products which were not separable by gel filtration chromatography.

\section{AEROBACTIN FROM Aerobacter aerogenes}

A sample of aerobactin (Figure 4) was generously provided by DI. J. B. Neilands of the University of California. A portion of the sample was tested with the $\mathrm{Fe}$ (III) $-\mathrm{HClO}_{4}$ reagent and using the extinction coefficient for schizokinen it was calculated that approximately 1.5 mg of aerobactin was present. The sample was then run through a Sephadex G-10 column to remove any salts or impurities present. The aerobactin eluted in a peak centered at $57.6 \mathrm{ml}$ from a 


\section{Figure 13}

NMR spectrum of acetyl-schizokinen in $\mathrm{D}_{2} \mathrm{O}$. The spectrum shows a new acetyl methyl resonance at $2.05 \mathrm{ppm}$ which is in a slightly less electron-withdrawing environment than the $2.1 \mathrm{ppm}$ methyl groups of the terminal acetates. The expected 1:2 intensity ratio for the methyl protons at 2.05 and $2.1 \mathrm{ppm}$ is observed. Furthermore, the citrate methylene protons have shifted from 2.6 to 2.9 ppm as expected for the addition of an electron-withdrawing group onto the citrate hydroxyl group. 


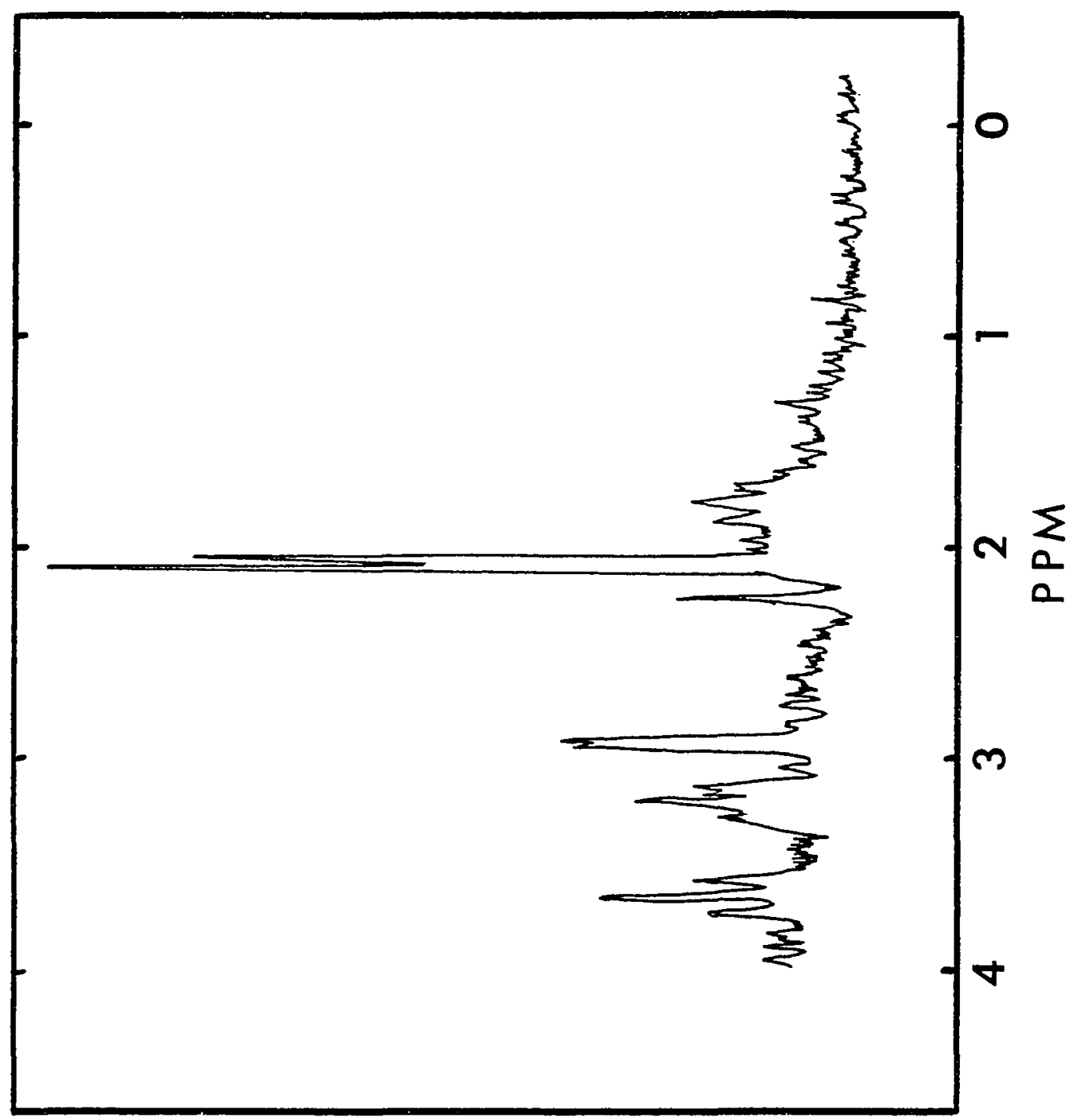


column where schizokinen eluted at $63.8 \mathrm{ml}$. The peak fractions were pooled and dissolved in $D_{2} \mathrm{O}$ for the NMR spectrum shown in Figure 14 along with a spectrum of authentic aerobactin for comparison.

The aerobactin was quantitated by spectrophotometric titration at $399 \mathrm{~nm}$ ( $\mathrm{pH} 7$ ), as described fo schizokinen.

\section{SIDEROPHORE ASSAYS}

\section{Csaky Assay for Hydroxamic Acids}

The Csaky assay for the detection of hydroxamates is based on the hydrolytic release of hydroxylamine which is then analyzed by colorimetry after reduction to nitrite (91). Because many siderophores contain the hydroxamic acid functional group, this assay has been widely used to detect siderophores. However, it is not very sensitive [detection limit about $10 \mu \mathrm{M} \mathrm{NH} \mathrm{NH}_{2} \mathrm{OH}(92)$ ] and not considered to be good guantitative tool (J. B. Neilands personal communication) due to variable release of the hydroxylamine group.

We utilized this assay for the detection of schizokinen during column chromotography and also to detect hydroxamic acids in Anabaena culture fluids. The procedure begins with hydrolysis of the sample $(1.0 \mathrm{ml})$ in an equal volume of $6 \mathrm{~N} \mathrm{H}_{2} \mathrm{SO}_{4}$ to release the hydroxylamine residue. The samples were then prepared as advised by Strickland and Parsons (93). The addition of $2.0 \mathrm{ml}$ 
Figure 14

NMR spectrum of aerobactin used in iron transport studies along with spectrum of authentic aerobactin (insert) taken from reference 54. The peak at $2.7 \mathrm{ppm}$ is possibly due to a splitting of the $2.9 \mathrm{ppm}$ peak (arising from multiple conformations of aerobactin) or to a contaminant in the preparation. 


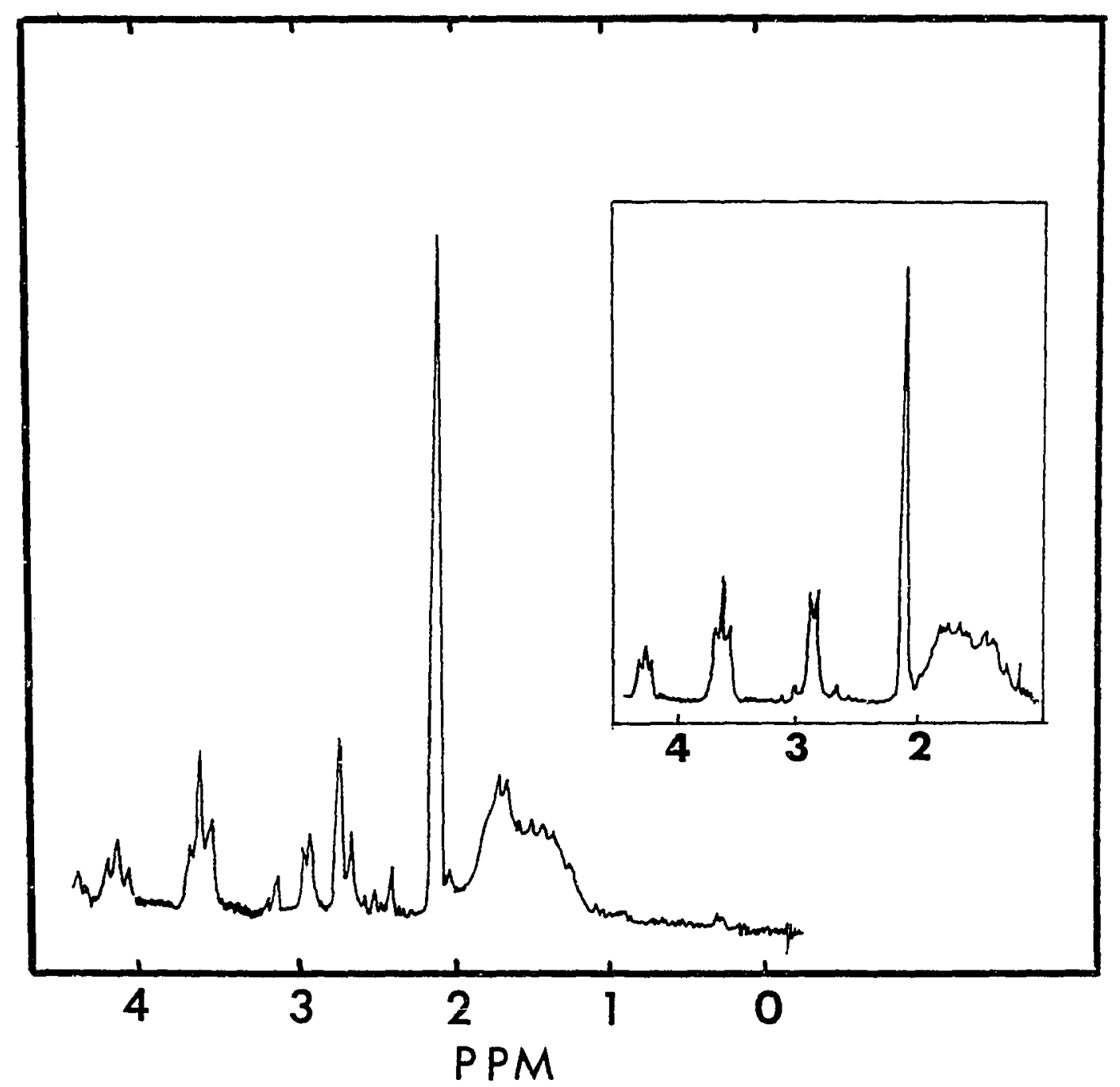


sulfanilic acid ( 10 grams in 1 İter $30 \%$ HOAC) and sodium acetate ( 358 ) followed by a five minute oxidation with $1.0 \mathrm{ml} \mathrm{I} 2$ ( $1.3 \mathrm{grams}$ in $100 \mathrm{ml}$ glacial acetic acid) produces nitrous acid from hydroxylamine. The excess iodine is neutralized with $2.0 \mathrm{ml}$ sodium arsenite ( 2 grams in $\left.100 \mathrm{ml} \mathrm{H}_{2} \mathrm{O}\right)$, and the nitrous acid is diazotized with $2.0 \mathrm{ml} \mathrm{N}-(1-$ naphthyl)-ethylenediamine $(0.1 \mathrm{gram}$ in $100 \mathrm{ml}$ $\mathrm{H}_{2} \mathrm{O}$ ) to form a colored product with maximal absorbance at $543 \mathrm{~nm}$. Samples were then diluted to $25 \mathrm{ml}$ in volumetric flasks and the absorbances determined in $10 \mathrm{~cm}$ cells. Standards used were hydroxylamine or schizokinen (Figure 15).

A recent paper has shown that quantitative release (85\%) of hydroxylamine from aerobactin required hydrolysis in $3 \mathrm{~N} \mathrm{H}_{2} \mathrm{SO}_{4}$ at $120^{\circ} \mathrm{C}$ for 4 hours (92). Simple hydroxamic acids including acetohydroxamic and benzohydroxamic acid were released within 30 minutes under these conditions $(>958)$. We had previously chosen a 15 minute hydrolysis based on an experiment testing the effect of hydrolysis time at $95^{\circ} \mathrm{C}$ on color formation from an actual Anabaena filtrate.

$\begin{array}{ccc}\text { Hydrolysis Time (Minutes) } & & \text { A543 } \\ & & 0.192 \\ 30 & 0.190 \\ 45 & 0.170 \\ 90 & 0.122\end{array}$

We observed maximum release by 15 minutes. Later experiments indicated that the discrepancy in optimum hydrolysis 


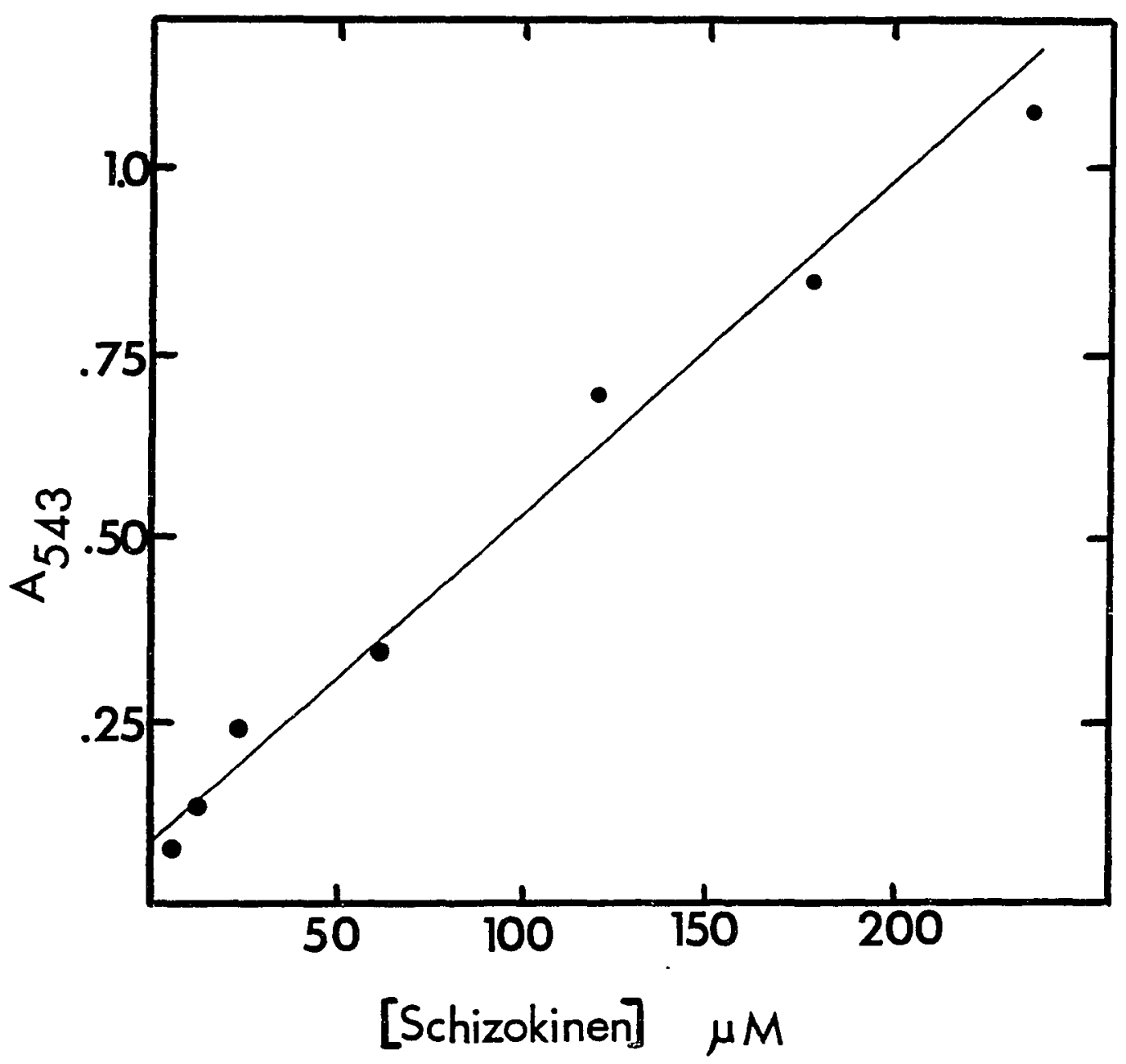

Figure 15. Standard curve for Csaky assay using purified schizokinen hydrolyzed four hours at $120^{\circ} \mathrm{C}$ in $3 \mathrm{~N} \mathrm{H}_{2} \mathrm{SO}_{4}$. Recovery of hydroxylamine nitrogen from schizokinen was approximately 658 based on non-hydrolyzed hydroxylamine standards. 
times was due to the presence of non-hydrolyzing, Csakypositive material in our filtrates. This material accounts for as much as $30 \%$ of the Csaky response obtained with 15 minute hydrolysis and its relative contribution decreases with time of hydrolysis. Subsequently, all Csaky assays were performed after 4 hour hydrolysis at $120^{\circ} \mathrm{C}$ in $3 \mathrm{~N}$ $\mathrm{H}_{2} \mathrm{SO}_{4}$. Although lower values were obtained under these conditions, they were still considerably higher than those from the Arthrobacter JG-9 bioassay (Table IV, extracted filtrates) or the iron-binding assay (see below). The lack of agreement was greatest for Anabaena filtrates from cells grown in $\mathrm{NaNO}_{3}$. Correction of Csaky data for non-hydrolyzable or non-extractable Csaky-positive material does not substantially improve the agreement with the other assays. We conclude that a variety of substances such as additional hydroxamates (schizokinen degradation products?), nitrite, or hydroxylamine present in Anabaena filtrates interfere with the csaky assay and make it unsuitable as a measure of schizokinen concentration.

It is recommended that investigators using the Csaky procedure to detect hydroxamates from cyanobacterial sources attempt an initial purification and concentration step prior to trying this assay as a quantitative tool. For example, adsorption to an XAD resin (Gilliam, personal communication) or an anion exchange resin for SK may allow separation of bound hydroxylamines from potential interferences. A further check on Csaky tests for siderophore 

CONCENTRATIONS TF SCHIZOKINEN $(\mu \mathrm{M})$ IN
ANABAENA FILTRATES

Iron ( $\mu M$ ) added to Anabaena cultures

\begin{tabular}{|c|c|c|c|c|c|}
\hline \multirow{2}{*}{$\begin{array}{l}\text { Nitrogen } \\
\text { Source }\end{array}$} & \multirow[t]{2}{*}{ Assayb } & \multicolumn{2}{|c|}{ unextracted filtrates } & extracted & filtrates ${ }^{c}$ \\
\hline & & 1.0 & 0 & 1.0 & 0 \\
\hline \multirow[t]{2}{*}{$\mathrm{N}_{2}$} & Bioassay & 0.2 & 0.9 & 0.8 & 2.1 \\
\hline & Csaky & 5.4 & 41.3 & n.a. & n.d. \\
\hline \multirow[t]{2}{*}{$\mathrm{NH}_{4}^{+}$} & Bioassay & 0.1 & 3.6 & 0.3 & 5.1 \\
\hline & Csaky & 4.3 & 19.6 & n.d. & $n \cdot d$. \\
\hline \multirow[t]{2}{*}{$\mathrm{NO}_{3-}$} & Bioassay & 0.1 & 0.5 & 2.2 & 6.6 \\
\hline & Csaky & 74 & 28 & 3 & 22 \\
\hline
\end{tabular}

a Anabaena grown on BG-II(mc) [without nitrate] with $\mathrm{N}_{2}, 1 \mathrm{mM}$ $\overline{\mathrm{NH}}_{4} \mathrm{Cl}$, or $13 \mathrm{mM} \mathrm{NaNO}_{3}$ as a nitrogen source.

bArthrobacter JG-9 bioassays performed on late log phase Anabaena filtrates. Values calculated from a standard curve obtained with purified schizokinen. (n.d. means not determined) Csaky assays performed on filtrates of 11 day Anabaena filtrates. Values calculated from a standard curve obtained with purified schizokinen subjected to identical hydrolysis conditions as the samples.

CAnabaena filtrates extracted as described below (page 69). 
production is the repression of hydroxamate synthesis when iron is added to the growth medium being tested. Without this important control, data generated with this assay must be considered questionable. In a previous study of Anabaena 6411, Simpson and Neilands (8) reported that the amount of Csaky-positive material was proportional to the degree of iron starvation when cells were grown in a medium containing $13 \mathrm{mM} \mathrm{NaNO} 3$ and $1 \mathrm{mM} \mathrm{NH} 4 \mathrm{Cl}$. Although we failed to observe this relationship in unextracted filtrates of cells grown only on $\mathrm{NaNO}_{3}$, it was observed for cells grown on $\mathrm{NH}_{4} \mathrm{Cl}$ (Table IV) or on a mixture of $\mathrm{NaNO}_{3}$ and $\mathrm{NH}_{4} \mathrm{Cl}$.

\section{Arthrobacter JG-9 Bioassay for Siderophores}

A semi-quantitative assay for schizokinen was developed using the JG-9 strain grown in the assay medium of Estep et.al. (24), supplemented with standard schizokinen solutions. A typical growth response curve to purified schizokinen is shown in Figure 16. A fresh standard curve was run with each assay, and new standard solutions were prepared from a concentrated stock solution (100 $\mu \mathrm{g} / \mathrm{ml})$ periodically. (Loss of SK to container walls was noted with standards greater than three weeks old.) Tubes containing Arthrobacter assay media were preincubated overnight at $34^{\circ}$ without shaking to monitor sterility. 


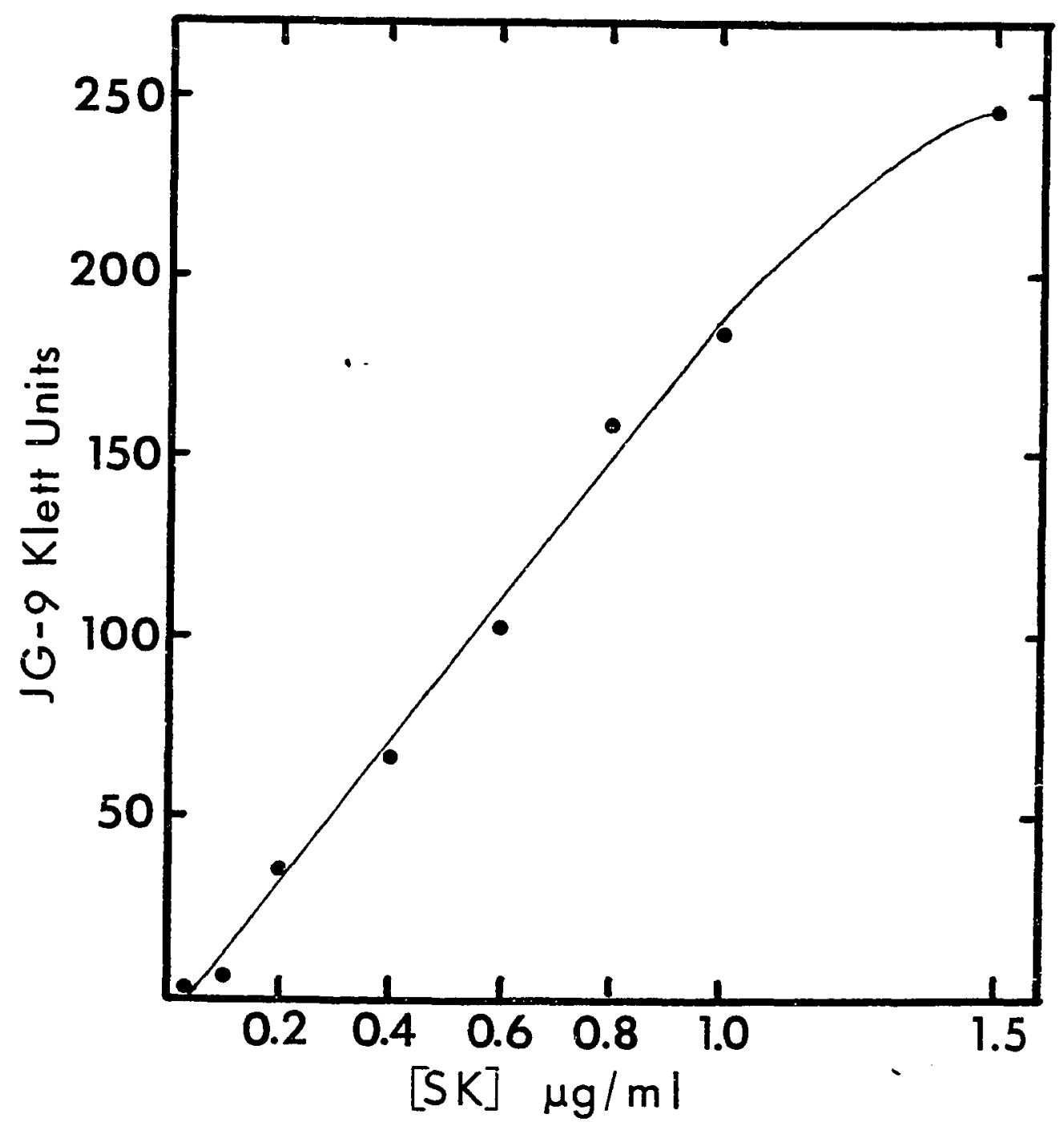

Figure 16. Growth response of Arthrobacter flavescens JG-9 to various concertrations of purified schizokinen. Cultures grown for 24 hours at $30^{\circ} \mathrm{C}$ as described above. Schizokinen concentration refers to the concentration of the $0.50 \mathrm{ml}$ test volume rather than the assay mixture which is ten-fold more dilute. 
The general procedure was to filter sterilize $(0.45 \mu \mathrm{m})$ culture fluid from the Anabaena species and add $0.50 \mathrm{ml}$ of the filtrate to $4.5 \mathrm{ml}$ of assay medium in $15 \mathrm{X}$ $180 \mathrm{~mm}$ culture tubes. The assay is linear over only a very small concentration range $(0.05-1.0 \mu \mathrm{g} / \mathrm{ml})$ so that occasionally it was necessary to add less than the $0.50 \mathrm{ml}$ test volume, in which case sterile water was added to make up the volume difference. The standards and test solutions were then innoculated with $0.1 \mathrm{ml}$ from an overnight culture of the JG-9 strain grown in assay medium supplemented with $0.05 \mu \mathrm{g} / \mathrm{ml}$ schizokinen. The cultures were incubated for 24-36 hours at $30^{\circ} \mathrm{C}$ on a rotary shaker set at $200 \mathrm{rpm}$. Growth was measured in a Klett-Sumerson colorimeter fitted with a red $(\# 66)$ filter. Both distilled water and media blanks were determined and subtracted from experimental values.

The JG-9 bioassay was also performed on $\mathrm{CHCl}_{3} /$ phenol extracts of Anabaena filtrates. The extraction was scaled down such that $1.0-2.0 \mathrm{ml}$ of filtrate $(\mathrm{pH} 2)$ was extracted three times with $5.0 \mathrm{ml}$ of $\mathrm{CHCl}_{3} /$ phenol ( $1: 1 \mathrm{wt} / \mathrm{wt}$ ). Ethyl ether $(80 \mathrm{ml})$ was added to the organic layer which was then extracted with $2 \times 5 \mathrm{ml}$ of distilled-deionized water. A known volume of this extract ( $\mathrm{pH}$ near 7) was then lyophilized to remove traces of the organics that might interfere with growth of the test organism. The residue was taken up in water, filter sterilized, and an appropriate dilution added to the test culture. 
A good control on the assay is the concericration of siderophore that gives a half-maximal growth response. In the case of schizokinen, our findings of $0.04-0.07 \mu \mathrm{g} / \mathrm{ml}$ (Figure 16) are in good agreement with the literature value of $0.05 \mu \mathrm{g} / \mathrm{ml}$ (Table II).

\section{Iron-Binding Assay for Siderophores}

Given the discrepancies between data generated with the Csaky assay and the JG-9 bioassay, we felt it necessary to confirm our confidence in the bioassay by using an independent technique to see if similar values could be obtained. The assay chosen was iron-binding ir $0.14 \mathrm{M}$ perchloric acid (see section on characterization of schizokinen). Because of the relatively low sensitivity of this procedure, $25 \mathrm{ml}$ Anabaena filtrate were concentrated by freeze-drying and then dissolved in a small volume 11.0 $\mathrm{ml}$ ) of $5 \mathrm{mM} \mathrm{Fe}(\mathrm{III})$ in $0.14 \mathrm{M} \mathrm{HClO}_{4}$. The residue always contained insoluble material that was removed by filtration (0.22 $\mu \mathrm{m}$ Millipore) or by centrifugation at $17,000 \times \mathrm{g}$ for 20 minutes. The visible spectrum was then determinea on a Cary-14 spectrophotometer between 400 and $600 \mathrm{~nm}$.

Spectra for Anabaena 6411 filtrates grown without combined nitrogen and $0.1,1.0$ or $10 \mu \mathrm{M}$ added iron are shown in Figure 17. As can be seen, the residual turbidity makes it difficult to determine with precision the true absorbance at the absorbance maximum for shizokinen ( 490 $\mathrm{nm})$. However, because the $10 \mu \mathrm{M}$ Fe culture appeared to 


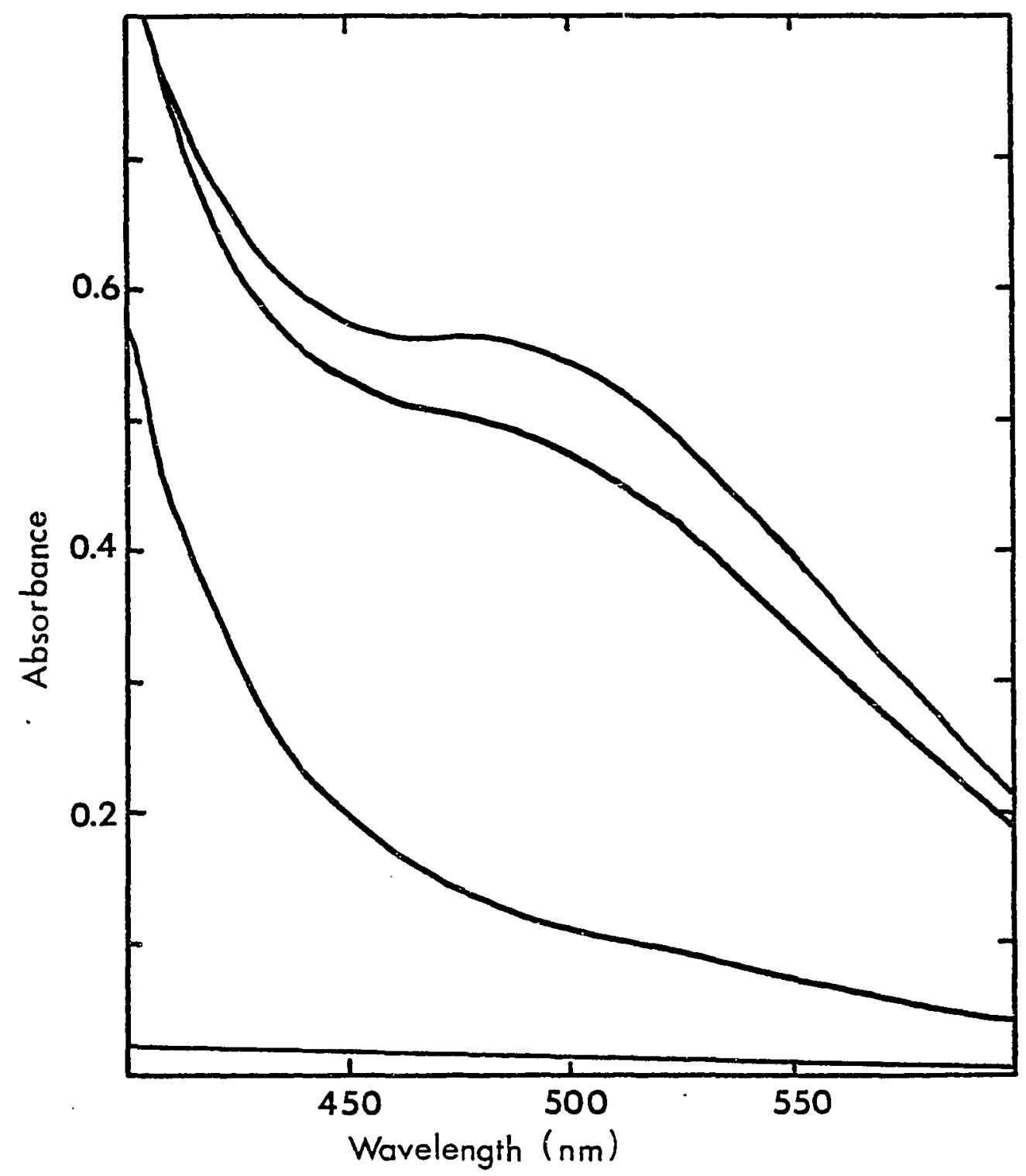

Figure 17. Visible absorption spectra for concentrated Anabaena 6411 filtrates dissolved in $5 \mathrm{mM}$ Fe(III) in $0.14 \mathrm{M}$ $\mathrm{HClO}_{4}$. Cultures were grown with 0.1 MM iron (top), $1.0 \mu \mathrm{M}$ iron (midale), or $10 \mathrm{\mu M}$ iron (bottom). 
have no ferric ion-reactive material, this curve provided a useful baseline. Using our extinction coefficient for SK in this reagent ( 2600 lit $\left.\mathrm{M}^{-1} \mathrm{~cm}^{-1}\right)$, it can be calculated that approximately 5.5 and $6.4 \mu \mathrm{M}$ schizokinen are present in the Anabaena filtrates containing 1.0 and $0.1 \mu \mathrm{M}$ added iron, respectively. These values are in general agreement with values obtained with the JG-9 bioassay (Table IV, see aiso RESULTS below). We conclude that the JG-9 bioassay is the most sensitive and accurate assay for schizokinen available.

\section{IRON UPTAKE ASSAYS}

\section{Radioactive Chelates and Counting Procedure}

In order to measure the small changes in concentration associated with iron uptake, it was necessary to utilize radioactive iron for these experiments. The isotope, ${ }^{55} \mathrm{FeCl}_{3}$ in $0.1 \mathrm{~N} \mathrm{HCl}$ was purchased from New England Nuclear at a specific activity of 25.9 millicuries per milligram of iron. This isotope decays via electron capture to $55 \mathrm{Mn}$, a stable non-radioactive isotope. In the process a weak $\mathrm{X}-\mathrm{ray}$ is emitted which can be detected by scintillation counting. The Mn(III) thus formed is readily reduced to $\mathrm{Mn}(\mathrm{II})$ in solution (94). Because $\mathrm{Mn}$ (II) is similar to iron (II) which does not form a stable complex with schizokinen, it is not likely that Mn-sK is a 
significant species. Furthermore, only 18 of the iron in the sample was $55 \mathrm{Fe}$.

$55 \mathrm{Fe}-\mathrm{containing}$ samples of 0.1 to $0.2 \mathrm{ml}$ were dispersed in $10 \mathrm{ml}$ of scintillation cocktail (Ready-Solv HP, Beckman Instruments). A counting "window" of $3 \mathrm{H}$ was programmed on a Beckman LS-9000 scintillation counter which corresponded to the experimentally determined energy distribution for $55_{\mathrm{Fe}}$ decay. The accumulation time for each sample was adjusted so that the sample counting error was less than 5\%. For the concentration of ${ }^{55} \mathrm{Fe}$ present at the beginning of a typical assay (20nM), five minutes accumulation of counts per sample yielded a sample counting error of $2.0 \%$. The overall counting efficiency, determined by comparison of the experimental counting rate (CPM) with the calculated disintegration rate (DPM), was $52 \%$.

The half-life of ${ }^{55} \mathrm{Fe}$ is 2.6 years and the fraction remaining was calculated using a decay constant of 0.021 per month. The concentration of iron in a given sample was determined from the CPM. The CPM per $m 1$ was first divided by the counting efficiency to yield DPM per $\mathrm{ml}$; then divided by $2.2 \times 10^{6} \mathrm{DPM}$ per $\mu \mathrm{Ci}$ to yield $\mu \mathrm{Ci}$ per ml; then divided by the specific activity (corrected for decay) to yield $\mu \mathrm{g}$ Fe per $\mathrm{mI}$; and finally divided by the molecular weight to obtain pmoles Fe per $\mathrm{ml}$.

The ${ }^{55}$ Fe complexes with schizokinen, Desferal, aerobactin, and acetyl-schizokinen were prepared by mixing ${ }^{55} \mathrm{FeCl}_{3}$ in $0.1 \mathrm{~N} \mathrm{HCl}$ with a two-fold molar excess of the 
ligand. The $\mathrm{pH}$ was adjusted to 7 with $0.1 \mathrm{~N} \mathrm{NaOH}$, and the solutions left overnight before use to insure complete chelation.

Procedure for Iron Uptake Assay

Anabaena filaments were harvested from cultures grown to 50-100 klett units by collection on $0.45 \mathrm{um}$ or $0.22 \mu \mathrm{m}$ filters (Millipore). The collected filaments were washed with uptake medium (Table I), and resuspended to the same cell density (unless otherwise noted) in uptake medium. The suspension was then incubated for 25 minutes at $34^{\circ} \mathrm{C}$ with light from a 100 watt incandescent light located approximately twelve inches from the solution. Both polyethylene and glass test tubes were used, each having previously soaked for at least one hour in $6 \mathrm{~N}$ $\mathrm{HCl}$ and extensively rinsed in deionized-distilled water. Uptake assays were initiated by the addition of 55 Fe-siderophore (2:1 excess ligand). At timed intervals $0.40 \mathrm{ml}$ aliquots were removed and rapidly filtered through $0.45 \mu \mathrm{m}$ filters (HA, Millipore) pre-wetted with uptake medium. Filters were then washed with one volume of ice cold uptake medium. (Better results were obtained when the aliquot was carefuliy spotted in the center of the filter to avoid contact with the walls of the vacuum manifold chamber.) The filtrate from each time point $10.20 \mathrm{ml}$ in $10 \mathrm{ml}$ Ready-Solv HP scintillation cocktail) was counted using the parameters described above. Duplicate blanks 


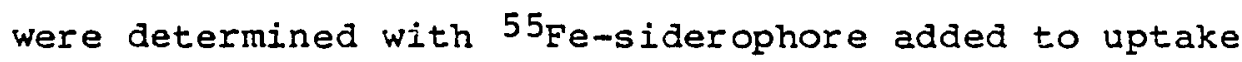
medium without Anabaena filaments present then filtered and counted in the same manner as the experimental samples. This value represents the total initial $55^{5} \mathrm{Fe}-s i d e r o p h o r e$ minus binding to the filter. Uptake of iron by cells was calculated by subtracting the experimental value for each filtrate from the blank value. For example, a blank for $20 \mathrm{nM} 55 \mathrm{Fe}, 40 \mathrm{nM}$ schizokinen gave $3,600 \mathrm{cpm}$ per $0.1 \mathrm{ml}$ filtrate. When cellular uptake was allowed to continue to completion the filtrate gave less than $100 \mathrm{cpm}$ per $0.1 \mathrm{ml}$ (i.e. background). For determination of initial rates, only values below 408 total uptake (i.e. $2160 \mathrm{cpm}$ per 0.1 ml filtrate) were utilized. The extrapolated zero-time intercept represented less than $10 z$ of the total uptake (i.e. was greater than $3,200 \mathrm{cpm}$ per $0.1 \mathrm{ml}$ filtrate). This assay procedure minimized the extrapolated zero time values (ascribed to specific and/or non-specific binding of $55^{\mathrm{Fe}-s i d e r o p h o r e) . ~ A l t e r n a t i v e ~ p r o c e d u r e s ~ s u c h ~}$ as pre-washing of filters or rinsing filtered cells with the reductant, thioglycolate, yielded no significant improvements. The zero-time values were fairly reproducible and, thus, did not interfere with our desired kinetic measurements. Furthermore, a control experiment on heatkilled cells yielded iron-binding levels similar to extrapolated zero-time values on normal cells. 
For experiments measuring the rate of iron uptake as a function of ${ }^{55}$ Fe-schizokinen consentration, nonradioactive ${ }^{56} \mathrm{Fe}-\mathrm{SK}$ ( $2: 1$ excess ligand) was added to a smaller concentration of $55 \mathrm{Fe}-\mathrm{SK}$ (usually $10 \mathrm{nM}$ ). This avoided the very large counting rates associated with the higher $55 \mathrm{Fe}$ concentrations which causes the difference between experimental and blank values to be small with respect to the total counting rate, introducing a large error. The uptake rates measured with carrier 56Fe-sK present were corrected for specific activity to give the appropriate total iron uptake rate.

Direct scintillation counting of $55 \mathrm{Fe}$ associated with Anabaena filaments trapped on filters was examined as an alternative to filtrate counting. However, the presence of a filter in the cocktail mixture decreased the overall $55_{\mathrm{Fe}}$ counting efficiency by at least 50\%. The Anabaena filaments also introduced an additional quenching that complicated the calculation of iron uptake. A procedure to bleach the Anabaena cells and help dissolve the membrane filter was employed in an attempt to overcome these difficulties. Treatment of the filters with $0.1 \mathrm{ml} 708 \mathrm{HClO}_{4}$ and $0.2 \mathrm{mI} \mathrm{H}_{2} \mathrm{O}_{2}(30 \%)$ for two hours at room temperature bleached the cells and partially dissolved the filters as well. This procedure improved the counting efficiency by 4-28\% but introduced yet another source of variability. Due to these difficulties and the overall acceptability of the filtrate counting method, this procedure was used 
exclusively for the work reported in this thesis. Recent studies by S. J. Goldman (personal communication) have shown that it is possible to obtain reproducible filter counts using Dynagel-SBS xylene-based scintillation cocktail (J. T. Baker) which completely dissolved the filters. Uptake rates and extrapolated zero-time intercepts are similar to those obtained from counting filtrates.

\section{Inhibitors of Iron Uptake}

Uptake experiments with inhibitors of energy production were carried out to test the energy dependence of iron uptake. Two inhibitors, N, $\mathrm{N}^{1}$-dicyclohexylcarbodiimide (DCCD) and carbonylcyanide-m-chlorophenylhydrazone (CCCP) are only sparingly soluble in water and so were dissolved in $95 \%$ ethanol. Potassium cyanide and sodium arsenate were dissolved in water and the $\mathrm{pH}$ of the sodium arsenate solution adjusted to $\mathrm{pH} 7.0$ prior to use. For controls, an equivalent volume of ethanol or water was used.

Anabaena filaments were harvested and resuspended in uptake medium as described previously. The resuspended cells were exposed to inhibitor or control solvent for 20 minutes ( $D C C D$ and $C C C P$ ) or 50 mintues ( $K C N$ and $\mathrm{Na}_{2} \mathrm{AsO}_{4}$ ) before addition of $55 \mathrm{Fe}-\mathrm{SK}$ to initiate the assay. For dark uptake experiments the resuspended filaments were first dark adapted for ten minutes then treated with inhibitors or control solvent as above. 


\section{RESULTS}

The Effects of Iron and Chelators on Growth of Anabaena $\underline{6411}$

The growth response of cyanobacteria to variable amounts of iron should fall into three categories. First are those concentrations that are less than adequate, which result in reduced growth. This nutrient limitation might manifest itself as an extended lag phase, slower growth rate, lower growth yields, or a combination of these effects. In the second group are those iron concentrations which give a maximal stimulation of growth, while the final category consists of those concentrations of iron that are high enough to be inhibitory due to toxic effects. The growth response of Anabaena 6411 to a wide range of iron concentrations is shown in Figure 18. In the cultures receiving no added iron (approximately $8.5 \mathrm{x}$ $10^{-8} \mathrm{M}$ by atomic absorption) or $1.0 \mu \mathrm{M}$ added iron an initial period of reduced growth was observed indicating an iron-limited state. However, once growth commenced, the rates approximate those observed with the 10 and 100 $\mu \mathrm{M}$ iron cultures. These latter cultures displayed no lag in growth and maximal initial growth rates. Only the 1.0 $\mathrm{mM}$ iron culture exhibited lack of growth due to unknown toxic effects at millimolar total iron. Metal toxicity to algal culture will be greatly affected by the solution chemistry in the growth medium. For example, copper 
Figure 18.

Growth of Anabaena 6411 in complete BG-11 medium as a function of added iron. Iron was added from a freshly prepared solution of filter-sterilized $\mathrm{FeSO}_{4}$ to insure that all iron was initially present in a soluble state. $1 \times 10^{-3} \mathrm{M}$ iron ( $\left.\Delta-\Delta\right), 1 \times 10^{-4} \mathrm{M}$ iron $(\Delta-\Delta)$ ), $1 \times 10^{-5} \mathrm{M}$ iron ( $), 1 \times 10^{-6} \mathrm{M}$ iron ( $0-0$ ), no added iron ( -0$)$ ). 


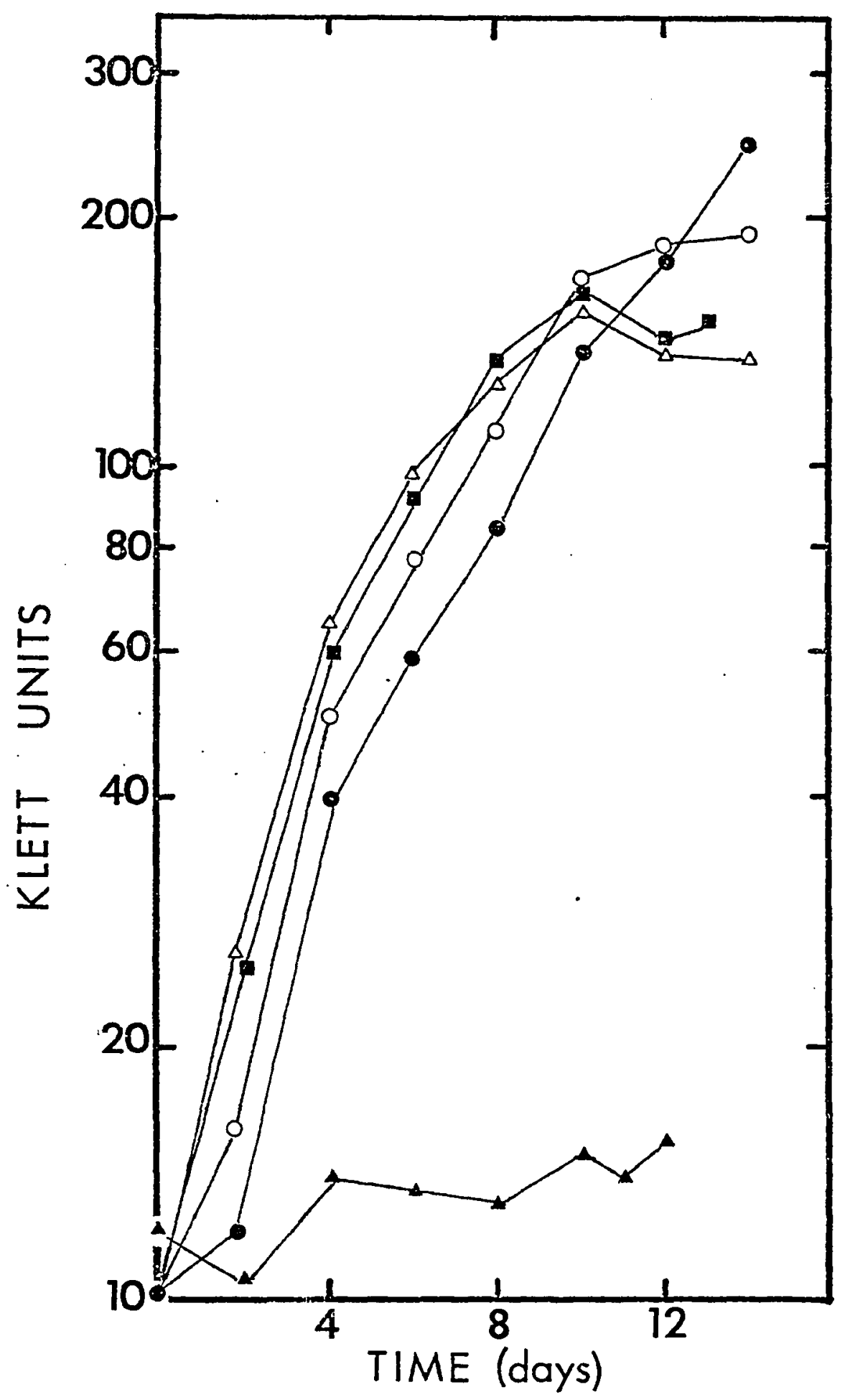


toxicity is known to be dependent on the free copper ion activity rather than the total amount of copper present (96). This is not likely to be the case for the observed toxicity of iron to Anabaena. Computer simulation of the solution chemistry predicts that the ferric ion activity and total soluble ferric hydroxides present in the cultures receiving $10^{-5}, 10^{-4}$, and $10^{-3}$ molar iron will be identical, with the excess iron occurring as colloidal ferric hydroxide precipitate (see Table VII). It seems probabie that the mechanism of iron toxicity relates most closely with the total amount of $\mathrm{Fe}(\mathrm{OH})_{3}$ precipitate formed. A more detailed examination of the solution chemistry in BG-II growth medium as it relates to Anabaena growth and siderophore production will follow in the Discussion Section.

It is interesting to note that under these conditions the final yields are not proportional to the amount of iron added to the medium. The culture without added iron actually achieved the highest klett values followed by the 1.0 $\mu \mathrm{M}$ added iron culture. These results suggest that iron limitation is not a significant threat to the growth of Anabaena 6411 in batch culture. Serial passage through at least three transfers in unsupplemented low iron medium had no serious effect on the growth of this strain, suggesting that stored iron was not responsible for the observed growth. Rather, the successful growth during iron limitation must be due to effective iron scavenging by Anabaena. 
The above experiment was conducted in complete BG-11 medium containing the chelators EDTA and citric acid. Because we felt it desirable to omit these chelators from cultures where siderophore production and iron uptake were to be studied, their effect on the growth of Anabaena 6411 was tested (Figure 19). In this experiment we have focused on those concentrations where iron limited growth is observed. It is apparent that cultures supplemented with the chelators grew slightly better than the unsupplemented cultures at every iron concentration. This behavior may reflect some copper toxicity since removal of the chelators should increase the copper ion activity from 10-11.1 $\mathrm{M}$ up to $10^{-7.2} \mathrm{M}$ (see Discussion). The differences in growth are slight however, and the overall pattern of growth is quite similar in this range of iron concentrations. Anabaena 6411 also grew without added chelators in media free of combined nitrogen (Figure 20). This strain demonstrates an increased requirement for iron when fixing nitrogen. Evidence for this stems from the fact that when nitrogen-fixing cells growing in BG-lI medium (minus nitrate) without added iron are serially passed in the identical medium without added iron, the cells quickly become chlorotic and fail to grow well after the first transfer. Cells grown in the same medium on nitrate grow at nearly the same rate through at least three transfers without added iron. A similar lack of growth in Anabaena 6411 under iron-limited, nitrogen-fixing conditions was 


\section{Figure 19.}

Growth of Anabaena 6411 in BG-11 medium with the chelators citric acid (6 mg/liter) and EDTA ( $1 \mathrm{mg} / \mathrm{liter}$ ) (closed symbols) and without these chelators (open symbols). Iron concentration added: $1.0 \mu \mathrm{M}$ (squares), $0.1 \mu \mathrm{M}$ (triangles), no added iron (circles). 


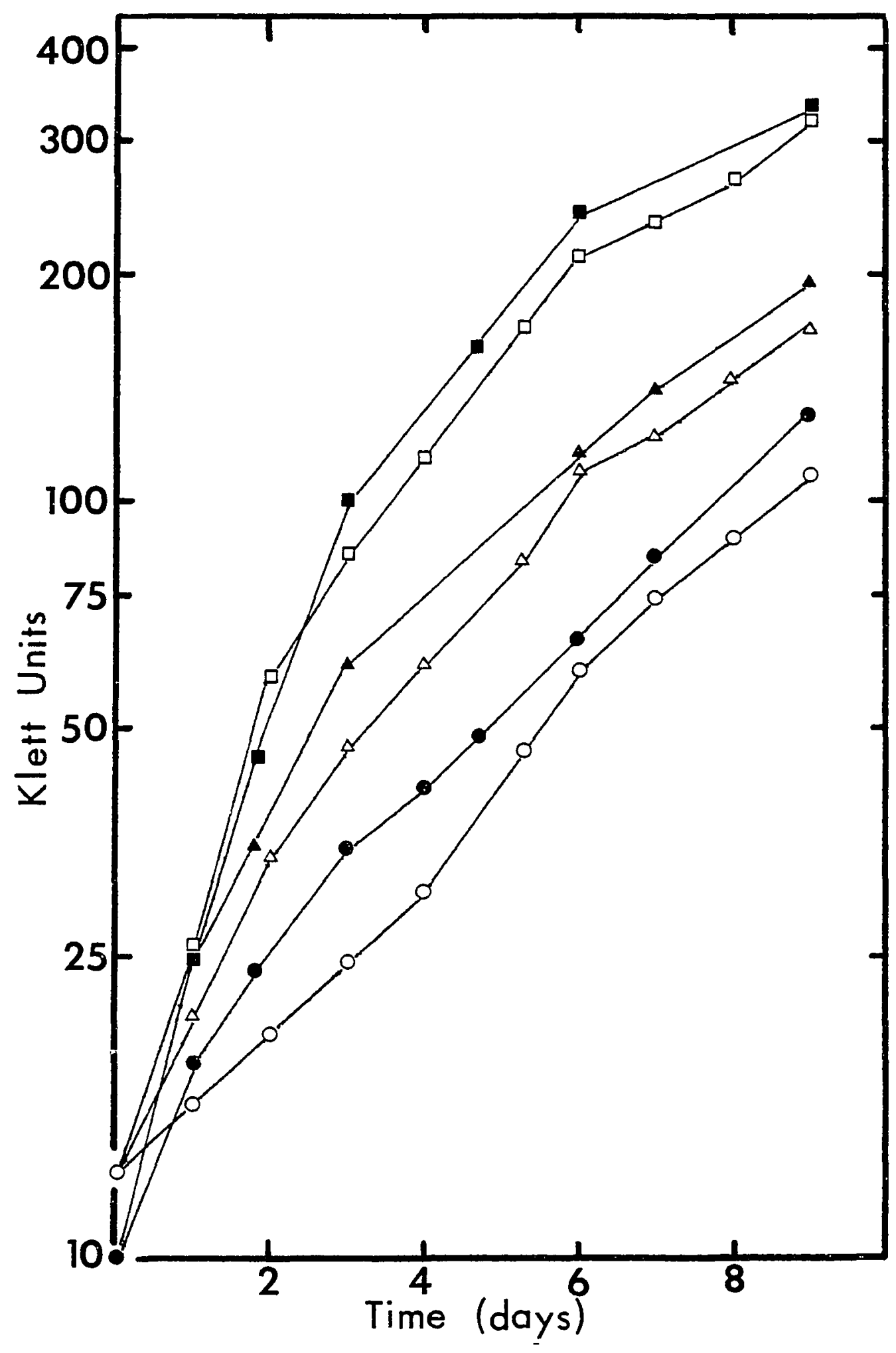




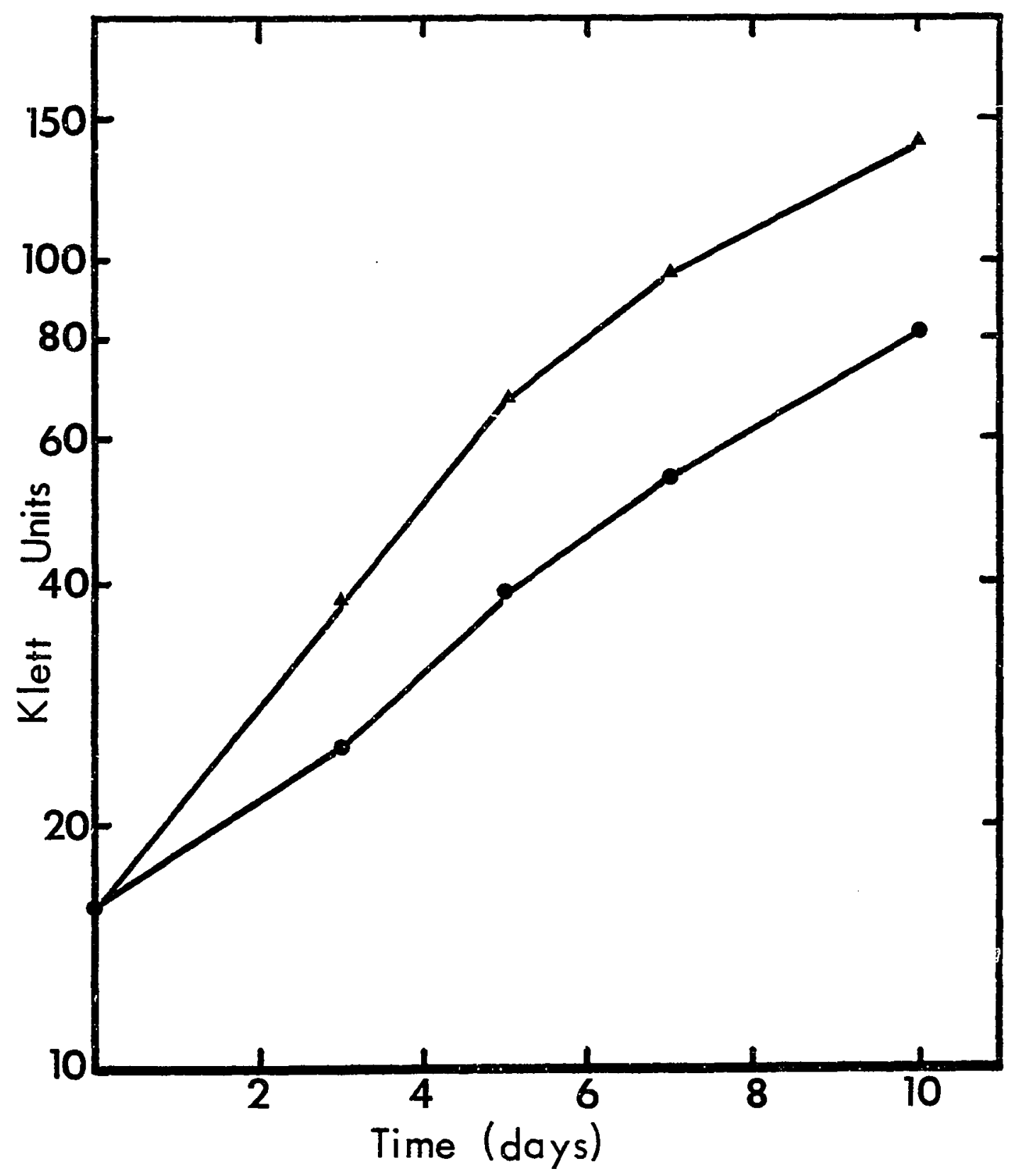

Figure 20. Growth of Anabaena 6411 in BG-11(mc) without combined nitrogen. ( $\longleftrightarrow$ ) $0.5 \mu \mathrm{M}$ added iron, ( $\longrightarrow$ ) 0.1 HM added iron. 
also observed by Simpson and Neilands ( 8 ). A possible explanation is that cells under these conditions are less capable of producing siderophore (Tables IV and V).

A final observation on the growth of Anabaena 6411 is that true $\log$ phase growth is limited to the first three to four days of growth. Afterwards, cultures grow at a reduced rate that is not usually linear with time. This pattern is observed regardless of the concentration or oxidation state of the iron added to the medium. Furthermore, it does not seem to be due to the induction of nitrogen-fixing metabolism since cultures pre-adapted to growth on $\mathrm{N}_{2}$ also show similar behavior (Figure 20). The most probable explanation for this effect is $\mathrm{CO}_{2}$ limitation induced as the added carbonate species are fixed into cellular carbon. Another possible factor is self-shading effects which would reduce the light intensity striking a portion of each culture, and thus slowing overall growth.

\section{Siderophore Production by Anabaena 6411}

It has been previously demonstrated by simpson and Neilands (8), that Anabaena 6411, when grown under ironlimiting conditions, produces csaky-detectable, extracellular hydroxamates and that schizokinen is present in the supernatant of iron-limited cultures. In order to measure schizokinen production in response to iron availability, we have employed a more sensitive assay system utilizing the siderophore auxotroph, Arthrobacter flavescens JG-9, as a 


\section{CONCENTRATIONS OF SCHIZOKINEN ( $M M$ ) IN ANABAENA FILTRATES}

\begin{tabular}{lcccc}
\hline & \multicolumn{3}{c}{ Iron added to Anabaena culture } \\
\cline { 2 - 5 } Nitrogen sourceb & \multicolumn{2}{c}{ None } & $\frac{1.0 \mu M}{2}$ & Filtrate Extract \\
\cline { 2 - 5 } $\mathrm{N}_{2}$ & 0.9 & 2.1 & 0.2 & 0.8 \\
$\mathrm{NH}_{4} \mathrm{Cl}, 1 \mathrm{mM}$ & 3.6 & 5.1 & 0.1 & 0.3 \\
$\mathrm{NaNO}_{3}, 13 \mathrm{mM}$ & 0.5 & 6.6 & 0.1 & 2.2 \\
\hline
\end{tabular}

a Schizokinen concentration determined by growth factor activity for Arthrobacter flavescens JG-9, relative to a standard curve obtained with pirified schizokinen. Errors were $+30 \%$ for values above 3 and $+70 \%$ for values below 2. Schizokinen concentrations were measured on untreated cell filtrates and on filtrates subjected to chloroform/phenol extraction as described above (p. 69).

b Anabaena grown to late log phase on BG-1l medium (minus citrate, EDTA, $\mathrm{NaNO}_{3}$ ) with nitrogen added as indicated. $\mathrm{NaNO}_{3}$ and $\mathrm{NH}_{4} \mathrm{Cl}$ concentrations are those used in uptake medium (8). $\mathrm{NaNO}_{3}$ in standard $\mathrm{BG}-11$ is somewhat higher, $18 \mathrm{mM}$. 
test organism. In time-course experiments on Anabaena 6411 filtrates, we have found that siderophore concentrations (based on a schizokinen standard curve) increased steadily during the first five days of growth in standard BG-1l(mc) medium. The amount of siderophore produced was inversely proportional to the amount of iron in the growth medium as expected. (See Table VII in the discussion.) After five days of growth all of the cultures showed an apparent drop in the Arthrobacter assay response with a complete loss of activity by fourteen days. In contrast, similar time course assays on Anabaena 6411 filtrates growing in BG-II(mc) without combined nitrogen did not drop off, but rather continued to increase for at least twelve days. One likely explanation for the observed differences was that growth of Anabaena on nitrate-containing media produces a substance which interferes with the Arthrobacter growth response and that this interfering substance is produced particularly in late growth phase. Therefore, we decided to determine whether organic extraction of schizokinen might separate it from interfering substances.

The effect of an organic extraction of filtrates prior to the Arthrobacter assay is shown in Table 5. The extraction was performed on late Anabaena filtrates from BG-Il(mc) containing $\mathrm{NaNO}_{3}(13 \mathrm{mM})$ or $\mathrm{NH}_{4} \mathrm{Cl}(1 \mathrm{mM})$ as a nitrogen source and cultures free of combined nitrogen. In the case of the nitrate-containing Anabaena filtrates, we found that the growth factor activity could be restored 
by extraction of the siderophore as in the standard purification procedure for schizokinen. Thus, it appears that siderophore levels continue to increase throughout the growth phase of Anabaena cultures in nitrate-containing medium and that the drop in growth factor activity noted in the time course experiments is due to the production of a substance which is inhibitory to the Arthrobacter test organism. The identity of this inhibitory substance remains a mystery. However, because extracted filtrates from nearly all cultures showed a slight stimulation of Arthrobacter growth response, it is not likely that production of the inhibitor is strictly limited to nitratecontaining medium.

Regardless of nitrogen source, all extracted Anabaena filtrates showed increased schizokinen production for cells grown in 0 added iron, relative to 1 uM added iron. Thus, this assay exhibits the expected response to iron limitation and can be used as a semi-quantitative measure of schizokinen production. Similar schizokinen levels were observed for cells grown in either $\mathrm{NaNO}_{3}$ or $\mathrm{NH}_{4} \mathrm{Cl}$. Twoto three-fold lower levels of schizokinen were found for cells utilizing $\mathrm{N}_{2}$. Apparently cells make less schizokinen when nitrogen supplies are limited, even though they have an increased requirement for iron in the production of nitrogen-fixing enzymes. Presumably under these conditions nitrogen is preferentially incorporated into other molecules (e.g. proteins and nucleic acids). 
The Arthrobacter bioassay also has been utilized to measure the effect of adding $1 \mathrm{mM}$ citrate to the BG-11(mc) growth medium on siderophore production. A thirteen day filtrate ( 155 klett units) from a culture containing lmM citrate and $0.1 \mu \mathrm{M}$ iron was extracted for Arthrobacter analysis. Prior to extraction $2.0 \mu \mathrm{M}$ schizokinen was measured, while after extraction $42 \pm 4 \mu \mathrm{M}$ schizokinen was obtained. This represents a dramatic increase in siderophore production relative to standard BG-ll(mc). The effect of lmM citrate on Arthrobacter JG-9 growth was negligible. Because citric acid is a component of the schizokinen molecule, it is tempting to suggest that the observed stimulation in siderophore production is due to high intracellular concentrations of a biosynthetic precursor. If citrate were merely behaving as a siderophore to increase iron uptake, schizokinen production would have decreased. The alternative explanation that citrate increases iron starvation by limiting iron availability seems unlikely in view of the growth-promoting effect of $0.03 \mathrm{mM}$ citrate (Figure 19) and the fact that cells can take up iron when it is arded as ferric citrate (see iron uptake below).

Transport of Ferric Schizokinen by Anabaena 6411

The ability of Anabaena 6411 to utilize radiolabeled iron complexed with a two-fold excess of schizokinen is 
shown in Figure 21. The removal of [ $\left.{ }^{55} \mathrm{Fe}\right]$ ferric schizokinen from the uptake medium was linear with time until approximately fifty percent of the label was taken up for every concentration tested. Accumulation of ferric schizokinen continued at decreasing rates until nearly all the added iron was removed from the medium. Since the cellular volume represents less than 0.18 of the solution volume, the complete uptake of $90 \mathrm{nM}$ iron from the medium has resulted in a cellular iron concentration greater than $0.09 \mathrm{mM}$. Since it is highly unlikely that this amount of iron would be merely associated with the cell surface (where the concentration would be greater than $1 \mathrm{mM}$ ), the cells appear to be actively accumulating iron.

A closer examination of the initial stage of ferric schizokinen uptake was conducted on Anabaena cultures grown with variable amounts of added iron (Figure 22). The iron uptake system in this organism appears to be under some type of metabolic control as evidenced by the invers: relationship between initial rate of [55 Fe] ferric schizokinen uptake and the amount of iron added to the growth medium. During the initial one minute period between addition of [ $55 \mathrm{Fe}]$ ferric schizokinen to initiate the assay and our first data point, rapid binding to the cells occurs probably in both a specific and non-specific fashion. Following this a period of linear uptake was noted similar to that observed in Figure 21. Subsequent studies have concentrated on this linear phase of iron transport, the 


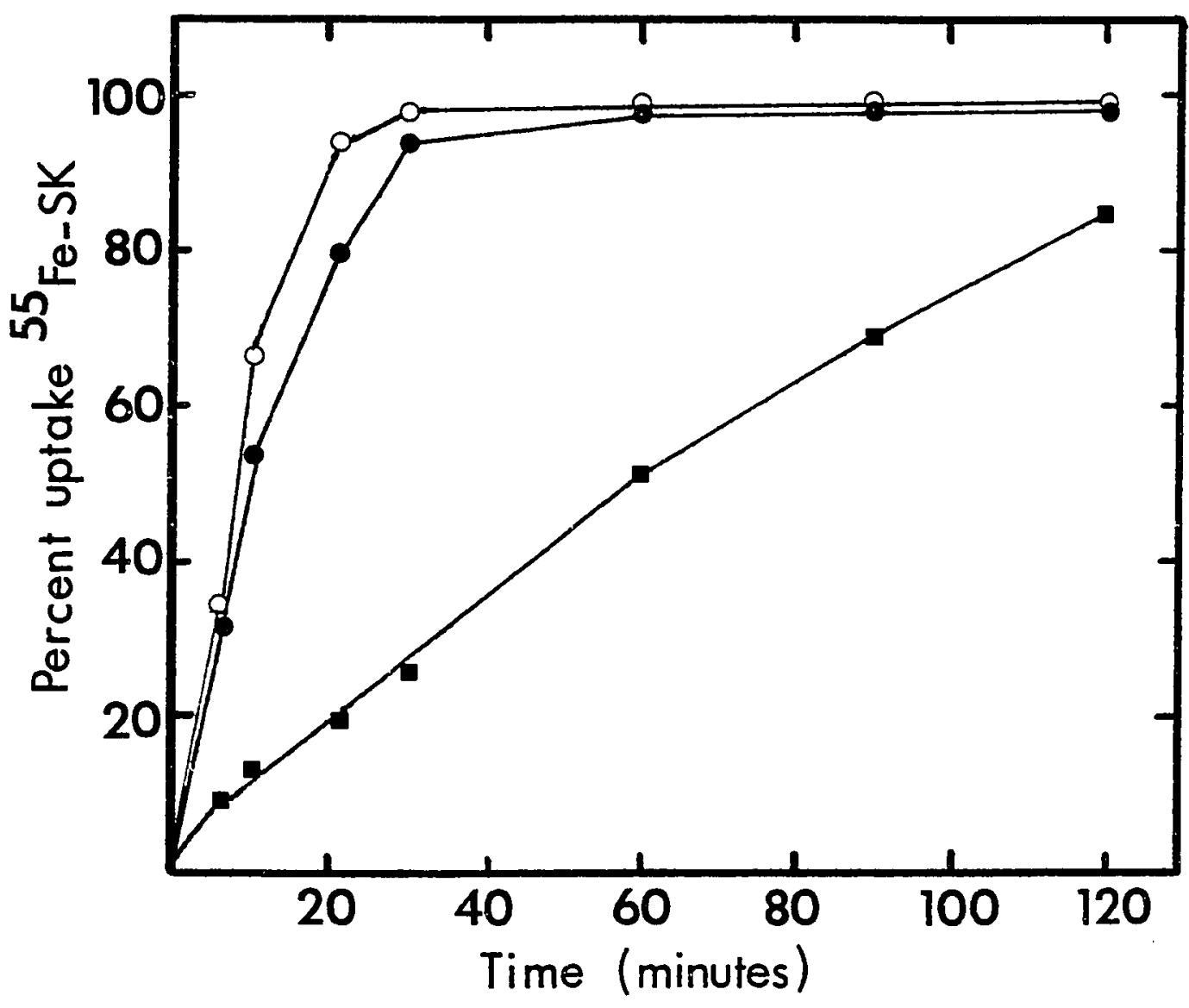

Figure 21. Uptake of [ $55 \mathrm{Fe}]$ ferric schizokinen; $0.9 \mathrm{nM}$ $(\longrightarrow), 9.0 \mathrm{nM}(-)$ ), and $90 \mathrm{nM}(0-0)$, by Anabaena 6411. Cells were grown in uptake medium ( $18 \mathrm{CO}_{2}$ bubbling) supplemented with $1.0 \mu \mathrm{M}$ iron(III) and trace metals to 83 Klett units. Schizokinen was present in a two-fold molar excess to $55 \mathrm{Fe}$. 


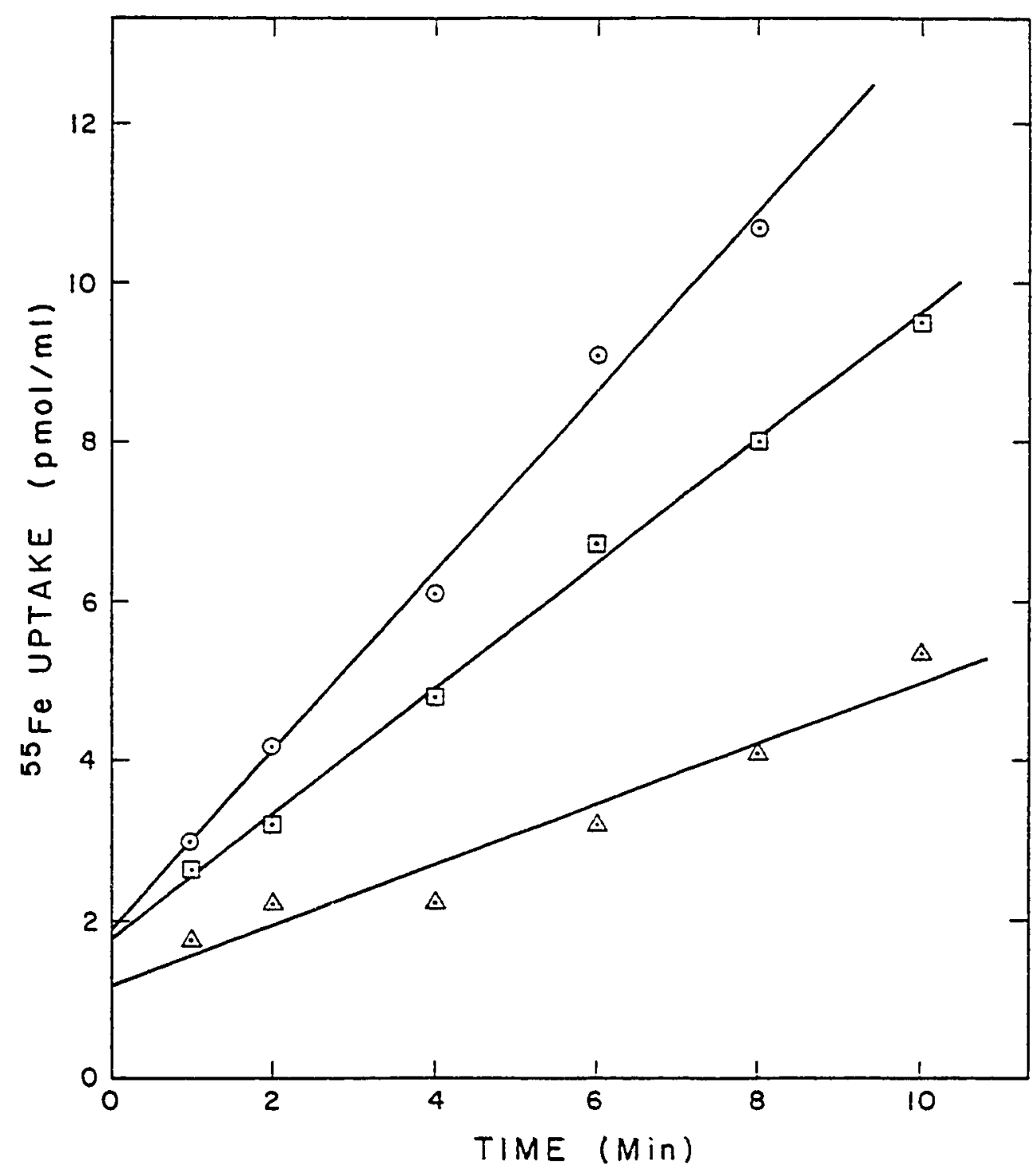

Figure 22. Rate of uptake of $55 \mathrm{Fe}$-schizokinen as a function of the iron concentration in the growth medium. Anabaena grown in zero $(0-0), 0.1 \mathrm{\mu M}(\square)$, and 1.0 $\mu \mathrm{M}(\Delta \longrightarrow)$ added iron. Cells resuspended to $52 \mathrm{klett}$ units in uptake medium containing $14 \mathrm{nM} 55 \mathrm{Fe}$ and $28 \mathrm{nM}$ schizokinen. 
duration of which is dependent on the concentration of radiolabeled iron added to the assay medium and the cell density. Washed cells and a two-fold excess of schizokinen have been utilized to insure that iron is siderophore-bound during assays. The presence of an equimolar amount of free schizokinen in the assay had no significant effect on iron uptake from ferric schizokinen because the cellular affinity for schizokinen is 50 times lower (i.e. assuming competitive inhibition, the $\mathrm{K}_{I}$ for schizokinen is approximately $1.5 \mu \mathrm{M})$.

Kinetics and Energy Dependence of Ferric Schizokinen Transport

If the observed removal of iron from the assay medium is due to specific biological transport, the uptake system should be saturatable at high solute concentrations. In addition, if the cellular accumulation of ferric schizokinen seen in Figure 21 is due to biological transport, it should require the input of metabolic energy.

Evidence for the involvement of specific carriers in the transport of [" Te]-ferric schizokinen was obtained by studying the kinetics of iron uptake as a function of solute concentration. Results presented in Figure 23 (insert) demonstrate that $\left[{ }^{55} \mathrm{Fe}\right]$-ferric schizokinen uptake occurs via a saturatable system. Double reciprocal plots yield an apparent $K_{\mathrm{M}}$ of $35 \mathrm{nM}$. A $\mathrm{V}_{\max }$ of approxi- 


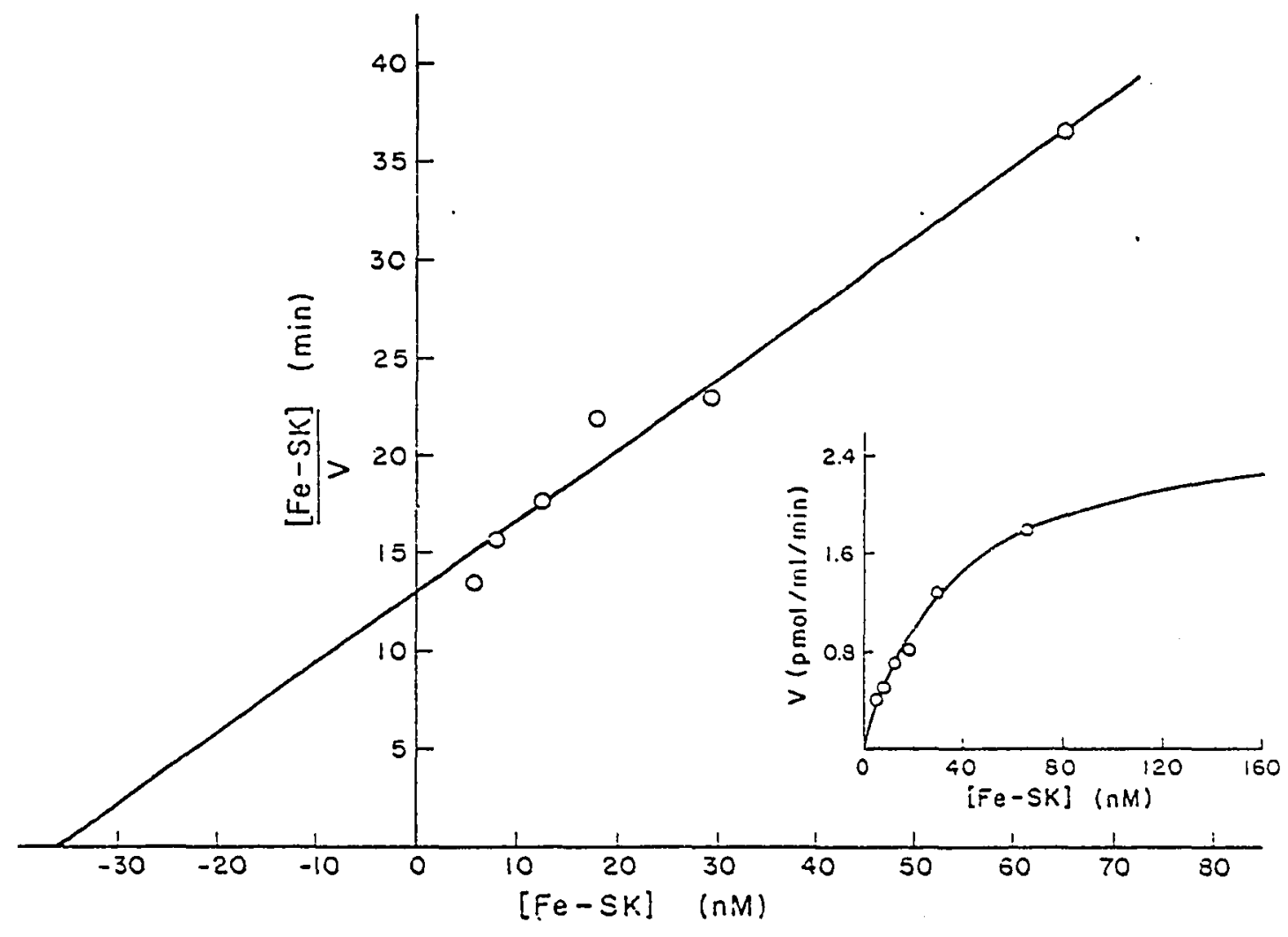

Figure 23. Kinet os of uptake of ferric schizokinen. Anabaena 6411 gro:n in uptake medium containing 0.1 uM added iron and resuspended to 47 klett units in uptake medium. Graphs show calculated curves for $K_{M}=36$ nM and $\mathrm{V}_{\max }=2.7 \mathrm{pmol} / \mathrm{min} / \mathrm{mI}$. 
mately 2.5 picomoles $/ \mathrm{min} / \mathrm{ml}$ was calculated for the conditions tested (Anabaena grown with $0.1 \mu \mathrm{M} F e$ at a cell density corresponding to 47 Klett units). The apparent $K_{M}$ value is at least three times lower than reported values for siderophore transport by E. coli $(72,76)$ and gives an indication of the extremely high affinity of the ferric schizokinen transport system for its substrate.

After showing that Anabaena 6411 is capable of accumulating ferric schizokinen against a concentration gradient, it was of interest to determine the energy requirements of the process. Since Anabaena 6411 is an obligate photoautotroph, light is the ultimate source of all metabolic energy. In order to determine whether Fe-SK uptake is energized directly by light-associated processes, uptake activity in the light and dark was measured. We found that uptake activity was only slightly decreased in the dark, ranging from 80-95\% of light controls; dark adaptation periods from 15 minutes to two hours had little effect.

In order to discriminate between possible sources of energy for iron uptake, the effect of various inhibitors on iron transport was tested. Representative uptake data are shown in Figure 24 and a summary of the inhibitor results is given in Table VI. Both light and dark uptake were sensitive to the uncoupler carbonylcyanide-m-chlorophenylhydrazone (CCCP) which dissipates the trans-membrane electrochemical hyarogen-ion gradient. In addition, $N$, 


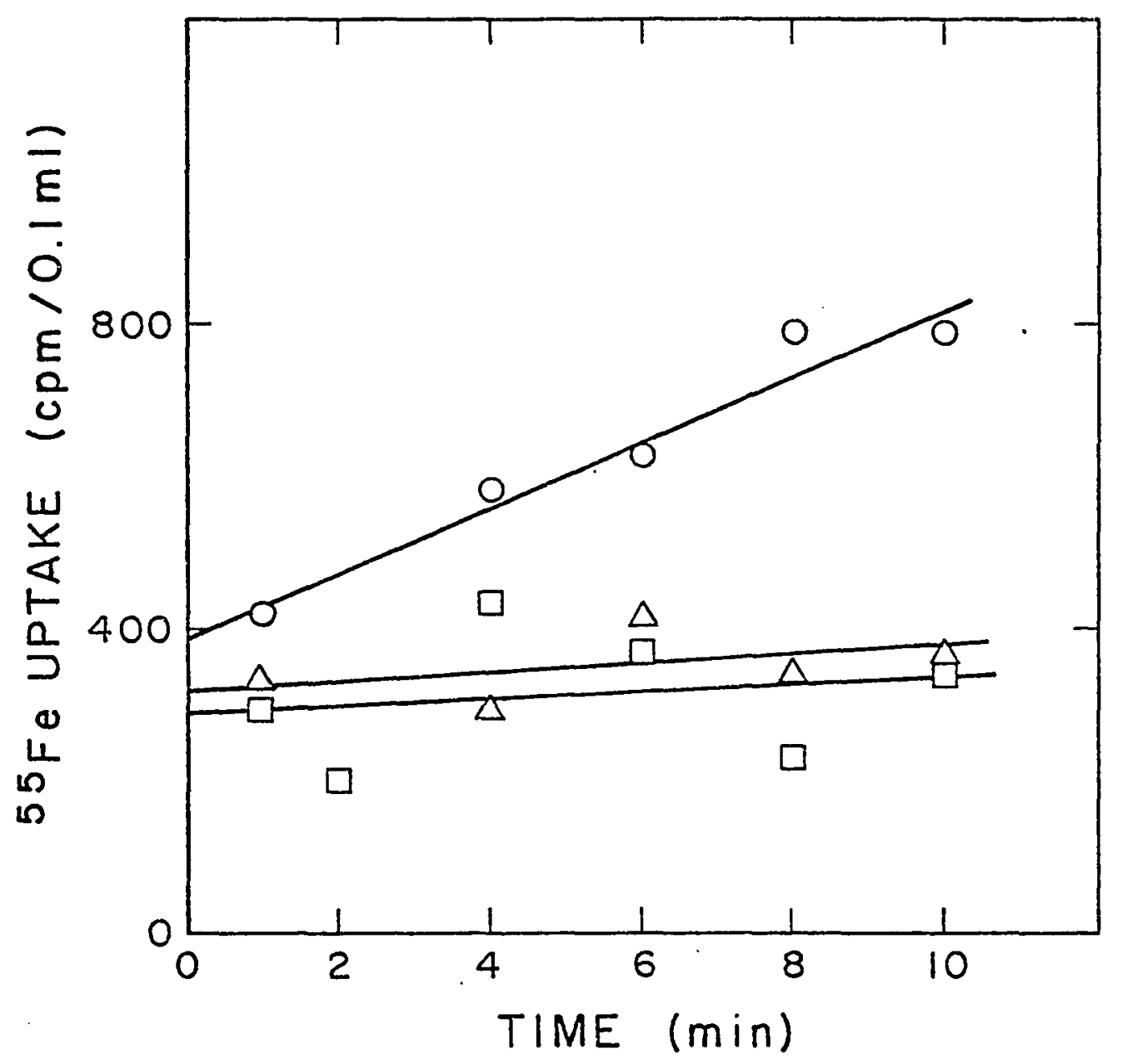

Figure 24. Effect of CCCP and DCCD on the uptake of ferric schizokinen in Anabaena 6411 in the light. Cells were exposed to $8 \mu \mathrm{M} \operatorname{CCCP}(\Delta \Delta), 5 \mu \mathrm{M} \operatorname{DCCD}(\square-\square)$, or no inhibitor $(0-0)$ for 20 minutes prior to the addition of $15 \mathrm{nM} 55 \mathrm{Fe}$, $30 \mathrm{nM}$ schizokinen. 
TABLE VI

EFFECT OF METABOLIC INHIBITORS

ON FERRIC SCHIZOKINEN UPTAKE

IN ANABAENA

\begin{tabular}{lccc}
\hline & & \multicolumn{1}{c}{ Uptake activity $(8)$ a } \\
\cline { 3 - 4 } Inhibitor & Concentration & Light & Dark \\
\hline CCCP & $8 \mu \mathrm{M}$ & 10 & 0 \\
DCCD & $40 \mu \mathrm{M}$ & 5 & 5 \\
Arsenate & $20 \mathrm{mM}$ & 50 & 15 \\
Cyanide & $100 \mu \mathrm{MM}$ & 90 & 20 \\
\hline
\end{tabular}

a Uptake activity relative to light or dark control in the absence of inhibitor. Values are $\pm 5 \%$ for CCCP, DCCD, and $\mathrm{Na}_{2} \mathrm{HASO}_{4}$ and $\pm 10 \%$ for $\mathrm{KCN}$. For dark uptake, cells were dark-adapted 10 minutes before adding inhibitor. Total time of exposure to inhibitor prior to addition of Fe-SK was 20 minutes for CCCP and DCCD, 50 minutes for $\mathrm{Na}_{2} \mathrm{HAsO}_{4}$ and $\mathrm{KCN}$. Anabaena cultures were grown in uptake medium containing $0.1 \mu \mathrm{M}$ added iron. 
$N^{l}$-dicyclohexylcarbodiimide (DCCD), an inhibitor of $\mathrm{H}^{+}$-translocating ATPases in bacteria, mitochondria, and chloroplasts (96), caused almost complete inhibition of iron uptake both in the light and dark. The DCCD-sensitivity of iron uptake implies that ATP is required for this process. The inhibition of iron uptake by arsenate, which inhibits ATP synthesis by acting as a substrate analog, supports this conclusion. The fact that $\left[55^{\mathrm{Fe}}\right]$-ferric schizokinen uptake in the light is less sensitive to arsenate inhibition than dark uptake may possibly be due to a higher overall rate of ATP formation in the light. The inhibition of $\left[5^{5} \mathrm{Fe}\right]$-ferric schizokinen uptake by potassium cyanide in the dark strongly suggests that dark iron uptake in Anabaena 6411 is ariven by respiratory electron transport. Cyanide is a well known inhibitor of electron transport in bacteria and mitochondria due to strong binding of $\mathrm{CN}^{-}$to the oxygen binding site in the terminal cytochrome oxidase of the electron transport chain. The lack of significant cyanide inhibition in the light indicates that Anabaena 6411 depends on photophosphorylation for light-driven iron uptake and oxidative phosphorylation for dark uptake.

\section{Specificity of Iron Uptake in Anabaena 6411}

We have examined the ability of Anabaena 6411 to utilize iron chelated by a structurally similar siderophore (aerobactin), a dissimilar siderophore (ferrioximine B or 
Desferal) and also a derivative of schizokinen (acetylschizokinen). The initial rates of uptake of $55 \mathrm{Fe}-$ siderophore ( 2 to 1 molar excess of ligand) are shown in Figure 26.

The rates of iron uptake from the schizokinen and acetylschizokinen complexes appear to be identical, although the $y$-intercepts, representing specific and non-specific binding, are different. Thus, iron transport is not significantly altered when the citrate hydroxyl group of schizokinen is modified by acetylation. In contrast, Arthrobacter JG-9 which generally shows much less siderophore specificity than Anabaena exhibited only $1 / 3$ as much growth activity with acetyl-schizokinen as it did with schizokinen. No iron uptake activity is observed when $55 \mathrm{Fe}$ is chelated by excess Desferal, in concentrations up to 55 nM ${ }^{55} \mathrm{Fe}$. [55 Fe]-ferric aerobactin also did not support iron transport by Anabaena 6411. This is consistent with results from other schizokinen-utilizing organisms like Bacillus megaterium which cannot assimilate ferric aerobacter despite its structural similarity to schizokinen ( 80$)$. The increased negative charge of this complex may be at least partially responsible.

When ${ }^{55} \mathrm{Fe}$ citrate ( $100 \mathrm{X}$ excess citrate: Fe) was used as an iron source, uptake rates approaching those with ferric schizokinen were observed. However, due to the fact that schizokinen has a much greater iron affinity than 
Figure 25.

Iron uptake activity by Anabaena 6411 for several ferric siderophore complexes. [5JFe]-ferric schizokinen (0-0), [55F]-ferric acetyl schizokinen ( -

[55Fe]-ferric Desferal ( $\longrightarrow$ ). Cells were grown in BG11 (mc) medium without added iron for six days, washed, and resuspended to 60 klett units in uptake medium. [55 $\mathrm{Fe}$ siderophores were added to a final concentration of $30 \mathrm{~nm}$ iron (40 $\mathrm{nM}$ siderophore) except [55Fe]-ferric Desferal (18 nM iron, $36 \mathrm{nM}$ Desferal). 
103

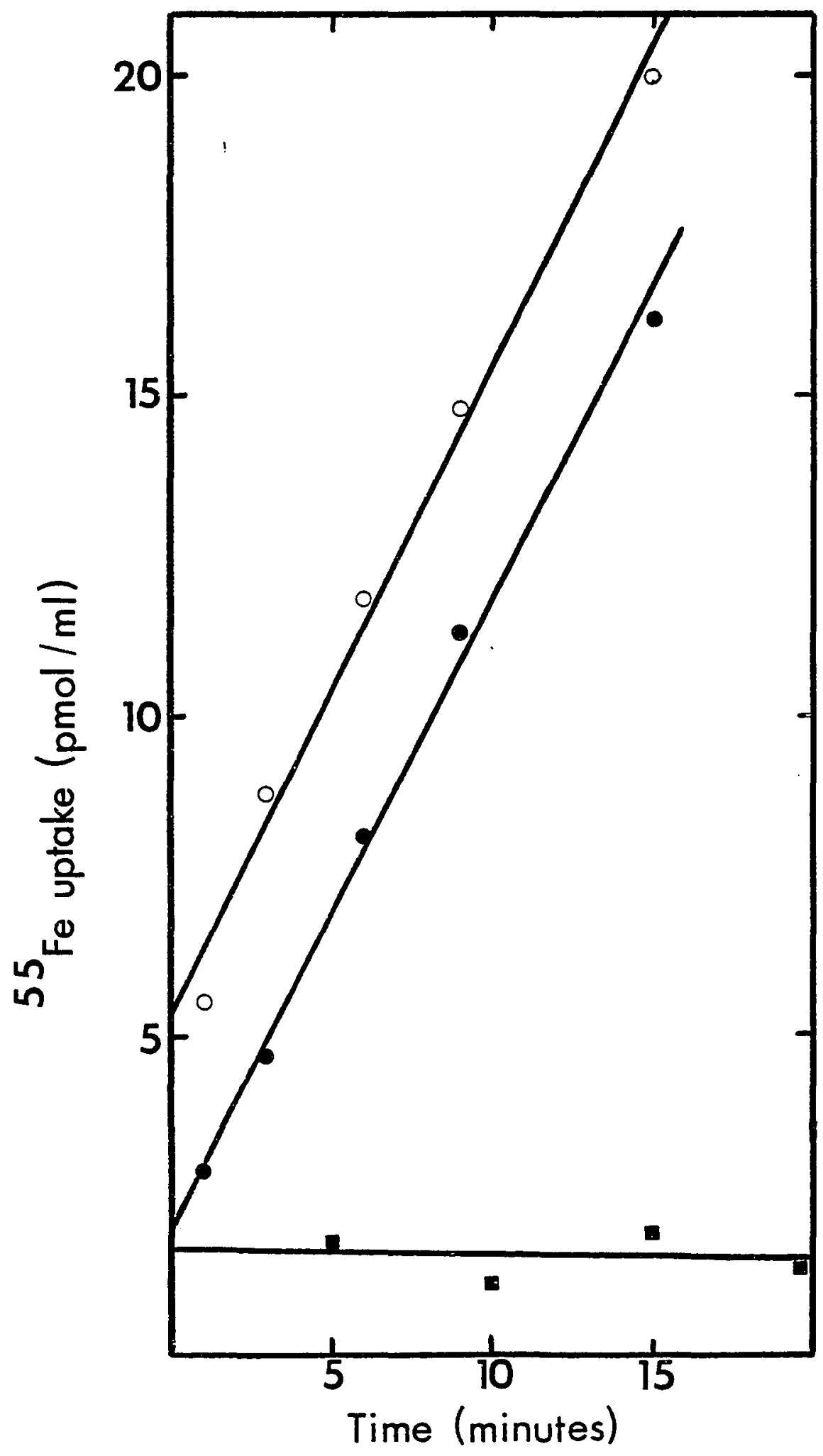


citrate $\left(K_{f}\right.$ of approximately $10^{23}$ versus $K_{f}$ of approximately $\left.10^{11}\right)$, it is difficult to rule out the possibility that the observed uptake was due to removal of iron from citrate by endogenous schizokinen. Accurate determination of ferric citrate utilization can only be performed with a mutant which produces no high-affinity siderophores.

Siderophore Activity in Different Strains of Anabaena

The genus Anabaena has been divided into two separate groups ( 82 ). The first group is characterized by a lack of mobility, a lack of akinetes (spores), lysis by the cyanophage $\mathrm{N}-1$, and cultures grow as an even suspension in liquid culture. This groups includes Anabaena 6411 and another species we have tested for siderophore activity, Anabaena 7120. The second group produces akinetes, is motile (gliding), is not lysed by the cyanophage $N-1$, and does not grow as an even suspension in liquid culture. We also chose an organism from this group, Anabaena cylindrica, to test for siderophore activity. Anabaena 7120 was tested for siderophore production using the Arthrobacter bioassay to examine filtrates from cultures grown without added iron. No activity at all was seen in filtrates unless they were first extracted with chloroform/phenol as described for schizokinen (see Experimental). After extraction 0.9-2.5 $\mathrm{MM}$ siderophore (as schizokinen) was detected (range of three independent assays), for an 11 day sample grown without added iron (110 
Klett units). We have also examined siderophore production by Anabaena 7120 using the iron-binding assay. A broad peak was observed centered near $490 \mathrm{nn}$, similar to the absorbance maximum of schizokinen in this test ( $5 \mathrm{mM}$ $\mathrm{Fe}(\mathrm{III}), 0.14 \mathrm{M} \mathrm{HClO}_{4}$ ). Using the extinction coefficient for ferric schizokinen (2600 liter mol-1 $\mathrm{cm}^{-1}$ ) a siderophore concentration of 1.4-1.9 $\mu \mathrm{M}$ was calculated for a 16 day filtrate grown without added iron to 125 klett units. The close agreement between the two assays is what would be expected if the majority of the siderophore activity from Anabaena 7121 is a hydroxamate $(\lambda \max =490 \mathrm{~nm}$ in acid) with growth factor activity similar to schizokinen.

The ability of Anabaena 7120 to utilize several ironsiderophore complexes as substrates for iron transport was examined using the same methods developed for Anabaena 6411. Results presented in Figure 25 are very similar to what was found in strain 6411. Both schizokinen and acetyl-schizokinen support iron uptake at similar rates. The rate of iron transport in strain 7120 was $50 \%$ of the rate demonstrated by strain 6411 with schizokinen and 758 of the rate with acetyl-schizokinen. Aerobacter and Desferal did not support iron uptake by Anabaena 7120 (data not shown). The similar pattern of iron uptake in the two strains of Anabaena in response to different siderophores is further indication that schizokinen is the siderophore produced by Anabaena 7120 . 
Figure 26.

Iron uptake activity by Anabaena 7120 for [55Fe]-ferric schizokinen ( $\bullet$ ), and [55Fe]-ferric acetylschizokinen $(\stackrel{0}{\circ}$ ). Cells were grown in BG-11(mc) medium without added iron for six days, washed, and resusyended to 60 Klett units in uptake medium. Labelled iron was added to a final concentration of $30 \mathrm{nM}$ iron, ( $40 \mathrm{nM}$ siderophore). 


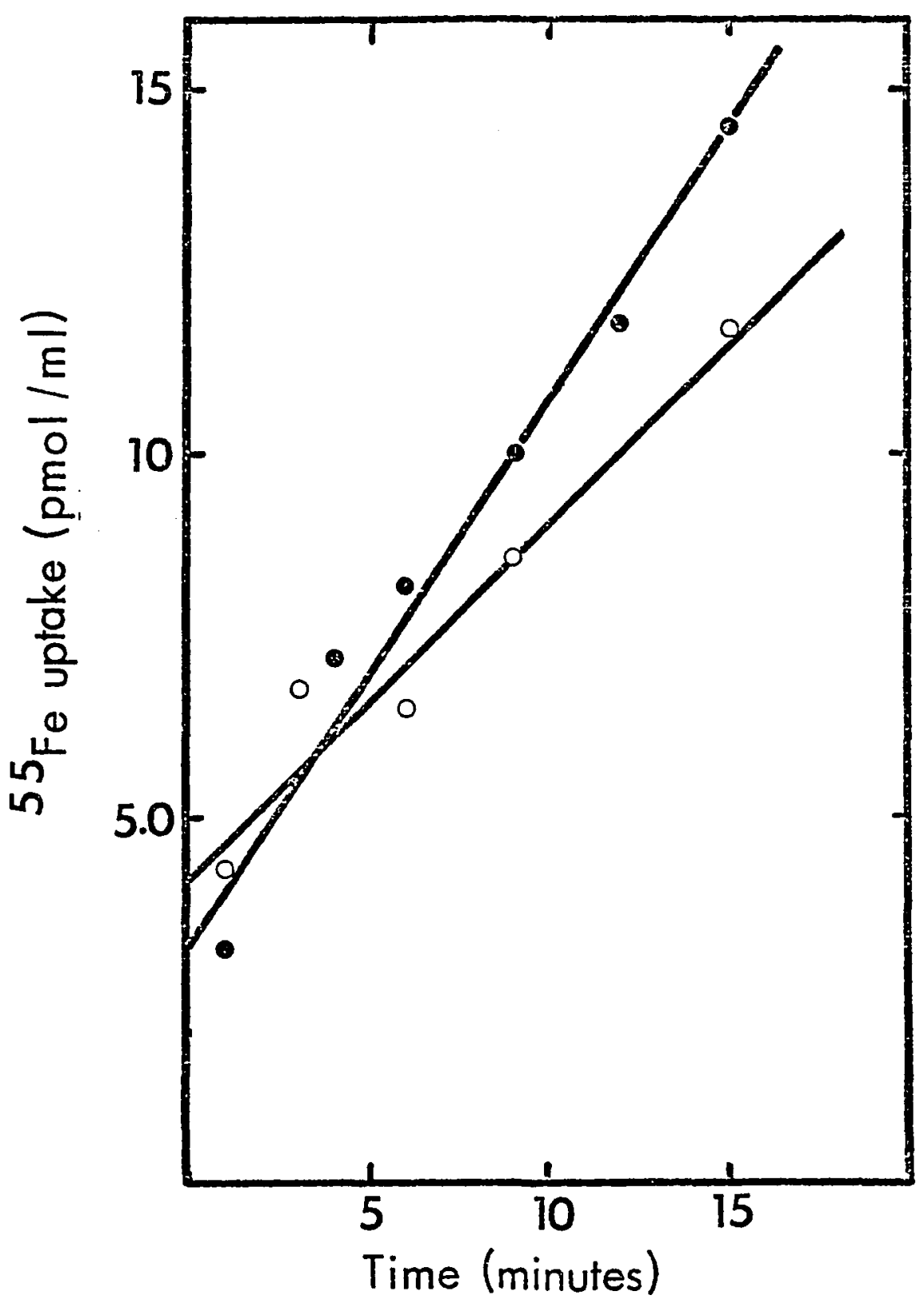


Siderophore Assays with Anabaena cylindrica

Anabaena cylindrica has also been examined for siderophore production as a representative species of the second grouping of the genus Anabaena. Cultures of A. cylindrica were grown without added iron in BG-ll(mc) medium under the same conditions as Anabaena 6411. Visual growth continued in the absence of added iron although at a slightly reduced level relative to $1.0 \mu \mathrm{M}$ Fe control cultures. The iron-free culture was harvested after two weeks and the supernatent concentrated twenty-five fold for Arthrobacter siderophore bioassays. No siderophore activity was found from these cultures when the concentrated culture fluid was subjected to the extraction procedure used with strains 6411 and 7120. Simpson and Neilands (8) have reported a finite level of hydroxamate positive material in extracellular fluids from A. cylindrica. However, this material was not repressed by added iron in a reproducible manner. These authors suggested that this hydroxamate was not likely to be a siderophore. However, because our extraction procedure may not work for all potential siderophores, and also because inhibition of the bioassay is known to occur with other Anabaena strains, it would be unwise to conclude that Anabaena cylindrica does not produce a siderophore. Iron uptake assays failed to show any marked uptake in the presence of schizokinen. Thus, it is unlikely that this species produces or utilizes schizokinen as a siderophore. 
DISCUSSION

The work presented in this dissertation was motivated, in part, by the findings of Murphy, et.al., who showed that the green alga Scenedesmus was inhibited by a cyanobacterial siderophore, presumably because it could not utilize siderophore-bound iron (7). More recent results have demonstrated that another green alga, Chlamydomonas reinhartii, is inhibited by schizokinen and also by desferrioxamine B mesylate. A third, Chlorella vulgaris, is not affected by either siderophore regardless of the ratio of ligand to iron (98). Thus, two of three eucaryotic algae tested have proven to be susceptable to inhibition by hydroxamate siderophores. The implications of these findings with respect to phytoplankton succession and diversity clearly warrant further research. In order to provide a better data base for evaluating the ecological significance of phytoplankton competition for iron, we have focused our efforts on learning the details of siderophoredependent iron acquisition by cyanobacteria. This work represents the first investigation of siderophore-mediated iron transport in this environmentally-significant group of organisms. 


\section{Siderophore Assays}

In order to evaluate the effect of siderophores upon aquatic ecology, one must be able to determine the amount of siderophore being produced by a cyanobacterium and the factors which influence this production capability. Several methods for detection and quantification of cyanobacterial siderophores have been evaluated; limitations to their use due to chemical interferences have been found. By far the most sensitive and useful method is the Arthrobacter JG-9 bioassay system. Using this method it is possible to detect as little as $10^{-7} \mathrm{M}$ siderophore (as schizokinen). However, use of this assay is not without its problems. We have shown that Anabaena produces a substance which is inhibitory to the test organism. This inhibition can be overcome by an organic extraction procedure that separates the siderophore from the inhibitory agent. The presence of the inhibitor is indicated by time-course experiments in which siderophore activity begins to drop in mid-log phase, and eventually declines to zero. Such behavior was also seen in the time-course data of Armstrong and Van Baalen on siderophore produced by Agmenellum quadruplicatum, a marine cyanobacterium (25). The identity of the inhibitory agent is not known at present. It is heat-stable and not extractable in chloroform/phenol. The presence of such an inhibitor in cyanobacterial filtrates is especially problematical for 
situations in which the bioassay is to be used to screen for the production of siderophores by cyanobacteria. Not all siderophores will be extractable in chloroform/phenol and it is impossible to know a priori how to separate the presumptive siderophore from the potential interference. Thus, several solvent systems would have to be tried in order to completely rule out the possibility of siderophore production by any given strain (see reference 25). Alternative procedures such as ion-exchange chromotography or absorption resins like XAD may be useful to both concentrate and partially purify the preparation.

The most widely used assay has been the Csaky method for detection of bound hydroxylamine. The major problem with this assay is its lack of sensitivity. The detection limit is approximately $10^{-5} \mathrm{M}$ or two orders of magnitude higher than the Arthrobacter assay (92). Furthermore, Anabaena produces substances that give a Csaky response, but are apparently not siderophores (i.e. production is unrelated to [Fe] in the growth inedium). The consistently higher values obtained with this assay relative to the bioassay procedure or the ferric perchlorate iron-binding assay suggest that this method does not give a true indication of the concentration of siderophore present in a given preparation. The added Csaky-positive material may be degradation products from intact siderophores or hydroxylamine or nitrite-containing compounds, since any of these will give a Csaky response. A preliminary 
purification and concentration of a test filtrate might make it possible to utilize the Csaky assay to detect cyanobacterial siderophores. However, our experience suggests that this method is not a useful tool for determining the concentration of siderophores in culture fluids. Our results show that Anabaena 6411 , in batch culture, produces schizokinen throughout its growth cycle, and that the concentration of this compound reaches 5-10 micromolar in cultures nearing stationary phase. Anabaena 7120 cultures achieve siderophore concentrations between 1 and 2.5 micromolar (as schizokinen) in late growth phase. These values are quite similar to the few 1iterature values available for siderophore production by other cyanobacteria. Agmenellum quadruplicatum produces approximately 1.4 micromolar siderophore (relative to ferrioxamine B mesylate) as measured with the Arthrobacter bioassay on untreated filtrates (25). This value corresponds to the maximum level prior to the decline in activity observed after three days growth. Thus it seems likely that the concentration could go higher if inhibitory substances are responsible for the reduction in siderophore activity in the Armstrong and Van Baalen time-course data. The only other values available for comparison are from the data published by McKnight and Morel on strong copper chelators produced by Anabaena flos-aquae (26). Using a coppersensitive eletrode for titrations, these investigators found approximately 5-15 micromolar chelator in stationary 
phase low-iron cultures. The compound contained hydroxamate liganding groups and its synthesis was repressed by added iron in the culture medium, strongly suggesting that it is a true siderophore. The conditional formation constant for the copper complex was indistinguishable from that with copper Desferal $\left(c_{K_{f}}=10^{8.4}\right)$. The in vivo function of this ligand would be primarily for iron binding, as bound copper is readily displaced by added iron. The excellent agreement between this data and our results using independent methods provides further support for the accuracy of the Arthrobacter data.

The marked stimulation of schizokinen production by Anabaena 6411 when grown in medium containing millimolar citrate provides a useful method for increasing schizokinen production from this organism on a preparative basis. Since the value of 42 micromolar schizokinen was determined with cells supplemented with 0.1 micromolar iron, it is possible that cultures unsupplemented with iron could produce even more schizokinen with citrate in the medium. This procedure may also be useful with Anabaena 7120 in order to produce enough siderophore for structural determination. In contrast to the cyanobacterial results, addition of 5 mil citrate had no stimulatory effect on schizokinen production in Bacillus megaterium (99). However, the organisms differ in that one uses carbon derived from photosynthesis, while the other uses carbon dervied from glycolysis and respiration. In addition, 
cyanobacteria do not possess a complete citric acid cycle, which may limit biosynthesis of this compound.

Our negative results concerning siderophore production by Anabaena cylindrica Lemm. should not be taken as definitive. Even though no activity was found with extracted or unextracted low-iron filtrates, this organism grows reasonably well through repeated transfers in lowiron media. Mcknight and Morel (26) found approximately 5 micromolar strong copper chelator from A. Eylindrica which had a higher conditional formation constant with copper than did the Anabaena Elos-aquae siderophore $\left(c_{K_{E}}=\right.$ 1010.2), presumably reflecting a different structure and, thus, possibly different solubility properties. This copper chelator also contained bound hydroxamate and was repressed by added iron.

\section{Iron Transport}

In general, the transport of iron siderophore chelates across cell membranes occurs via a specific transport system and requires metabolic energy (32). There are three common mechanisms for energy-mediated transport of nutrients across bacterial cell membranes (100). Membrane proteins (permeases) can behave as nutrient carriers or channels through the membrane. These systems are often driven by the electrochemical potential gradient of hydrogen ions $\left(\Delta \bar{\mu} H^{\dagger}\right)$. Binding protein syscens are characterized by periplasmic proteins that utilize ATP hydrolysis 
to increase their affinity for a nutrient or to facilitate passage of the nutrient through the membrane. These systems are sensitive to osmotic shock due to the loss of the periplasmic proteins. Finally, group translocation systems make use of intracellular modification of the nutrient by ATP or other high energy donors to drive the accumulation of the substrate.

Results presented here have shown that Anabaena 6411 accumulates $\left[55^{5 e}\right]$-ferric schizokinen and that this process requires the input of metabolic energy. The complete inhibition of both light and dark [55Fe]-ferric schizokinen uptake by the ATPase inhibitor DCCD, which is not expected to affect electron transport or the development of a membrane potential (101), clearly shows that ATP is required and that the energized membrane state alone is not sufficient to drive the transport of iron. Similar results were obtained with arsenate which blocks ATP formation. Because membrane level phosphorylation is the only mechanism for ATP synthesis in cyanobacteria (102), it has not been possible to determine whether the inhibition caused by uncouplers is due only to interference with ATP formation or if a membrane potential is also required for iron trans port.

In several other iron transports sytems there has been a clear indication of a requirement for an electrochemical gradient. Ferrichrome transport in E. coli has been shown to occur in inner membrane vesicles via a 
permease system which responds to the electrical component $(\Delta \Psi)$ of the membrane potential (72), possibly via a symport process with $\mathrm{Ca}^{2+}$ or $\mathrm{Mg}^{2+}$ bound to the ferrichrome molecule to produce a divalent cation (73). Ferric enterobactin uptake also requires an energized membrane state (69). Ferric enterobactin receptors with possible permease activity are present in both the outer and inner membranes (62), with the inner membrane system presumably accounting for the $\Delta \bar{\mu}_{H^{+}}$dependence. In addition, there appears to be an ATP requirement for ferric enterobactin uptake in E. coli. However, in this heterotrophic organism, it is difficult to rule out the possibility that the primary target of ATP inhibitors is glucose uptake rather than iron uptake (69).

It is perhaps significant that ferric schizokinen and ferric enterobactin are monovalent and trivalent anions, respectivel $\ddot{y}$, at physiological pH. As a result both must be transported against the electrical component of the membrane potential (interior negative). The ATP requirement of both systems suggests that transport is more complicated than a simple permease-type system, yet whether either system will fit the binding protein or group translocation models (100) or some combination of both remains to be determined. These questions would be more easily answered if it were possible to follow the intracellular localization of iron with time. However, such experiments are fraught with difficulties due to the fact that cell 
fractionation procedures tend to disturb iron aistribution patterns within cells (103). As stated by Christensen (104): "Unfortunately, measurement of activities for cell compartments is at best difficult. Solutes are frequently shown to be dialyzable and free after cytolysis, but conceivably cytolysis could release them from bound forms existing in vivo." In gram negative bacteria such as cyanobacteria such studies are further complicated by the existence of a periplasmic fluid between the inner and outer cell membranes; i.e. it is difficult to determine whether soluble iron has been derived from the cytoplasm or the periplasmic space.

The affinity of siderophore transport systems for their substrates is generally higher in bacterial than in eucaryotic systems. For comparison, Neurospora crassa accumulates iron via its siderophore, coprogen, with a $K_{M}$ of $20 \mu \mathrm{M}(105)$. The ferrichrome and ferric enterobactin systems in E.coli are characterized by $K_{M}$ 's of $0.15-0.25$ micromolar and 0.1 - 0.36 micromolar respectively $(72,76$, 106). The apparent $K_{M}$ for ferric schizokinen uptake in Anabaena 6411 is 0.03 micromolar, approximately one third of the E.coli values. The fact that the system reaches half-saturation at such a low concentration suggests that the affinity of the Anabaena siderophore transport system is high even by bacterial standards. This adaptation may help to counteract the large potential for dilution of the 
extracellular products of cyanobacteria in aquatic environments.

It is not clear what step in the transport of ferric schizokinen by Anabaena is being saturated, since the detailed molecular mechanism of transport for this siderophore (or any other siderophore transport system studied to date) is not known. Given the small size of ferric schizokinen (476 daltons) relative to the cutoff for the molecular sieving action of outer membrane porins of E.coli (about 600 daltons for oligosaccharides [107]), it is possible that rapid equilibration across the outer membrane of Anabaena may occur via passive diffusion, followed by a slower transport across the inner membrane into the cytoplasm. The reverse situation is just as possible however, and both ideas must be regarded as speculative at this point.

The specificity of the Anabaena siderophore transport system has been studied in two strains, 6411 and 7120 . Virtually identical results have been found in that each strain will transport ferric schizokinen and ferric acetylschizokinen. However, the structurally similar siderophore, aerobactin, does not support iron transport by either strain. The same situation is found with other schizokinen-utilizing bacteria, Bacillus megaterium and Salmonella typhimurium, which also cannot assimilate ferric aerobactin $(80,94)$. A structurally dissimilar siderophore, ferrioxamine B mesylate or Desferal, also did not support 
iron transport by Anabaena 6411 or 7120 . B. megaterium, in contrast, does assimilate ferric Desferal. However, competitive binding assays have shown that this is a separate function, distinct from the schizokinen-dependent transport system (80). We conclude that Anabaena 6411 and 7120 are somewhat specific in their requirement for schizokinen, but that modification of the citrate hydroxyl liganding group does not significantly alter the activity of the molecule as a iron transport cofactor. It would be of interest to determine the activity of ferric arthrovactin in iron transport studies with Anabaena. This siderophore differs from schizokinen only in the length of the side arms, has the same charge (a monovalent anion versus aerobactin's trivalent negative charge), and has a molecular weight only 56 daltons higher than schizckinen.

Responses to Iron Limitation

Biological responses to metals are often difficult to establish due to the fact that the chemical speciation, or form of the metal, must be considered as well as the total amount present. For some metals the most important parameter is the free ion activity. This has been established for copper toxicity (96), zinc limitation (108), and manganese nutrition (109). A relevant question then is whether the biological response of Anabaena to ironlimitation can be related to a particular solution species of iron or whether the total amount of iron present is the 
important parameter. In order to shed some light on this issue, the computer program MINEQL has been utilized to simulate the non-biological solution chemistry of BG-11 medium with and without the chelators EDTA and citric acid (110). One can then compare the biological responses with the predicted iron speciation for the various growth and siderophore production experiments that have been conaucted.

The fundamental response of Anabaena to iron limitation is the production of the high affinity chelator schizokinen. Determinations of schizokinen production by Anabaena have been performed on cultures grown in BG-11(mc) medium that does not contain the chelators EDTA or citrate. A comparison of measured schizokinen concentrations and the major computer-predicted iron species as a function of added iron is given in Table VII. In the absence of synthetic chelators the iron speciation in $B G-11(\mathrm{mc})$ is fixed by the insolubility of $\mathrm{Fe}(\mathrm{OH})_{3}$. As a result, the concentration of the major solution species $\mathrm{Fe}(\mathrm{OH})_{2}^{+}$is constant regardless of the amount of iron added to the medium. Thus, it seems likely that the activities of the soluble iron species $\mathrm{Fe}(\mathrm{OH})_{2}^{+}, \mathrm{Fe}(\mathrm{OH})^{2+}$, and $\mathrm{Fe}^{3+}$ are not the critical parameters that control the production of schizokinen. This is in contrast to the situation with copper toxicit mentioned above, and is most likely related to the presence of regulatory systems which respond to the concentration of soluble iron species inside of cells 
TABLE VII

IRON SPECIATION IN BG-11 MEDIUM AS PREDICTED BY MINEQL. (ALL CONCENTRATIONS IN MOLAR TERMS)

Experiments without added chelators

\begin{tabular}{llll} 
& \multicolumn{3}{l}{ Estimated total [Fe] in medium } \\
\cline { 2 - 3 } & $10^{-8}$ & $10^{-7}$ & $10^{-6}$ \\
[SK] 5 days growth & $1.3 \times 10^{-6}$ & $4.0 \times 10^{-7}$ & $1.0 \times 10^{-7}$ \\
$\mathrm{Fe}^{3+}$ & $2.3 \times 10^{-18}$ & $2.3 \times 10^{-18}$ & $2.3 \times 10^{-18}$ \\
$\mathrm{Fe}(\mathrm{OH})^{2+}$ & $1.58 \times 10^{-9}$ & $1.58 \times 10^{-9}$ & $1.58 \times 10^{-9}$ \\
$\mathrm{Fe}(\mathrm{OH})_{3}(\mathrm{~B})$ & $8.3 \times 10^{-9}$ & $1.09 \times 10^{-7}$ & $1.0 \times 10^{-6}$
\end{tabular}

Experimente with added chelators

\begin{tabular}{|c|c|c|c|c|c|c|}
\hline & $10^{-8}$ & $10^{-7}$ & $10^{-6}$ & $10^{-5}$ & $10^{-4}$ & $10^{-3}$ \\
\hline $\mathrm{Fe}_{x}(\mathrm{OH})_{y}$ & $6.7 \times 10^{-13}$ & $7.9 \times 10^{-12}$ & $1.4 \times 10^{-10}$ & $1.6 \times 10^{-9}$ & $1.6 \times 10^{-9}$ & $1.6 \times 10^{-9}$ \\
\hline Fe-citrate & $5.5 \times 10^{-10}$ & $6.5 \times 10^{-9}$ & $1.2 \times 10^{-7}$ & $1.2 \times 10^{-6}$ & $1.2 \times 10^{-6}$ & $1.2 \times 10^{-6}$ \\
\hline Fe-EDTA & $9.5 \times 10^{-9}$ & $1.0 \times 10^{-7}$ & 8. $9 \times 10^{-7}$ & $1.6 \times 10^{-6}$ & $1.6 \times 10^{-6}$ & $1.6 \times 10^{-6}$ \\
\hline $\mathrm{Fe}(\mathrm{OH})_{3}$ & - & - & - & $7.2 \times 10^{-6}$ & $9.8 \times 10^{-5}$ & $1.0 \times 10^{-3}$ \\
\hline
\end{tabular}


rather than in the medium. As long as the intracellular iron levels are limiting, schizokinen production would continue as would accumulation of ferric schizokinen complexes formed in the culture medium. In cultures with lictle iron available, essentially all the iron present is scavenged by the cells. For cultures receiving larger amounts of iron (more than $10^{-6} \mathrm{M}$ ) the total amount present can be considered to be available, if needed, through the chelating capacity of secreted schizokinen. Whether the solubilization occurs by chelation of the soluble iron species followed by dissolution of $\mathrm{Fe}(\mathrm{OH})_{3}$ to regain equilibrium, or by direct attack of the solid phase iron by schizokinen is not known.

The growth of Anabaena has been assessed in BG-11 medium both with and without the chelators EDTA and citrate. The predicted iron speciation in BG-11 medium containing chelators is also shown in TableVII. Comparison of the growth response (Figure 18) with the major iron species reveals that in the range $10^{-8}$ to $10^{-5} \mathrm{M}$ iron the ferric citrate, ferric-EDTA, and soluble ferric hydroxide complexes all show some correlation with the growth lag. However, we know that schizokinen is being produced in BG-11 with EDTA and citrate present at levels similar to those in $B G-11$ (mc) (Table V). Since these levels approximate those of citrate and EDTA, some of the iron must be chelated by schizokinen, especially in 
cultures recieving less than $10^{-6} \mathrm{M}$ added iron. Thus, equilibrium predictions from the computer model are not likely to be representative of speciation in the culture medium. Furthermore, attempts to model the effect of schizokinen release into the medium by incorporating this ligand into the computer program would require a greater knowledge of the kinetics of schizokinen release than is presently available.

Abcve $10^{-5} \mathrm{M}$ iron the precipitation of ferric hydroxide fixes the iron speciation in BG-Il containing EDTA and citrate. The only difference then between $10^{-5}$ and $10^{-4} \mathrm{M}$ iron where growth was normal, and $10^{-3} \mathrm{M}$ iron where little growth occurred, is the amount of $\mathrm{Fe}(\mathrm{OH})_{3}(\mathrm{~s})$ present. One interpretation of the "toxic" effects of millimolar iron (III) is that adsorption of essential trace metals by the solid phase $\mathrm{Fe}(\mathrm{OH})_{3}$ prevents Anabaena from acquiring the trace metals required for growth. Another possibility involves physical effects associated with the cell surface where the presence of large amounts of precipitated iron might interfere with normal functioning of the cell surface components. At present it is not possible to discriminate between these or other possibilities.

A major difference betweeen BG-II medium with chelators versus without chelators involves the speciation of copper. As noted below, the free copper ion activity 
increases dramatically in the absence of EDTA and citrate. The biological response of Anabaena at a given iron concentration is lowered growth without the chelators (Figure 19). The growth enhancement effect of EDTA and citrate occurs regardless of the amount of iron added to the medium. Thus, the most likely explanation of the growth enhancement of EDTA and citrate is lowered toxicity by complexation of free copper ions. This interpretation is consistent with the findings of Jackson and Morgan (11I) who showed that the growth promoting effect of EDTA on algal populations in seawater was due to lowered free copper activity. In addition, free copper ion activities in the range of $10^{-7}$ molar are in the same range as those previously found to be toxic to green alga ( 96 , 109).

\section{Copper Speciation}

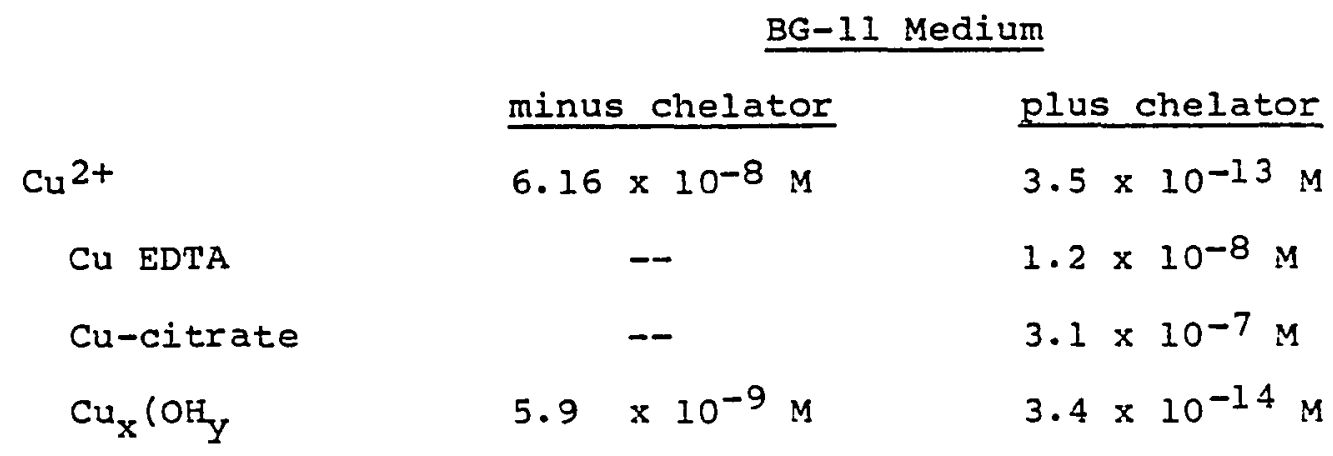


Environmental Implications

Experiments presented here have demonstrated that Anabaena is capable of very efficient iron scavenging, to the extent that growth is not significantly limited by iron availability in our batch cultures. This finding supports the notion that siderophore-producing cyanobacteria possess a competitive advantage over other phytoplankton when iron becomes limiting in natural systems. However, since the extent of cyanobacterial siderophore Rroduction has barely been explored, it is not clear how general this phenomenon will be. For example, the report by Morton and Lee (112) showing an increased green to blue-green ratio at low iron, and a lower (G/BG) ratio at high iron, has often been cited as evidence that low iron levels favor eucaryotic green algae. It may be significant, however, that two one of the three cyanobacteria used for their experiments, Anabaena circinalis (Wis 1038) and Gloeotrichia echinulata (Wis 1052), were found to be unable to grow in synthetic medium without chelators (27), suggesting that siderophores are not produced by these strains. What is clear at this point is that more information is needed relative to both cyanobacterial siderophore production and the mechanisms of iron acquisition by eucaryotic algae.

Finally, it should be pointed out that Anabaena 6411 , at high cell densities such as what might be expected near the surface of shallow or stratified lakes during a bloon, 
may produce 10 micromolar schizokinen in iron limited waters. Even if this gets diluted one thousand fold, it will still be enough to stimulate ferric-schizokinen uptake (at approximately one-third the apparent $K_{M}$ for uptake). Thus, the combined action of the powerful iron-chelating capability of schizokinen towards colloidal ferric hydroxides, and the high-affinity of the uptake system for the ferric-siderophore, virtually assures Anabaena of a steady supply of iron.

\section{CONCLUSIONS}

We have shown that Anabaena 641 i produces schizokinen in response to iron limitation and that concentrations between five and ten micromolar siderophore are achieved in batch cultures without added iron. It is also possible to increase schizokinen production at least four-fold by the adition of citric acid to the medium. We have also been able to show that Anabaena 7120 produces a siderophore in low iron medium.

Iron-schizokinen uptake activity in Anabaena 6411 is also enhanced in response to iron limitation. This activity requires ATP bond energy as demonstrated by the use of metabolic inhibitors. Iron uptake displays saturation-type kinetics with an apparent $K_{M}$ of $30 \mathrm{nM}$. The ferricsiderophore uptake system will respond to schizokinen and acetyl-schizokinen; but the structurally similar siderophore, aerobactin, and the trinydroxamate, Desferal, do 
not support iron uptake by Anabaena 6411. The response of Anabaena 7120 to the above set of ferric-siderophores was virtually identical, suggesting that schizokinen may be the native siderophore for this strain.

Anabaena cylindrica (ATCC $\# 27899$ ) was tested for siderophore activity using the Arthrobacter bioassay system on concentrated culture fluids and chloroform/phenol extracts. No siderophore activity was detected in either case. This strain does not appear to produce or utilize schizokinen as a siderophore.

\section{FUTURE DIRECTIONS}

It would be of interest to test the question of whether iron limitation and the resulting production of siderophores does indeed favor the establishment of cyanobacterial "blooms" in natural waters. An opportunity to study this question and also to screen natural problemcausing cyanobacteria for siderophore production exists in Klamath Lake, Oregon. This lake supports a large annual bloom of Aphanizomenon flos-aquae. The appearance of this cyanobacterium each spring correlates with the cessation of flow of the williamson River which carries large amounts of humic material into the lake (E. M. Perdue personal communication). This is an especially attractive system for study since it affords the opportunity to test the effect of humic acids on iron metabolism; in particular whether humics increase or decrease iron bioavailability in 
natural waters and also potential siderophore-humic acid interactions. Techniques described in this paper should facilitate the search for any siderophore activity produced by Aphanizomenon in situ, and also once it is established in axenic culture.

There are many unanswered questions concerning the mechanism of iron transport by Anabaena. For example, does schizokinen serve as an iron "taxi" delivering iron only to the cell surface, or is it co-transported inside the cell? This question can be answered by preparing radio-labelled acetyl-schizokinen using $\left[{ }^{3} \mathrm{H}\right]$-acetic anhydride. One could then independently follow the fate of the ${ }^{3} \mathrm{H}$ and $55_{\mathrm{Fe}}$ labels in simultaneous transport assays. It would also be of interest to know if new outer membrane proteins are produced by iron-limited cells which facilitate ferricsiderophore uptake across the outer membrane. Also, can the outer membrane be removed with lysozyme in osmotically stable buffer to produce spheroplasts that retain ferricschizokinen transport activity? Should such preparations become available it would be possible to study the effects of the ionophores valinomycin and nigerium upon iron uptake by Anabaena. These experiments would make it possible to determine if an energized membrane is required only for ATP formation or whether the electrical or chemical components of the membrane potential are also required. It would be of great interest to measure the apparent $K_{M}$ of transport for spheroplasts and compare this with that from whole 
cells. This would give an indication of the location of the saturatable step(s) for ferric schizokinen transport. Spheroplast preparations would also facilitate experiments designed to determine the intracellular localization of iron following transport.

The isolation of a mutant incapable of schizokinen synthesis would make possible several interesting lines of investigation. With such a mutant it would be possible to unambiguously study any low affinity iron transport systems that might exist in Anabaena 6411. For example, is ferric citrate utilized directly for transport and is there a nonchelated low affinity system analogous to the E.coli low affinity iron transport system?

Another question relates to the mechanism of iron removal from the schizokinen chelate once the complex is transported inside the cell. Are specific ferric-siderophore reductases involved and, if so, where are they located? Is the schizokinen molecule modified to make it easier to remove the iron and protect the iron centers inside the cell from attack by intracellular schizokinen? This research has raised many more questions than it has answered, some of which are more important and significant than others. I leave it to the curiosity and interests of any who might follow to make the determination of which, if any, of these questions are worth answering. 


\section{REFERENCES}

1) Burris, R. H. (1977). Overview of nitrogen fixation p. 9-18 in A. Hollaender (ed.) Genetic Engineering for Nitrogen Fixation, Plenum, New York.

2) Talley, W. N., Talley, B. J. and D. W. Rains (1977). Nitrogen fixation by Azolla in rice fields, p. 259281, ibid.

3) Fogg, G. E., Stewart, W. D. P., Fay, P. and A. E. Walsby (1973). Freshwater ecology, p. 255-280 in the Blue-green Algae, Academic Press, London.

4) Carmichael, W. W. and P. R. Gorham (1981). Freshwater blue-green algae (cyanobacteria) toxins - a review, p. 1-13, in W. W. Carmichael (ed.), The Water Environment - Algal Toxins and Health, Plenum Publishing, New York.

5) Neilands, J. B. (1972). Evolution of biological iron binding centers, Structure and Bonding 11: 145170.

6) Neilands, J. B. (1973). Microbial iron transport compounds (siderochromes), p. 167-200, in G. L. Eichorn (ed.) Inorganic Biochemistry, Vol. 1 , Elsevier, New York.

7) Murphy, T. P., Lean, D. R. S., and C. Nalewajko (1976). Blue-green algae: their excretion of ironselective chelators enables them to dominate other algae, Science 192: 900-902.

8) Simpson, F. G. and J. B. Neilands (1976). Siderochromes in Cyanophycea: isolation and characterization of schizokinen from Anabaena sp. J. Phycol 12: $44-48$.

9) Spiro, T. G. and P. Saltman (1974). Inorganic Chemistry, P. 1-26, in A. Jacobs and M. Worwood (eds.) Iron in Biochemistry and Medicine Academic Press, New York.

10) Dr. D. Barnum, unpublished results. 
11) Carnahan, J. E. and J. E. Castle (1958). Some requirements of biological nitrogen fixation, J. Bacteriol 75: 121-126.

12) Davies, A. G. (1970). Iron, Chelation, and the growth of marine phytoplankton, J. Mar. Biol. Assoc. (UK) 50: 65-86.

13) Lewin, J. and C. Chen (1973). Changes in the concentration of soluble and particulate iron in seawater enclosed in containers, Limnol. Oceanogr. 18: $590-596$.

14) Lange, W. (1971). Limiting nutrient element in filtered Lake Erie water, Water Res. 5: 1031-1048.

15) Menzel, D. W. and J. R. Ryther (1961). Nutrients limiting the production of phytoplankton in the Sargossa sea, with special reference to iron, Deep-Sea Res. 7: 276-281.

16) Tranter, D. J. and B. S. Newell (1963). Enrichment experiments in the Indian Ocean, Deep-Sea Res. 10: $1-9$.

17) Schelske, C. L., Hooper, F. F., and L. Haert (1962). Responses of a marl lake to chelated iron and fertilizer. Ecology 43: 646-653.

18) Mackereth, F. J. H. (1966). Some observations in post-glacial lake sediments, Phil. Trans. Roy. Soc. London, Ser. B. 250: 165-213.

19) Murphy, T. P. and D. R. S. Lean (1975). The distribution of iron in a closed ecosystem, Verh. Internat. Verin. Limnol. 19: 258-266.

20) Lange, W. (1970). Blue-green algae and humic substances. Proc. 13th Conf. Great Lakes Res., p. 58-70.

21) Fogg, G. E. and D. F. Westlake (1955). The importance of extracellular products of algae in freshwater. Verh. Internat. Verein Limnol 12: 219-232.

22) Fogg, G. E. (1952). The production of extracellular nitrogenous substances by a blue-green alga, proc. Royl. Soc. London Series B 139: 372-397.

23) Walsby, A. E. (1974). The extracellular products of Anabaena cylindrica Lemm. Isolation of a macromolecular pigment-peptide complex and other components, Br. Phycol. J. 9: $371-381$. 
24) Estep, M., Armstrong, J. E. and C. Van Baalen (1975). Evidence for the occurrence of specific iron (III)binding compounds in nearshore marine ecosystems. Applied Murobiol. 30: 186-188.

25) Armstrong, J. E. and C. Van Baalen (1979). Iron transport in microalgae: The isolation and biological activity of a hydroxamate siderophore from the bluegreen alga Agmenellum quadruplicatum. J. Gen. Microbiol. 111: 253-262.

26) McKnight, D. M. and F. M. M. Morel (1980). Copper complexation by siderophores from filamentous bluegreen algae, Limnol. Oceanogr. 25: 62-71.

27) Lange, W. (1974). Chelating agents and blue-green algae. Can. J. Microbiol. 20: 1311-1321.

28) Neilands, J. B. (1952). A crystalline organo-iron pigment from a smut fungus Ustilago sphaerogena. J. Am. Chem. Soc. 74: 4846-4847.

29) Ehrenberg, A. (1956). Magnetic Properties of Ferrichrome and Ferroverdin. Nature (London) 178: 379-380.

30) Epstein, L. M. and Straub, D. K. (1969). Mossbauer Spectra of some ferric hydroxamates. Inorganic Chem. 8: $453-457$.

31) Lorenberg, W., Buchanan, B. B. and Rabinowitz, J. C. (1963). Studies on the chemical nature of clustridial ferredoxin. J. Biol. Chem. 238: 3899-3913.

32) Lankford, C. E. (1973). Bacterial assimilation of iron. Crit. Rev. Microbiol. 2: 273-331.

33) Emery, T. (1971). Role of ferrichrome as a ferric ionophore in Ustilago sphaerogena. Biochemistry 10: 1483-1488.

34) Leong, J., Neilands, J. B. and K. N. Raymond (1974). Coordination isomers of biological iron transport compounts III. Transport of 1 -cis-chromic desferriferrichrome by Ustilago sphaerogena. Biochem. Biophys. Res. Comm. 60: 1066-1071.

35) Raymond, K. N. and C. J. Carrano (1979). Coordination chemistry and microbial iron transport. Accounts Chem. Research 12: 183-190. 
36) Emery, T. and L. Emery (1973). The biological activity of some siderophore derivitives. Brochem. Brophys. Res. Comm. 50: 670-675.

37) Emery T. (1980). Malonichrome, A new iron chelate from Fusarium roseum. Biochem. Brophys. Acta 629: $382-3 \overline{90}$.

38) Bickel, H., Hall, G. E., Keller-Schierlen, W., Prelog, V., Visher, E., and A. Wettstein (1960). Stof fwechselprodukte von Actinomyceten $u$ ber die Konstitution von Ferrioxamin B. Helv. Chim. Acta 43: 2129-2133.

39) Enery, T. (1971). Hydroxamic acids of natural origin. Adv. Enzymol. 35: 135-180.

40) Prelog, V. and A. Walser (1962). Stof fwechselprodukte von Actinomyceten, uber die synthese der Ferrioxamin $B$ und D. Helv. Chim. Acta 45: 631-635.

41) Carrano, C. J. and K. N. Raymond (1978). Coordination chemistry of microbial iron transport compounds 10. Characterization of the complexes of Rhodotorulic acid, a dihydroxamate siderophore. J. Am. Chem. Soc. 100: $5371-5374$.

42) Atkin, C. L. and J. B. Neilands (1968). Rhodotorulic acid, a diketopiperazine dihydroxamic acid with growth factor activity. I. Isolation and characterization. Biochemistry 7: $3734-3739$.

43) Harris, W. R. , Carrano, C. J., and K. N. Raymond (1978). Spectrophotometric determination of the proton dependent stability constant of ferric enterobactin. J.Am. Chem. Soc. 101: 2213-2214.

44) Peters, W. J. and R. A. J. Warren (1968). Itoic Acid synthesis in Bacillus subtilis. J. Bacterial 95: $360-366$.

45) Corbin, J. L., and W. A. Bulen (1969). The isolation and identification of 2,3-Dihydroxybenzoid acid and $2-N, 6-N-D i-(2.3-d i h y d r o x y b e n z o y l)-L-1 y$ sine formed by iron deficient Azotobaster vinelandir Biochemistry 757-762.

46) Peterson, T., and J. B. Neilands (1979). Revised structure of a catecholamide spermidine siderophore from Paracoccus denitrificans. Tetrahedron Lett. 50: 4805-4808. 
47) Ong, S. A., Peterson, T., and J. B. Neilands (1979). Agrobactin, a siderophore from Agrobacterium tumefaciens J. Biol. Chem. 254: $18600-1865$.

48) Petersson, T., Falk, K. E., Leong, S. A., Klein, M. P. and J. B. Neilands (1980). Structure and behavior of spermidine siderophores. J. Am. Chem. Soc. 102: 7715-7718.

48a) Leong, S. and J. B. Neilands (1981). Relationship of siderophore-mediated iron assimilation to virulence in crown gall disease. J. Bacterial 147: 482-491.

49) Snow, G. A. (1970). Mycobactins: iron chelating growth factors from mycobacteria. Bacterial. Rev. 34: $99-125$.

50) Snow, G. A. (1960). Metal complexes of mycobactin $P$ and of desferrisideramines. Biochem J. 115: 199205.

51) Snow, G. A. and A. J. White (1969). Chemical and biological properties of mycobactins isolated from various mycobacteria. Biochem. J. 115: 1031-1045.

52) Mullis, K. B., Pollack, J. R., and J. B. Neilands (1971). Structure of schizokinen, an iron-transport compound from Bacillus megaterium. Biochemistry 10: 4894-4898.

53) Burton, M. O., Snowden, F. J., and A. G. Lockhead (1954). Studies on the isolation and nature of the "terregen factor." Can. J. Biochem. Physiol. 32: $400-410$.

54) Gibson, F. and D. L. Magrath (1969). The isolation and characterization of a hydroxamic acid (Aerobac$t i n)$ formed by Aerobacter aerogenes 62-1. Biochem. Biophys. Acta 192: 175-184.

55) Harris, W. R. , Carrano, C. J., and K. N. Raymond (1979). Coordination chemistry of microbial iron transport compounds. 16. Isolation, characterization, and formation constants of ferric aerobactin. J. Am. Chem. Soc. 101: 2722-2727.

56) Plowman, J., Sanders-Loehr, J. and T. Loehr. Unpublished results.

57) Egawa, Y., Umino, K., Awataguchi, S., Kawana, Y., and T. Okuda (1970). Antibiotic YC 73 of Pseudomonas Origin. J. Antibiot. 23: 267-270. 
58) Cox, C. D., Rinehart, K. L., Moore, M. L., and J. C. Cook, Jr. (1981). Pyochelin: Novel structure of an iron-chelating growth promotor for Pseudomonas aeruginosa. Proc. Natl. Acad. Sci. USA 78: 42564260 .

59) Fernandez-Pol, J. A. (1978). Isolation and characterization of a siderophore-like growth factor from mutants of SV-40-trans formed cells adapted to picolinic acid. Cell 14: 489-499.

60) Bezkorovainy, A. (1980). Biochemistry of Nonheme Iron, p. 342, Plenum Press, New York.

61) Neilands, J. B. (ed.) (1974). Microbial Iron Metabolism, Academic Press, New York.

62) Silver, S. (1978). Transport of anions and cations, p. 243-324. In B. P. Rosen (ed.), Bacterial transport, Marcel Dekker, Inc., New York.

63) Neilands, J. B. (1981). Microbial Iron Compounds. Annual Rev. Biochem. 50: 715-732.

64) Crosa, J.H. (1980). A Plasmid associated with virulence in the marine fish pathogen Vibrio anguillarum specifies an iron-sequestering system. Nature 284: $566-568$.

65) Warren, P. J., Williams, P. H., Bindereif, A., and J. B. Neilands (1981). Col V plasmid specified aerobactin synthesis by invasive strains of Escherichia coli. Infection and Immunity 33: 540-545.

66) Kadner, R. J., Heller, K., Coulton, J. W., and V. Braun (1980). Genetic control of hydroxamatemediated iron uptake in Escherichia coli. J. Bacteriol 143: 256-264.

67) Postle, K. and W. S. Reznikoff (1979). Identification of the Escherichia coli ton $B$ gene product in minicells containing ton B hybrid plasmids. J. Mol. Biol. 131: 619-636.

68) Plastow, G. S. and J. B. Holland (1979). Identification of an Escherichia coli inner membrane polypeptide specified by a $\lambda$-ton $B$ transducing bacteriophage. Biochem. Biophys. Res. Commun. 90: 1007-1014. 
69) Pugsley, A. P. and P. Reeves (1977). Uptake of ferrienterochelin by Escherichia coli: Energy dependent stage of uptake. J. Bacteriol. 130: 26-36.

70) Rosenberg, H. and I. G. Young (1974). Iron transport in the enteric bacteria, p. 67-82, in J. B. Neilands (ed.), Microbial Iron Metabolism. Academic Press, New York.

71) Leong, J. and J. B. Neilands (1976). Mechanisms of siderophore iron transport in enteric bacteria J. Bacteriol. 126: 823-830.

72) Negrin, R. S. and J. B. Neilands (1978). Ferrichrome transport in inner membrane vesicles of Escherichia coli K-12. J. Biol. Chem. 253: 2339-2342.

73) Hider, R. C., Drake, A. F., Kuroda, R., and J. B. Neilands (1980). Symport transport of ferrichrometype siderophores. Naturwissenschaften 67: 136-139.

74) Hartmann, A., and V. Braun (1980). Iron transport in Escherichia coli: Uptake and modification of ferrichrome. J. Bacteriol. 143: 246-255.

75) Schneider, R., Hartmann, A. and V. Braun (1981). Transport of the iron ionophore ferrichrome in Escherichia coli $\mathrm{Kl} 2$ and Salmonella typhimurium LT-2. Microbiol Letters 11: $115-119$.

76) Frost, G. E. and H. Rosenberg (1973). The inducible citrate-dependent iron transport system in Escherichia coli K12. Biochim. Biophys. Acta 330: 90-101.

77) Frost, G. E. and H. Rosenberg (1975). Relationship between the ton $B$ locus and iron transport in Eschericia coli. J. Bacteriol 124: 704-712.

78) Byers, B. R., Arceneaux, J. E. I., Hayden, A. H. and J. E. Aswell (1977). Siderophore transport in Bacillus megaterium, p. 371-378, in E. B. Brown, P. Aisen, J. Fielding, and R. R. Chrichton (eds.), proteins of Iron Metabolism, Grune and Stratton, New York.

79) Arceneaux, J. E. I. and B. R. Byers (1976). Ferric hydroxamate transport without subsequent iron utilization in Bacillus megaterium. J. Bacteriol 127: 1324-1330. 
80) Aswell, J. E., Haydon, A. H. , Turner, H. R. , Dawkins, C. A., Arceneaux, J.E. L. and B. R. Byers (1977). Specificity of siderophore receptors in membrane vesicles of Bacillus Megaterium. J. Bacteriol 130: $173-180$.

81) Eng-Wilmot, D. L. and D. F. Martin (1979). Uptake of iron by Gamphosphaeria aponina, a possible control organism for the Florida red tide Pytochodiscus brevis. Microbios 26: 103-113.

82) Rippka, R., Deruelles, J., Waterbury, J. B., Herdman, M. and R. Y. Stanier (1979). Generic assignments, strain histories and properties of pure cultures of cyanobacteria. J. Gen. Microbiol. 111: 1-61.

83) Fogg, G. E. (1942). Studies on nitrogen fixation by blue-green algae. I. Nitrogen fixation by Anabaena cylindrica Lemm. New Phytol. 43: 164-175.

84) Stanier, R. Y., Kunisawa, R., Mandel, M. and G. Cohen-Bazire (1971). Purification and properties of unicellular blue-green algae (order Chroococcales). Bacteriol. Rev. 35: 171-205.

85) Allen, M. M. (1968). Simple conditions for growth of unicellular blue-green algae on plates. J. Phycol. 4: $\quad 1-4$

86) Lang, N. J., Simon, R. D., and C. P. Wolk (1972). Correspondence of cyanophycin granules with structured granules in Anabaena cylindrica. Arch. Mikrobiol. 83: $313-320$.

87) Carmichael, W. W. and P. R. Gorham (1974). An improved method for obtaining axenic clones of planktonic blue-green algae. J. Phycol. 10: 238-240.

88) Burton, M. O. (1957). Characteristics of bacteria requiring the terregens factor. Can. J. Bacteriol. 3: $\quad 107-112$.

89) Drew, S. W. (1981). Liquid culture, p. 156, in Phillip Gerhardt (ed.) Manual of Methods for General Bacteriology. American Society for Microbiology, Washington, D.C.

90) Akers, Llinas, and J. B. Neilands (1972). Protonated amino acid precursor studies on rhodotorulic acid. Biosynthesis in deuterium oxide media. Biochemistry 11: $2283-2291$. 
91) Csaky, T. (1948). On the estimation of bound hydroxylamine. Acta. Chem. Scand. 2 : 450-454.

92) Gilliam, A. H., Lewis, A. G., and R. J. Anderson (1981). Quantititative determination of hydroxamic acids. Anal. Chem. 53: 841-844.

93) Strickland, J. D. H., and R. T. Parsons (1972). A practical guide to seawater analysis. Fish. Res. Bd. Can. Bull. 167, 2nd ed., pp. 95-98.

94) Lucky, M., Pollack, J. R., Wayne, R., Ames, B. N., and J. B. Neilands (1972). Iron uptake in Salmonella typhimurium: utilization of exogenous siderophores as iron carriers. J. Bacteriol. 111: 731-738.

95) Cotton, F. A. and G. Wilkinson (1980). Advanced Inorganic Chemistry, 4th ed., p. 741, J. Wiley and Sons, New York.

96) Sunda, W. G. and R. R. Guillard (1976). Relationship between cupric ion activity and the toxicity of copper to phytoplankton. J. Mar. Res. 34: 511-529.

97) Abrams, A. (1976). Structure and function of membrane-bound ATPase in bacteria, p. 67-69. In A. $N$. Martonosi (ed.). The Enzymes of Biological Membranes, Vol. 3, Plenum, New York.

98) Bailey, K. M. and F. B. Taub (1980). Effects of hydroxamate siderophores (Strong Fe(III) chelators) on the growth of algae. J. Phycol. 16: 334-339.

99) Mullis, K. B. (1973). Ph.D. Dissertation, University of California, Berkeley.

100) Wilson, D. B. (1978). Cellular transport mechanisms. Ann. Rev. Biochem. 47: 933-965.

101) Bohler, M. C. ind A. Binder (1980). Photosynthetic activities of a membrane preparation of the thermophilic cyanobacterium. Mastigocladus laminosus. Arch. Microbiol. 124: 155-160.

102) Stanier, R. Y. and G. Cohen-Bazire (1977). Phototrophic procaryotes: The cyanobacteria. Ann. Rev. Microbiol. 31: $225-274$.

103) DeVoe, I., personal communication.

104) Christensen, H. (1975). Biological Transport, p. 15, W. A. Benjamin, Reading, Massachusetts. 
105) Winkelmann, G. (1974). Metabolic products of microorganisms. Uptake of iron by Neurospora crassa. Arch. Microbiol. 98: 39-50.

106) Wang, C. C. and A. Newton (1971). An additional step in the transport of iron defined by the ton $B$ locus of Escherichia coli. J. Biol. Chem. 246: 2147-2151.

107) Lugtenberg, B. (1981). Composition and function of the outer membrane of Escherichia coli. Trends Biochem. Sci. 6: 262-266.

108) Rueter, J. G. and F. M. M. Morel (1981). The interaction between zinc deficiency and copper toxicity as it affects the silicic acid uptake mechanism in Thalassiosira pseudonana. Limnol. Oceanogr. 26: 67-73.

109) Sunda, W. G. and S. A. Huntsman (1982). Effect of Manganese and cupric ion activities on manganese cellular concentrations and growth rate of estuarine and oceanic species of the diatom Thalassiosira. Limnol. Oceanogr. in press.

110) Westall, J. C., Zachary, J. I. and F. M. M. Morel (1976). MINEQL, a computer program for the calculation of chemical equilibrium composition of aqueous sytems. Water Quality Laboratory, Department of Civil Engineering, Massachusetts Institute of Technology. Technical Note No. 18.

111) Jackson, G. A. and J. D. Morgan (1981). Trace metalchelator interactions and phytoplankton growth in seawater media: Theoretical analysis and comparison with reported observations. Limnol. Oceanogr. 23: 268-282.

112) Morton, S. D. and T. H. Lee (1974). Algal blooms possible effects of iron. Environ. Sci. Technol. 8: $673-674$. 